US Army Corps

of Engineers ${ }_{\circledast}$

Engineer Research and

Development Center

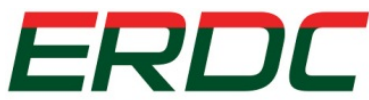

INNOVATIVE SOLUTIONS

for a safer, better world

Airfield Damage Repair Modernization Program

\title{
Analysis of Lightweight Materials for the AM2 System
}

Paul G. Allison, Timothy W. Rushing, and Lyan Garcia

June 2014

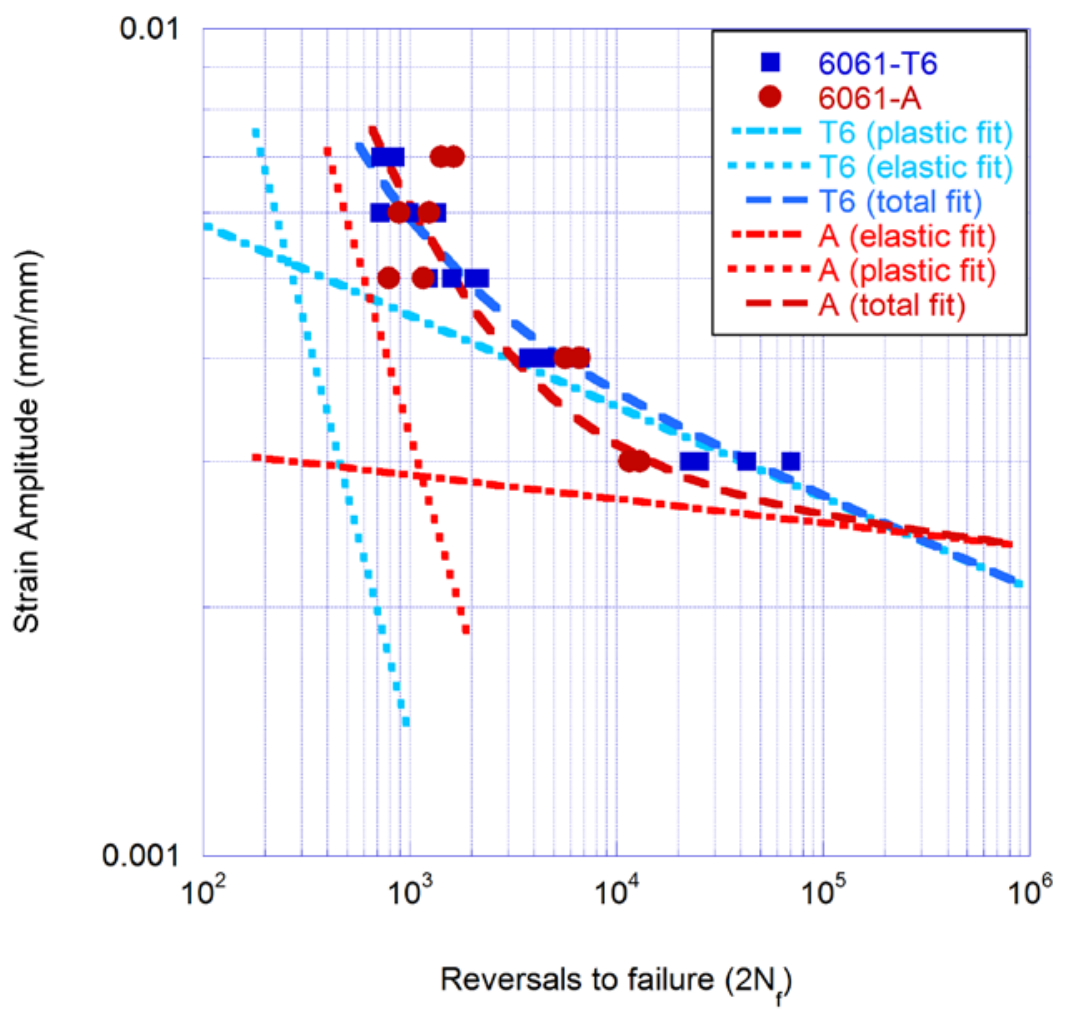


The US Army Engineer Research and Development Center (ERDC) solves the nation's toughest engineering and environmental challenges. ERDC develops innovative solutions in civil and military engineering, geospatial sciences, water resources, and environmental sciences for the Army, the Department of Defense, civilian agencies, and our nation's public good. Find out more at www.erdc.usace.army.mil.

To search for other technical reports published by ERDC, visit the ERDC online library at http://acwc.sdp.sirsi.net/client/default. 


\section{Analysis of Lightweight Materials for the AM2 System}

Paul G. Allison, Timothy W. Rushing, and Lyan Garcia

Geotechnical and Structures Laboratory

US Army Engineer Research and Development Center

3909 Halls Ferry Road

Vicksburg, MS 39180-6199

Final report

Approved for public release; distribution is unlimited.

Prepared for Headquarters, Air Force Civil Engineer Center

Tyndall Air Force Base, FL 32403-5319

Under Airfield Damage Repair Modernization Program 


\section{Abstract}

An analysis was performed on potential materials that could replace the 6061-T6 aluminum alloy currently used in the AM2 airfield matting for the purpose of light-weighting the design. An in-depth analysis was performed on metal and polymer matrix composites. However, neither groups of materials produced a suitable material based on operating conditions of the AM2. Newly developed extruded magnesium alloys were identified that could potentially provide weight savings of 30 to $40 \%$ while maintaining the current performance of the AM2. In addition, traditional high-strength aluminum alloys were identified that could provide substantial weight savings. However, manufacturing issues existed due to the high strength of these aluminum alloys. Finally, analysis was performed to determine the cost of manufacturing the AM2 using these alternate materials.

DISCLAIMER: The contents of this report are not to be used for advertising, publication, or promotional purposes. Citation of trade names does not constitute an official endorsement or approval of the use of such commercial products. All product names and trademarks cited are the property of their respective owners. The findings of this report are not to be construed as an official Department of the Army position unless so designated by other authorized documents. 


\section{Contents}

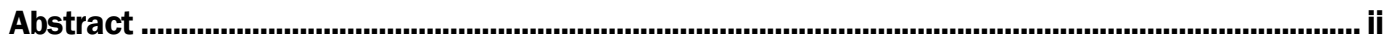

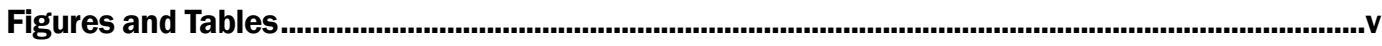

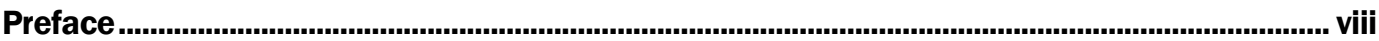

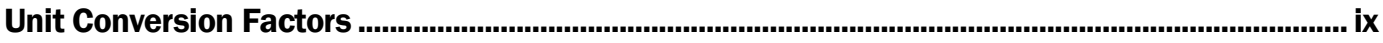

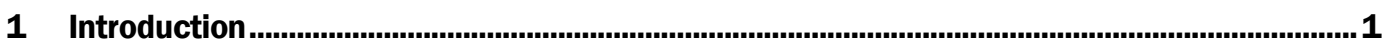

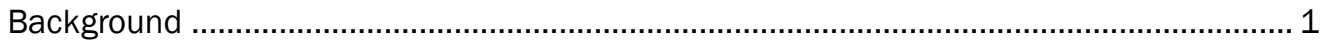

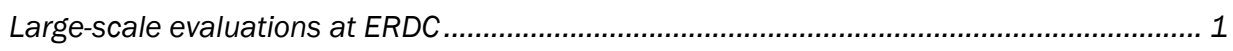

High-power run-up tests....................................................................................................... 5

Objective and scope of investigation ..................................................................... 9

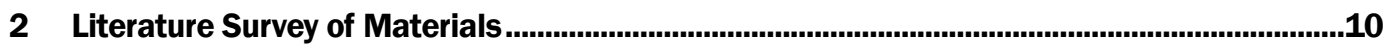

Metal matrix composites .............................................................................................. 10

Nanoparticle reinforced metal matrix composites............................................................ 21

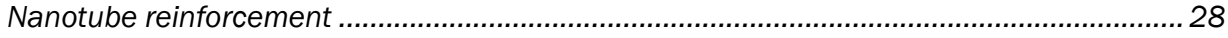

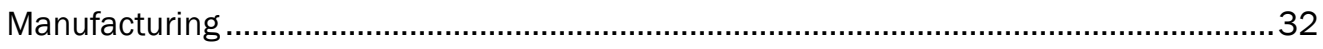

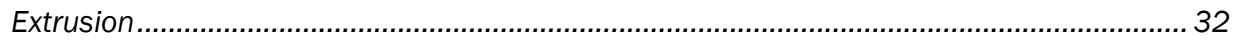

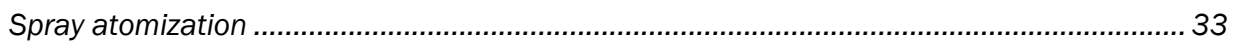

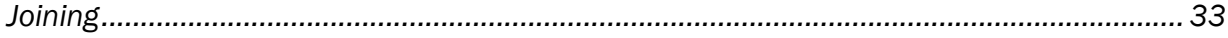

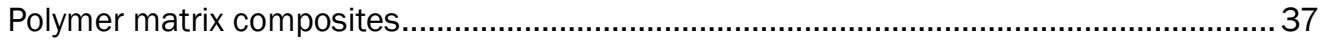

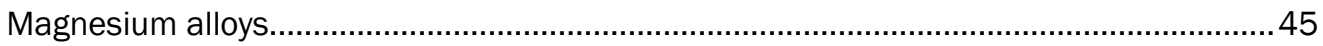

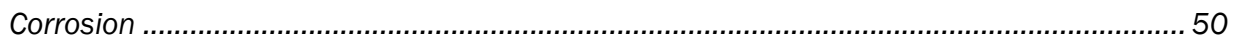

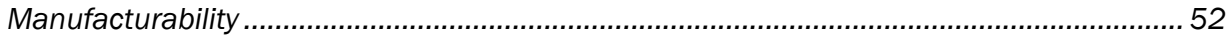

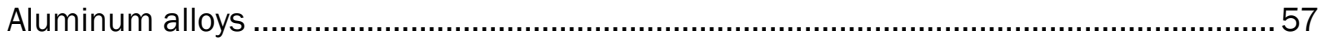

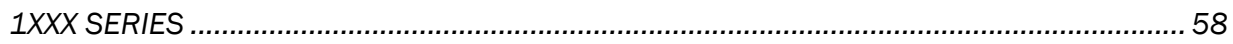

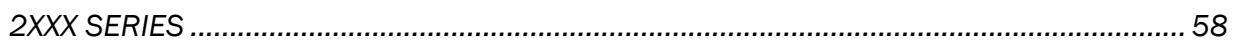

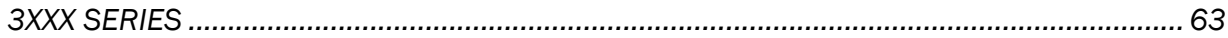

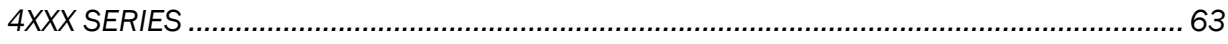

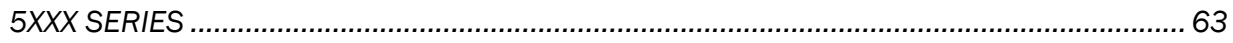

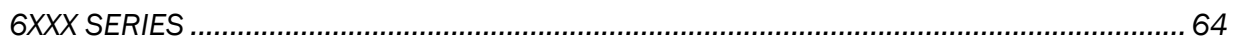

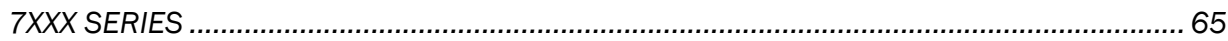

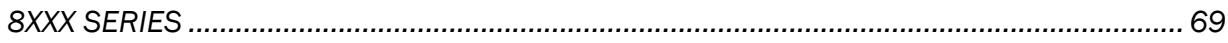

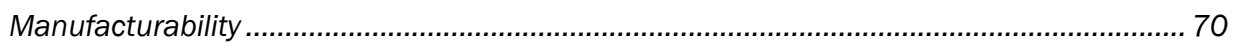

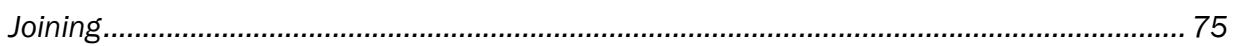

3 Market Cost Analysis .......................................................................................................83

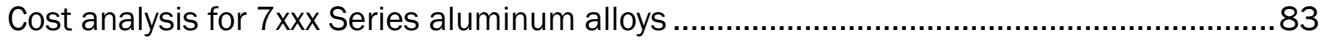

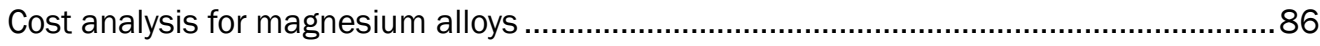

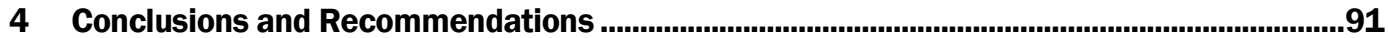




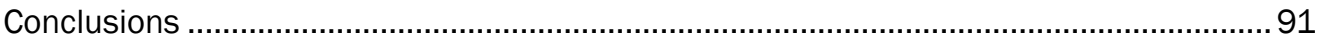

Recommendations for further research............................................................... 92

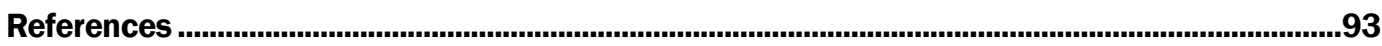

Report Documentation Page 


\section{Figures and Tables}

\section{Figures}

Figure 1. Matting surface grid (Rushing and Mason 2008)............................................................

Figure 2. Normally distributed traffic lanes (Rushing and Mason 2008)............................................

Figure 3. An example of a high-powered run-up test of a F-16 Fighter using full

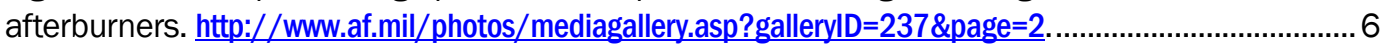

Figure 4. Contour maps of ultimate strengths for top and bottom sheets of Mat A........................... 7

Figure 5. Strength performance of Mat A top and bottom layers along with minimum

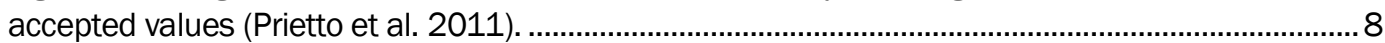

Figure 6. $\mathrm{Al}_{2} \mathrm{O}_{3}$ particles suspended in 6061 Aluminum (Hartmann et al. 2002)............................12

Figure 7. Stress-strain diagrams (a) 6061-T6 Alloy at ambient temperature, (b) 6061-T6

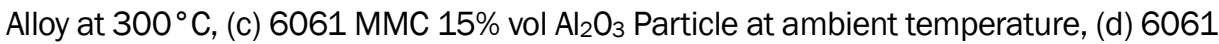
MMC $15 \%$ vol $\mathrm{Al}_{2} \mathrm{O}_{3}$ particle at $300^{\circ} \mathrm{C}$ (Perng et al. 1993).

Figure 8. Difference in particle cracking and debonding between COMRAL-85 and powder sintered $\mathrm{MMC}$ vol\% $20 \mathrm{Al}_{2} \mathrm{O}_{3}$ (Park et al. 2008)..............................................................................

Figure 9. Micrograph of SiC particle reinforcement (Ding et al. 2002).

Figure 10. Fatigue stress life results at ambient temperature for alumina and silicon carbide reinforcements $(R=-1)$.

Figure 11. Constant strain fatigue life of MMCs and unreinforced alloy at ambient temperature between $25^{\circ} \mathrm{C}$ to $27^{\circ} \mathrm{C}(\mathrm{R}=-1)$.

Figure 12. Constant strain fatigue life of MMCs and unreinforced alloy at elevated temperatures $\left(300^{\circ} \mathrm{C}\right)(\mathrm{R}=-1)$.

Figure 13. SiC particle debonding (Srivatsan et al. 2002) ................................................................17

Figure 14. SiC particle cracking (Srivatsan et al. 2002) ...................................................................17

Figure 15. Particle failure dependence on vol\% (Park et al. 2008). ...................................................18

Figure 16. Crack initiation in Sic particles (white areas denote debonding or volume cracking). (a)-(e) is under tension and (f)-(j) is under compression (Romanova et al. 2009)

Figure 17. Chart of number of publications on carbon nanotube reinforced materials per year (Bakshi et al. 2010)

Figure 18. Tensile properties of Al MMC with 0-7 vol\% $\mathrm{Al}_{2} \mathrm{O}_{3}(25 \mathrm{~nm})$ and $10 \%$ vol\% $\mathrm{SiC}$ (13 $\mu \mathrm{m})$ (Tjong 2007).

Figure 19. Stress strain charts of pure magnesium and its nano-MMC peers at (a) ambient temperature, (b) $100^{\circ} \mathrm{C}$, (c) $200^{\circ} \mathrm{C}$, and (d) $300^{\circ} \mathrm{C}$ (Tjong 2007).

Figure 20. Increase in agglomeration that is seen in $1 \mathrm{vol} \%$ (a) to 4 vol\% (b) of $\mathrm{Al}_{2} \mathrm{O}_{3}$ (Tjong 2007).

Figure 21. Stress-strain curve of 7075 aluminum and the $50 \mathrm{~nm} \mathrm{Al}_{2} \mathrm{O}_{3}$ reinforced $\mathrm{MMC}$ at 1 and 5 vol\%, (Ren 2007).

Figure 22. Examples of A356 without Ultrasonic Dispersion with a 20 micro-meter rule (a) and A356 with Ultrasonic dispersion with a 1 micrometer rule (b) (Yang et al. 2004).

Figure 23. Micrographs of Pre-FSP 10 vol\% (Left) and Post-FSP 30 vol\% after 4 passes (Lee et al. 2011). 
Figure 24. Tensile (T) and compressive (C) stress-strain curve of friction-stir processed MMCs versus pure aluminum (Lee et al. 2011).

Figure 25. Stress strain chart of carbon nanotube reinforced magnesium MMCs, label numbers represent wt\% (Goh et al. 2008).

Figure 26. Stress-strain chart of CNT reinforced pure titanium (Kondoh et al. 2009).

Figure 27. Plastic strain fields in ultra-fine grain (a) and nanoscale grain (b) aluminum

MMC. Tensile (top chart) and Shear Stress (bottom chart) for ultra-fine grain (c) and nanoscale grain (d) aluminum MMC (Choi et al. 2008).

Figure 28. Example of Spray Atomization (Srivatsan et al. 2002)

Figure 29. Friction-stir welded 7005 particle reinforced $\mathrm{Al}_{2} \mathrm{O}_{3}$ (Ceschini et al. 2007).

Figure 30. Micrograph of a FSW 6061 Al203 sample. BM - Base Metal, TMAZ -

Thermallyand mechanically affected region (Outer Ring), and DXZ - Directional

Recrystallized Region (Center of the Weld) (Storjahann et al. 2005).

Figure 31. Wear of a FSW Pin tool at various rotational speeds and transverse distances at a constant transverse speed of $6 \mathrm{~mm} / \mathrm{s}$. (a) $\mathrm{R}=500 \mathrm{rpm}$, (b) $\mathrm{R}=750 \mathrm{rpm}$, and (c) $\mathrm{R}=$ 1000 rpm (Femandez and Murr 2004).

Figure 32. Fatigue life comparison between IM7/PETI-5 and IM7/K3B materials (Counts and Johnson 2002).

Figure 33. Comparison of common extruded magnesium alloys to 6061 aluminum alloy..

Figure 34. Influence of temperature on fatigue properties of extruded AZ61 magnesium alloy (Sajuri et al. 2005).

Figure 35. Tensile properties of magnesium alloy AZ91 tested at 150C. Note that 1RE represents addition of $1 \%$ rare earth, $2 \mathrm{RE}$ represents addition of $2 \%$ rare earth; $3 \mathrm{RE}$ represents addition of $3 \%$ rare earth (Li et al. 2000).

Figure 36. $\sigma-\mathrm{N}$ curves for extruded ZK60, AM50 and AZ31 alloys in air (a) and in 3.5\% $\mathrm{NaCl}$ solution saturated with $\mathrm{Mg}(\mathrm{OH}) 2$ (b) (Unigovski et al. 2003).

Figure 37. (a) Peak load versus peak displacement for AZ31, 6063-T6 and 7075-T6 (D/t = $15)$ and $A Z 31(D / t=10)$ at different indenter diameters and $(b)$ Load versus indenter displacement plot using a displacement rate of $1 \mathrm{~mm} / \mathrm{s}$.

Figure 38. Aluminum and Magnesium Alloy Extrusion Limit (Atwell and Barnett 2007; Davies and Barnett 2004). .57

Figure 39. S-N comparison of peak-aged 2024 versus peak-aged 6061 (Wang 2010).

Figure 40. S-N curve comparing 2026 against 2024 in four-point bending (Li et al. 2005).............62

Figure 41. Strain-life results of 6061-T6 aluminum alloy (Wong 1984). ............................................66

Figure 42. S-N curve for 7050 at different stress ratios (MMPDS).

Figure 43. (Left) Stress-life fatigue data for 7055 at ambient temp. (Right) Stress-life fatigue data at $190^{\circ} \mathrm{C}$ (Srivatsan et al. 2000). 68

Figure 44. S-N curve comparing 6061 and 7075 (Wang 2010).

Figure 45. Flow stress versus extrusion rate for aluminum alloys (ASM 1993).

Figure 46. Schematic illustration of the friction-stir-weld process: (a) rotating tool prior to penetration into the butt joint; (b) tool probe makes contact with the part, creating heat; (c) shoulder makes contact, restricting further penetration while expanding the hot zone; and (d ) part moves under the tool, creating a friction-stir-weld nugget (Mahoney et al. 1998).

Figure 47. Image of the cross section of a non-heat-treated FSW 7075 tensile specimen with the edge of fracture surface visible. Image is orientation so the weld seam is transverse to the visible plain (Mahoney et al. 1998). 
Figure 48. Tensile strength of eight alloys as a function of average cooling rate during quenching (Nelson et al. 2003).

Figure 49. Stress/Strain Graph of water quenched, air cooled, base 7050 aluminum alloy specimens (Rui-Dong et al. 2011).

Figure 50. Graph comparing ultimate strength and elongation of water quenched, air cooled, base 7050 aluminum alloy specimen (Rui-Dong et al. 2011).

Figure 51. Stress amplitude (R=.1) fatigue life curves for 5083 MIG and FSW joints (Zhou 2005).

Figure 52. Stress amplitude fatigue life chart for MIG-pulse, TIG, and FSW high and low speed specimens (Ericsson and Sandstram 2003).

\section{Tables}

Table 1. Ultimate strength, yield strength, and hardness for top layer of Mat A.................................. 7

Table 2. Ultimate strength, yield strength, and hardness for bottom layer of Mat A............................ 7

Table 3. AM2 Matting Extrusion Profile Mechanical Properties (Brown et al. 2006) ........................53

Table 4. Static deflection test results (Brown et al. 2006). ................................................................53

Table 6. Chemical composition of AA2024 (Wt. \%) (Wang 2011) . ........................................................58

Table 7. Tensile properties of the alloys AA2024 or the T3 and T81 temper designations

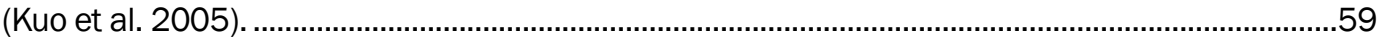

Table 8. Comparison of aging conditions in 2090 alloy (Venkateswara et al. 1988).......................63

Table 9. Chemical composition of AA6061 (wt.\%) (Jogi et al. 2008). ................................................65

Table 10. Heat degradation of the fatigue limit for 7049 (Jones 1972).............................................66

Table 11. Nominal chemical composition (Srivatsan 2002) ..........................................................68 


\section{Preface}

This study was conducted for the US Air Force Civil Engineer Center (AFCEC). Technical oversight was provided by Mr. J eb S. Tingle. Program management for the USAF was provided by the AFCEC East, Tyndall Air Force Base, Florida.

Principal Investigators for this study were Dr. Paul Allison, GSL, Concrete and Materials Branch (GM-C); and Timothy W. Rushing and Lyan Garcia, of the Airfields and Pavements Branch (GM-A). The research team also included Dr. J . Brian J ordon, Dr. Yuebin Guo, Andrew Brammer, and Robert McCullough, Department of Mechanical Engineering, University of Alabama under BAA\# A11-4799. At the time of this publication, Chris M. Moore was Chief, CEERD-GM-C; Dr. Larry N. Lynch was Chief, CEERDGM; and Dr. David A. Horner, CEERD-GV-T was the Technical Director for Force Projection and Maneuver Support. The Deputy Director of ERDC-GSL was Dr. William P. Grogan, and the Director was Dr. David W. Pittman.

COLJ effrey R. Eckstein was the Commander of ERDC, and Dr. J effery P. Holland was the Director. 


\section{Unit Conversion Factors}

\begin{tabular}{|l|c|l|}
\hline Multiply & By & To Obtain \\
\hline degrees Fahrenheit & (F-32)/1.8 & degrees Celsius \\
\hline feet & 0.3048 & meters \\
\hline inches & 0.0254 & meters \\
\hline microinches & 0.0254 & micrometers \\
\hline mils & 0.0254 & millimeters \\
\hline ounces (mass) & 0.02834952 & kilograms \\
\hline pounds (force) & 4.448222 & newtons \\
\hline pounds (force) per inch & 175.1268 & newtons per meter \\
\hline pounds (force) per square foot & 47.88026 & pascals \\
\hline pounds (force) per square inch & 6.894757 & kilopascals \\
\hline pounds (mass) & 0.45359237 & kilograms \\
\hline pounds (mass) per cubic foot & 16.01846 & kilograms per cubic meter \\
\hline pounds (mass) per cubic inch & $2.757990 \mathrm{E}+04$ & kilograms per cubic meter \\
\hline
\end{tabular}




\section{Introduction}

\section{Background}

The US military's requirement for rapid mobility includes the need to quickly expand existing airfield facilities to support increased throughput and staging requirements at intermediate staging bases and forward airfields. The nature of contingency operations precludes the construction of additional permanent pavements to support the increased parking and throughput requirements. Expedient surfacings have been used to rapidly expand existing airfield facilities to support increased numbers of aircraft during contingency operations. The primary expeditionary airfield surfacing for the US military is AM2 landing mat, which has been in service as a temporary runway, taxiway, and parking apron surface since the 1960s. Although AM2 has a long history of satisfactory performance, the US military's renewed emphasis in force projection requires a lighter, more agile force. AM2's weight and dimensions are limiting factors in its deployability, exceeding aircraft payload limits without approaching cubage limits. Thus, in recent operations, the use of AM2 has been inhibited by its excessive requirements for aircraft to transport significant quantities to contingency locations. For this reason, the US Air Force (USAF) initiated the Rapid Parking Ramp Expansion (RPRE) program, now called the AMX Airfield Mat Development Program, to develop a lightweight replacement for AM2. A lighter airfield mat would reduce airlift requirements and provide a substantial increase in airfield expansion capability.

An additional issue with the current AM2 is that many of the new aircraft systems using these runways have substantially higher landing gear loadings than their earlier predecessors. This weight makes the possibility of a matting failure during its typical service life much higher. This is in addition to the fact that the majority of the military operations during the system's development were based in the damper clay-based soil of eastsoutheast Asia, or Europe, which has now shifted to the drier sand and soil of the Middle East and North Africa.

\section{Large-scale evaluations at ERDC}

Recently, researchers (Rushing and Tingle 2007; Rushing et al. 2008; Rushing and Mason 2008; Garcia et al. 2014) investigated the effects of 
different engineered subgrades, with soil strengths having California Bearing Ratios (CBR) of 6 and above on matting performance. The study concentrated particularly on the subgrade's effect on the fatigue and loadcarrying capabilities of the existing AM2 matting system to determine a desirable set of design parameters for future matting designs or revisions.

For background purposes, a brief review of the tests by Rushing and Mason (2008) over a CBR of 15 is presented. For testing, a 2,400-sq-ft section of matting was placed on a sheltered test bed with a minimum of 3-ft engineered subgrade laid under it. The subgrade was constructed in various lifts with bearing capacities that measured 15 to $20 \mathrm{CBR}$, with the focus of the testing system being on producing a subgrade with an overall 15 CBR strength. This layer was then, in turn, supported by a foundational layer with a $+15 \mathrm{CBR}$ rating to reduce the effects of softer subgrades residing below the test section's engineered profile. The system was anchored along its perimeter by several one-ton blocks to simulate the effect of a fully deployed matting system.

A grid of sensors for detecting displacement and strain were placed along two lines as can be seen in Figure 1. These sensors were laid at various depths within the subgrade, with only a set of strain gauges making physical contact with the matting system. The position of the sensors corresponded to the center of the taxiing paths for the C-17 and F-15E simulations. To better simulate the effect of aircraft loading, a normally distributed taxiing scheme for both aircraft was laid out around the centerline produced by the sensors. For the F-15 segment, the distribution grid contained five 12-in. lanes and, for the C-17 segment, six 18-in. lanes were plotted on the grid seen in Figure 2.

Two separate vehicles were used to simulate the various loadings of an F-15 and C-17 aircraft taxiing along the matting's surface. The F- 15 load cart used an 11-in.-wide single-wheel configuration loaded to 35,235lb. The C-17 load cart used a six-wheel platform (three front and three back) to simulate a full rear landing gear segment. This tire set was loaded to 269,560 lb, with an average single tire width of $18 \mathrm{in}$. and load distribution of 44,930 lb. During the actual loading, the simulation was run continuously until $10 \%$ or more of the matting panels had failed. For the experiment, $10 \%$ failure represented the number of panels divided by the total number of panels in the aircraft's taxi lane, with the failed panels posing a safety risk to the aircraft by either substantially compromising the surface integrity or 
exposing sharp edges that could damage the rubber tires. For the F-15, which had a 24-ft-by-40-ft lane, the total number of panels was estimated to be 36, with four panels having to fail before the matting was considered compromised. For the C-17, which had a substantially larger lane of $36 \mathrm{ft}$ by $40 \mathrm{ft}$, the total number of panels was determined to be about 64 panels, with six having to fail before the matting was considered compromised.

Figure 1. Matting surface grid (Rushing and Mason 2008).

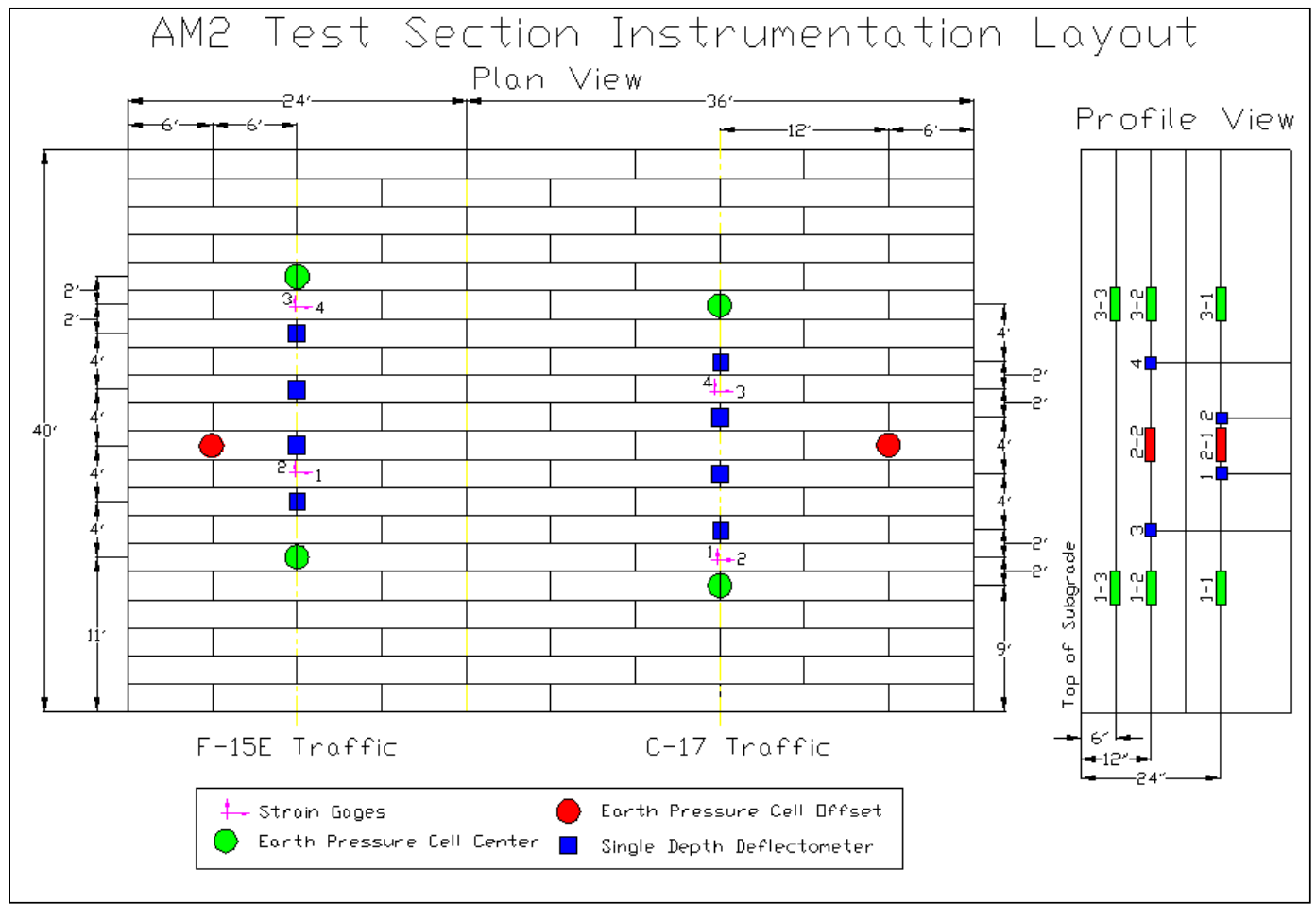

Figure 2. Normally distributed traffic lanes (Rushing and Mason 2008).

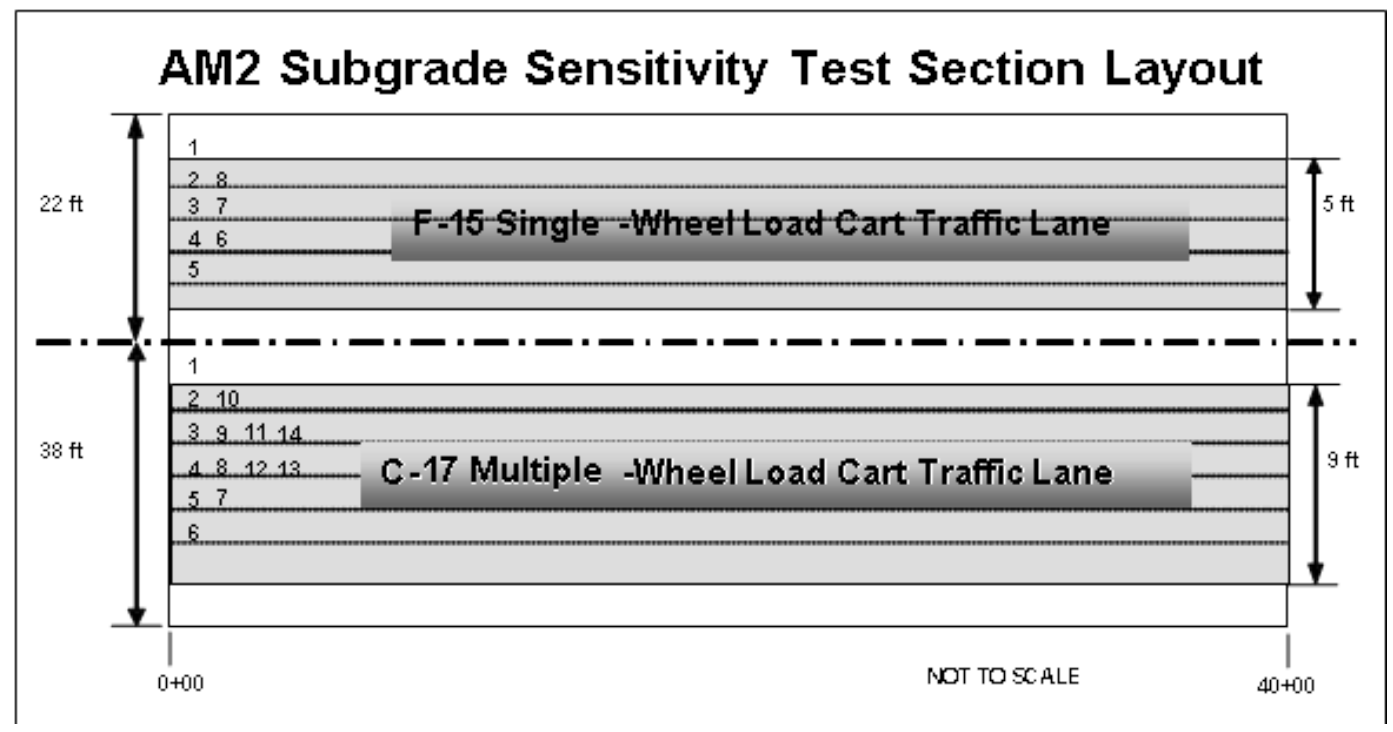


After running both tests, the investigators were able to make several important conclusions about the mechanical reaction of the matting to taxiing loading. First, the heavy dependence of the matting on the quality and overall hardness of the subgrade it is being placed over was confirmed. Investigating the passes-to-failure data found that the results confirmed a trend seen previously when testing the matting on 6 and 10 CBR-rated subgrades with similar loadings. Under F-15 loadings, the matting performed $175 \%$ better $(4,100$ passes versus 1,500 passes) with a 15 CBR subgrade than when a 6 CBR subgrade was used. The improvement was even more pronounced in the C-17 test with the matting performing $367 \%$ better (7,000 passes versus 1,500 passes) when using the $15 \mathrm{CBR}$ subgrade. The advantage was not as pronounced between the $10 \mathrm{CBR}$ and $15 \mathrm{CBR}$ subgrades under $\mathrm{C}$-17 loadings, with only a $16 \%$ increase (6,000 passes versus 7,000 ) seen in the overall performance. This was much less than observed with the matting performance under F-15 loading, which increased $36 \%$ (3,000 passes to 4,100 passes).

The second observation made from the results was that the matting seemed to be greatly affected by the ratio of vertical deflection versus the loading area of the gear set. The C-17, which had the largest surface-loading characteristic, had an average subgrade rut width of about $18 \mathrm{ft}$ or $216 \mathrm{in}$. and a max depth of $1.28 \mathrm{in}$. for a ratio of 0.00593 . This was a much lower ratio than that found for the F- 15 test item, which was recorded as having a width of $7 \mathrm{ft}$ or $84 \mathrm{in}$. and a mat depth of $1.05 \mathrm{in}$. for a ratio of 0.0125 . This would indicate that the test segment for the $\mathrm{F}-15$ experienced a larger amount of localized elongation, possibly incurring a higher percentage of plastic deformation early in the test than seen in the C-17 segment, causing the fatigue life of these panels to decrease substantially. In fact, in the first 100 passes under F-15 loading, the deflection reached almost $80 \%$ of the max deflection of $1.2 \mathrm{in}$. This result is in sharp contrast to the C-17, which took 2,000 passes to finally reach the $80 \%$ deflection mark.

The overall conclusion based on the subgrade experiments is that the AM2 matting surface is extremely dependent on the subgrade supporting the matting. As such, the lower CBR-rated subgrades were shown to greatly decrease the fatigue life of the matting when subjected to similar testing conditions, as confirmed in prior testing. After observing the performance increase in each subsequent test, it was concluded that the decrease in deflection due to subgrade deflection resistance played a substantial role in this increase in endurance. It was also noted that the two rail extruded 
flanges welded to the 24-in. edges of each mat segment was the major weak point under the characteristic loading of the experiment. In addition, it was observed that while the matting tests were set up to simulate full-scale trafficking, the small area and controlled nature of the testing did not completely account for the taxiing path made by the aircraft during field operations. Also, the small size of the matting system tested did not completely account for the actual size of the deployed matting configurations, which can reach hundreds of feet in width and length. This large size could create a tensile loading across the matting surface, thus reducing the deflection of the panel and decreasing the vertical shear loading placed on the joints.

\section{High-power run-up tests}

With the addition of the new F-35J oint Strike Fighter with the capability of vertical takeoff, an analysis of the performance of the AM2 exposed to elevated temperature is presented. Here the performance of the 6061-T6 aluminum alloy AM2 was exposed to the jet exhaust during a high-powered run-up (Prietto et al. 2011). An example of powered run-up is shown in Figure 3. The high-power run-up test is a test of the jet engine system after maintenance and requires the aircraft to be firmly anchored to the runway surface. The high-temperature nature of the jet exhaust can reach in excess of $700^{\circ} \mathrm{C}$. As such, this is an excellent simulation of the possible endurance capability of the matting to high-temperature thrust. After undergoing exposure to the high-power run-up, the affected panels were observed to be covered with varying degrees of oxidation and was an indicator of specific regions of matting that were distinctly affected by the heat blast.

During the high-powered run-up, anchors were used to secure the aircraft. The implementation of these anchors, integrated directly into the matting, allowed a constant thermal loading to be placed on the AM2 matting surface. In this examination, an analysis of the gradient strength and hardness readings of the panel is provided. Analyzing the ultimate strength contour map provided in Figure 4, an orientation for the nozzle thrust jet can be approximated as projecting across the length of the matting panel. For the analysis, the panel was cut into 14 segments along its 12-ft length.

In the study of the elevated temperature effect on the AM2 matting panels, two particular panels were received and processed for evaluation. The panel labeled "Mat A" showed very distinct results in that several regions of visible physical differences could be noted. Tables 1 and 2 were derived 
Figure 3. An example of a high-powered run-up test of a F-16 Fighter using full afterburners. http://www.af.mil/photos/mediagallery.asp?gallerylD=237\&page=2.

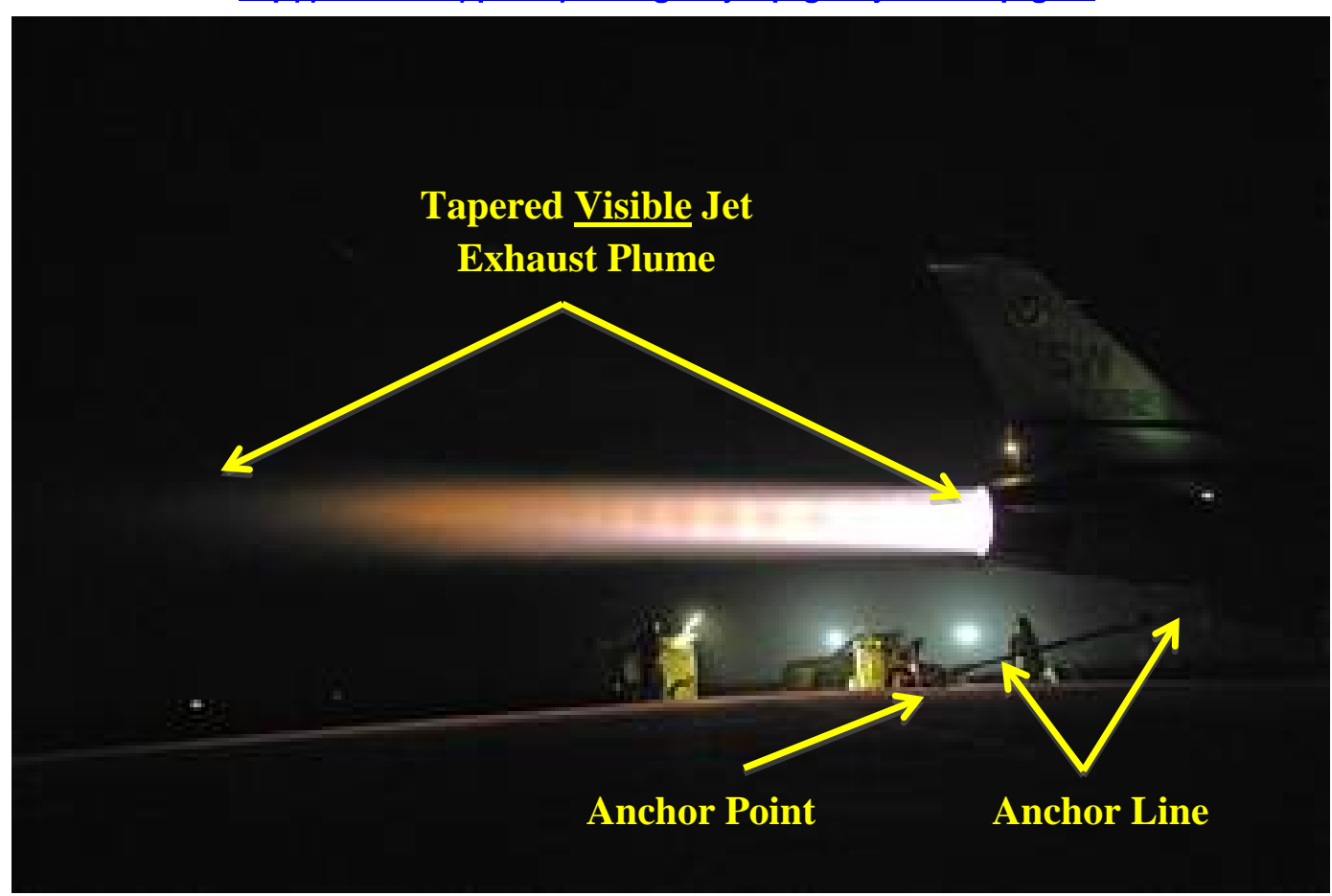

from individual analysis of both segments from the top and bottom surfaces. By deduction, a notation was made that the top layer of the matting should be more susceptible to the effects of heat as it will be in direct contact with the jet exhaust. The results seen in Tables 1 and 2 are directly in accordance to this observation.

Many of the affected segments still showed results that were above the minimum values for the material's ultimate ( $42 \mathrm{ksi}$ ) and yield ( $35 \mathrm{ksi})$ strengths that would be accepted. However, several points exhibited severe degradation. This degradation was observed as tending toward one end of the test panel and receding dynamically along its length, consistent with the known profile of a jet exhaust emission. A special notation was made that the material was weaker through the center line of the panel, which was seen in both the top and bottom surfaces and indicates that, while the surface is shielded to a degree, the high-temperature exhaust still significantly impacts the entire segment's performance, especially in Regions 1 through 3. 
Figure 4. Contour maps of ultimate strengths for top and bottom sheets of Mat A.

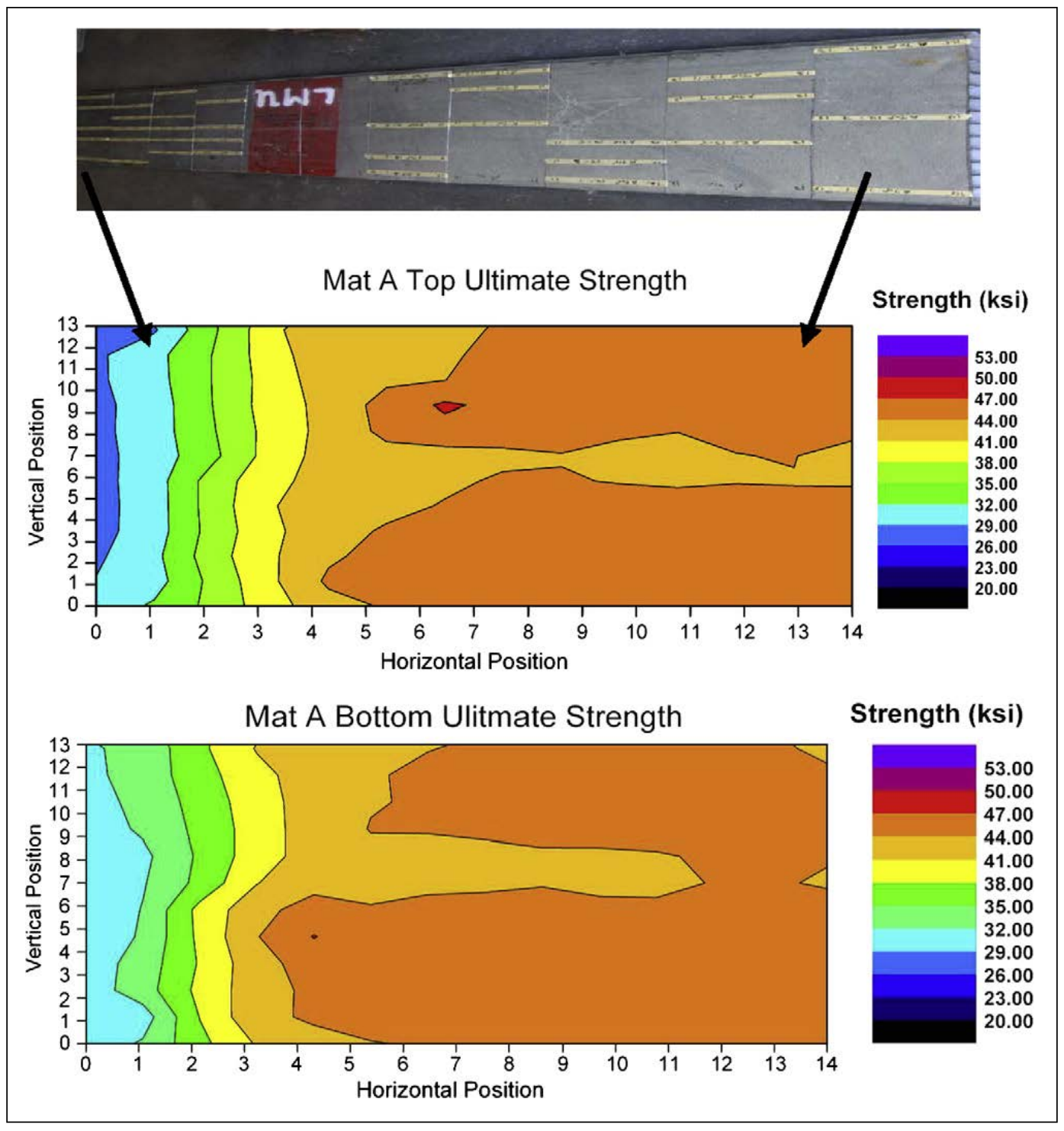

Table 1. Ultimate strength, yield strength, and hardness for top layer of Mat A.

\begin{tabular}{cccccccccccccccc}
\hline Mat A, top & 1 & 2 & 3 & 4 & 5 & 6 & 7 & 8 & 9 & 10 & 11 & 12 & 13 & 14 & Avg. \\
Ultimate Strength (ksi) & 30.1 & 35.4 & 39.2 & 43.4 & 43.8 & 44.1 & 44.3 & n/a & n/a & 45.3 & 44.2 & 45.4 & 44.9 & 44.3 & 42.03 \\
Yield Strength (ksi) & 23.4 & 31.3 & 36 & 40.5 & 40.5 & 41.4 & 41.3 & n/a & n/a & 42.5 & 41.6 & 42.4 & 41.9 & 41.8 & 38.72 \\
Hardness (Rockwell 15T) & 69.1 & 75.1 & 79 & 80.7 & 82.2 & 80.6 & 80.7 & n/a & n/a & 81.8 & 81.2 & 81.3 & 81.1 & 80.8 & 79.47 \\
\hline
\end{tabular}

Table 2. Ultimate strength, yield strength, and hardness for bottom layer of Mat A.

\begin{tabular}{cccccccccccccccc}
\hline Mat A, top & 1 & 2 & 3 & 4 & 5 & 6 & 7 & 8 & 9 & 10 & 11 & 12 & 13 & 14 & Avg. \\
Ultimate Strength (ksi) & 30.1 & 35.4 & 39.2 & 43.4 & 43.8 & 44.1 & 44.3 & n/a & n/a & 45.3 & 44.2 & 45.4 & 44.9 & 44.3 & 42.03 \\
Yield Strength (ksi) & 23.4 & 31.3 & 36 & 40.5 & 40.5 & 41.4 & 41.3 & n/a & n/a & 42.5 & 41.6 & 42.4 & 41.9 & 41.8 & 38.72 \\
Hardness (Rockwell 15T) & 69.1 & 75.1 & 79 & 80.7 & 82.2 & 80.6 & 80.7 & n/a & n/a & 81.8 & 81.2 & 81.3 & 81.1 & 80.8 & 79.47 \\
\hline
\end{tabular}

The degradation report due to the exposure of the elevated temperature was seen to have quite a substantial impact on the performance of the 
matting, with the ultimate strength of the material dropping as much as $28 \%$ below the minimum accepted value. The information in Tables 1 and 2 also show that there was a large amount of softening in the significantly affected regions. As can be seen on the contour map, some regions experienced even greater weakening (Figure 5).

Figure 5. Strength performance of Mat A top and bottom layers along with minimum accepted values (Prietto et al. 2011).

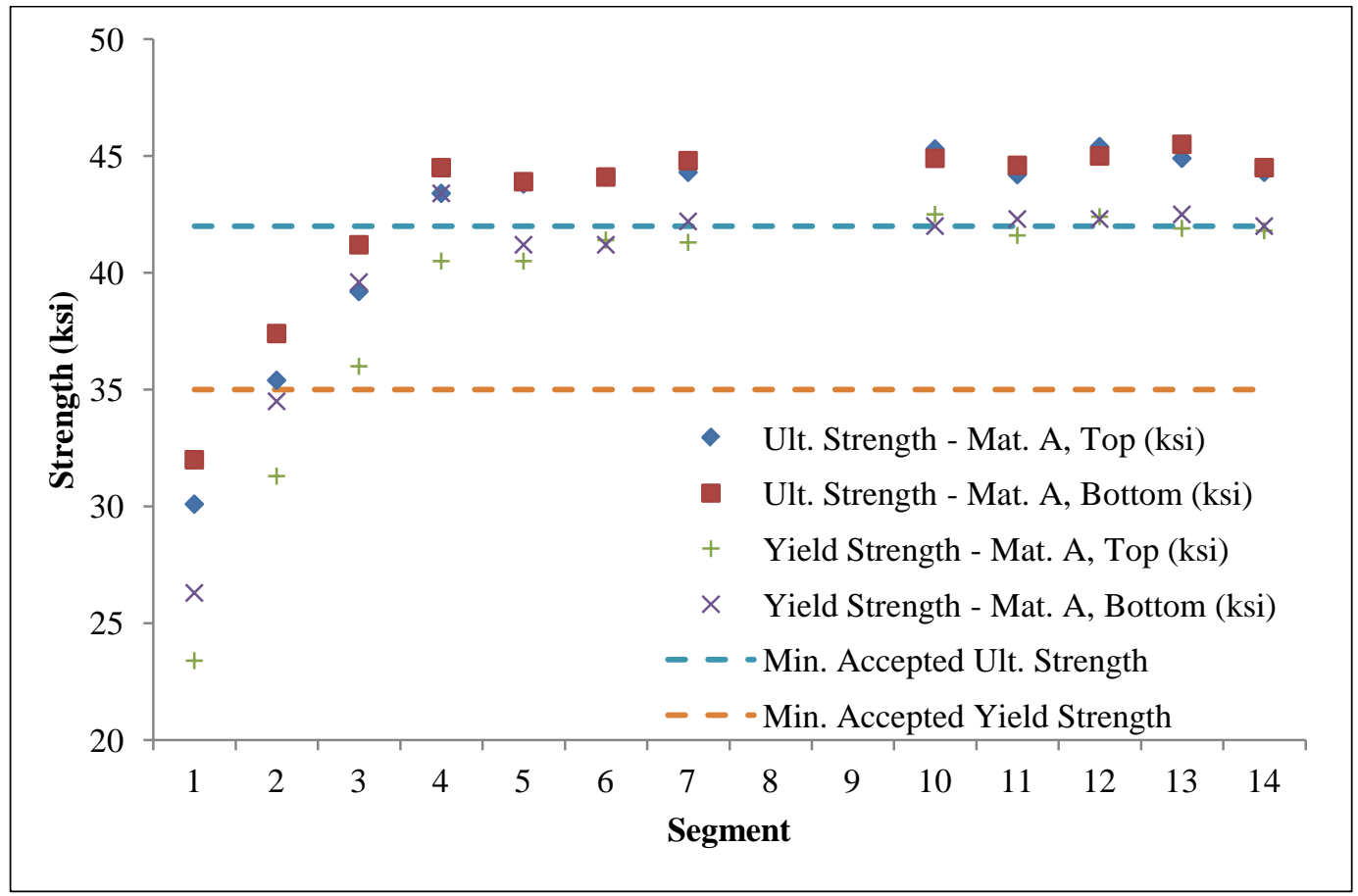

While this weakening is significant and gives a very good idea of the potential performance of the matting in high-temperature environments, high-power run-ups are sustained over an extended period of time (not specifically reported), which most likely is a much longer period of time than that which will have to be sustained by panels subjected to vertical lift thrust forces. This study highlighted a weakness that the 6061-T6 aluminum alloy possesses in view of high-temperature conditions. This weakness could become very prevalent if a region is used repeatedly for vertical takeoff and landings, as well as repetitive taxiing.

In conclusion, the matting performance using current deployment scenarios did do well overall during its effective period of testing until failure. However, the endurance of the matting is still in need of improvements because, when failures do occur, they are in the low-cycle regime and tend to fail rapidly. Also, in analyzing the effects of the high-power run-up on the 
matting, a clear diagnosis can be made that the combination of this hightemperature reaction and weak operation performance could pose a significant issue in the effectiveness of AM2 runway deployment with future generation military aircraft systems.

\section{Objective and scope of investigation}

The primary objective of this evaluation was to analyze possible material for replacement of the current 6061 aluminum alloy for the purpose of lightweighting the AM2. The analysis included a survey of traditional lightweight metals as well as more advanced materials and composites. An in-depth analysis of the metal matrix composites is presented. In addition to micro-scale metal matrix composites, a review of nano-scale metal matrix composites is also presented. The feasibility of polymer matrix composites was also conducted. Finally, potential high-strength aluminum alloys were identified as well as extruded magnesium alloys.

A secondary objective of the research was to perform material characterization and material modeling on 6061-T6 aluminum alloy from the current AM2. The purpose here is to calibrate microstructure sensitivity material models for the purpose of optimizing the AM2 design.

This report includes the analysis of the literature review and the results of the cost analysis. The literature review is described in Chapter 2. Chapter 3 presents the cost analysis of high-strength aluminum and magnesium alloys. Pertinent conclusions are presented in Chapter 4. 


\section{Literature Survey of Materials}

\section{Metal matrix composites}

In this section, a review of literature regarding the use of advanced materials, such as metal matrix composites (MMCs), in the AM2 airfield matting system for the purpose of lightweighting is presented.

The properties of many metals have been found through the years to be greatly improved by combining multiple materials into a single amalgamation with those metals. In the case of the 6xxx series aluminum alloys, the integration of magnesium and silicon into the pure aluminum material makes a composite material that is substantially stronger than the pure metal, as well as harder and tougher. Additionally, the new material maintains a good range of manufacturability and the characteristic density of the 6xxx material. The same property-enhancing characteristics that are foundational to alloys is also core to the MMCs being developed today.

In general, an MMC is a type of material that encompasses a very wide range of compositions and differs physically from one another, mainly in the size and shape of the added reinforcement material. These reinforcement materials can be anything from plastics to ceramics. However, unlike a traditional alloy, these materials are integrated into the base metal (matrix) as either a large amalgamation of molecules or massive molecular chains (such as carbon fibers), forming regions within the matrix that are very distinct from the base material structure.

The end goal of these composites is to be able to design a material that greatly increases distinct mechanical properties of the base material. For example, the theoretical integration of plastics could increase the vibration properties of the metal matrix, as well as improve the composite's elastic performance. Large metal reinforcement particles could improve the matrix's existing properties, but also could have the advantage of decreasing the use of more expensive matrix materials by diluting the matrix with a more cost effective metal. The large size of the particle reinforcement allows for the reinforcement to interact more with the physical structure of the matrix material, interacting directly with the grain structure of the material and allowing a greater degree of control over grain shifting, much like the alloying particles inhibit atomic dislocations. 
The key point of focus in the investigation of MMCs for use in the AM2 airfield matting system is in the area of durability endurance under cyclic loading. In addition, a study of the material's elasticity, high temperature endurance, and potential benefits and hindrance in its manufacturing are addressed. In order to provide a concise and detailed analysis on the feasibility of the MMCs, the analysis herein concentrates on the effect of microscale reinforcement in the already utilized 6061-T6 material, for its wellknown material properties and stable manufacturability.

To start, the primary 6061 aluminum alloy MMCs typically contain either alumina (typically $\mathrm{Al}_{2} \mathrm{O}_{3}$ ) or silicon carbide ( $\mathrm{SiC}$ ) ceramic reinforcement as either large particles or short, drawn fibers. By far, the alumina particle based MMCs were the most prevalently documented in the area of fatigue loading.

Regarding static properties, the addition of 10 to $21 \%$ vol of alumina in the 6061 alloy MMC (Perng et al. 1993; Papakyriacou et al. 1996), was observed to lead to a considerable increase in the yield and ultimate strength versus the standard unreinforced 6061-T6 alloy. The $\mathrm{Al}_{2} \mathrm{O}_{3}$ particle MMCs having a noticeably increased hardness versus the standard alloy with a substantial decrease in ductility, ranging as much as $50 \%$ of that observed in the standard alloy was also noted. An example of $\mathrm{Al}_{2} \mathrm{O}_{3}$ particle reinforced MMCs is shown in Figure 6. In most of the tests, MMCs with an Alumina $15 \%$ vol (Perng et al. 1993) showed the greatest increases in strength. This reinforcing trend was also seen to continue almost completely unchanged at elevated temperatures, with the material being tested as high as $300^{\circ} \mathrm{C}$ $\left(572^{\circ} \mathrm{F}\right)$. Figure 7 shows the static stress strain data for unreinforced and reinforced MMCs at ambient and elevated temperatures.

Lastly, observations were also made in the performance of powder metallurgy versus liquid metallurgy based MMCs. These MMCs, typically COMRAL- $85^{\mathrm{TM}}$, an $\mathrm{Al}_{2} \mathrm{O}_{3} 20 \%$ vol reinforced MMC manufactured using molten techniques, exhibited similar static performance to MMCs produced using a powder metallurgy technique, such as a standard cold compacting press and sintering process. However, the fatigue life of the liquid-based MMCs was much lower when compared to that of a similar powder-based MMC. Also at failure, particle cracking was much more prevalent in the liquid-based MMCs, than their powder-based peers, as shown in Figure 8 (Park et al. 2008). This was hypothesized as being caused by interface stresses developing due to differences in the thermal expansion properties of the materials. 
Figure 6. $\mathrm{Al}_{2} \mathrm{O}_{3}$ particles suspended in 6061 Aluminum (Hartmann et al. 2002).

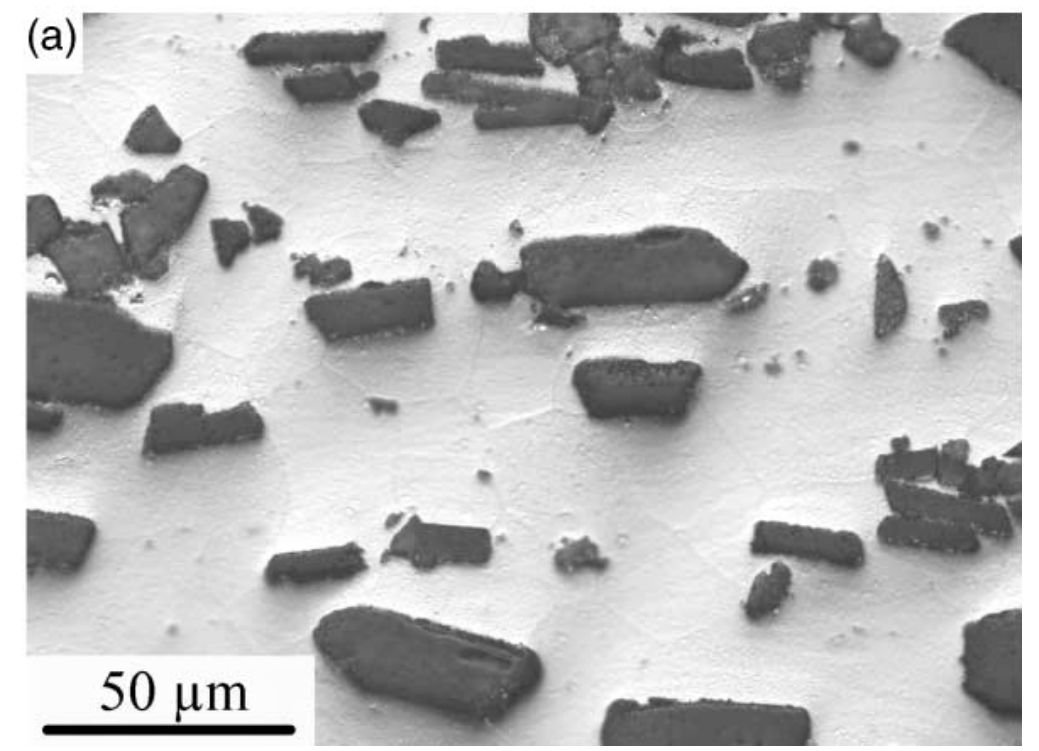

Figure 7. Stress-strain diagrams (a) 6061-T6 Alloy at ambient temperature, (b) 6061-T6 Alloy at $300^{\circ} \mathrm{C}$, (c) $6061 \mathrm{MMC} 15 \%$ vol $\mathrm{Al}_{2} \mathrm{O}_{3}$ Particle at ambient temperature, (d) $6061 \mathrm{MMC} 15 \%$ vol $\mathrm{Al}_{2} \mathrm{O}_{3}$ particle at $300^{\circ} \mathrm{C}$ (Perng et al. 1993).
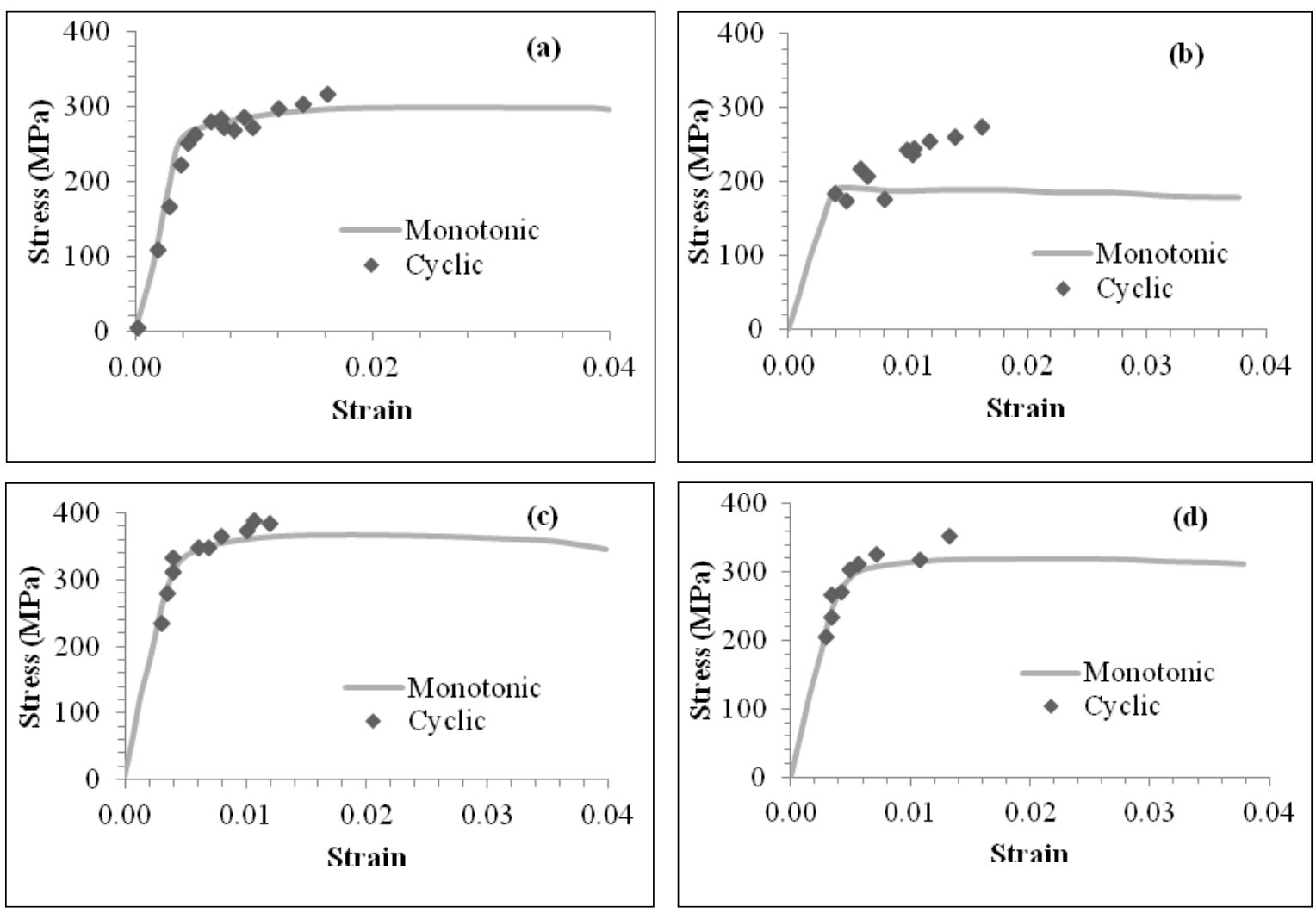
Figure 8. Difference in particle cracking and debonding between COMRAL-85 and powder sintered MMC vol\% $20 \mathrm{Al}_{2} \mathrm{O}_{3}$ (Park et al. 2008).

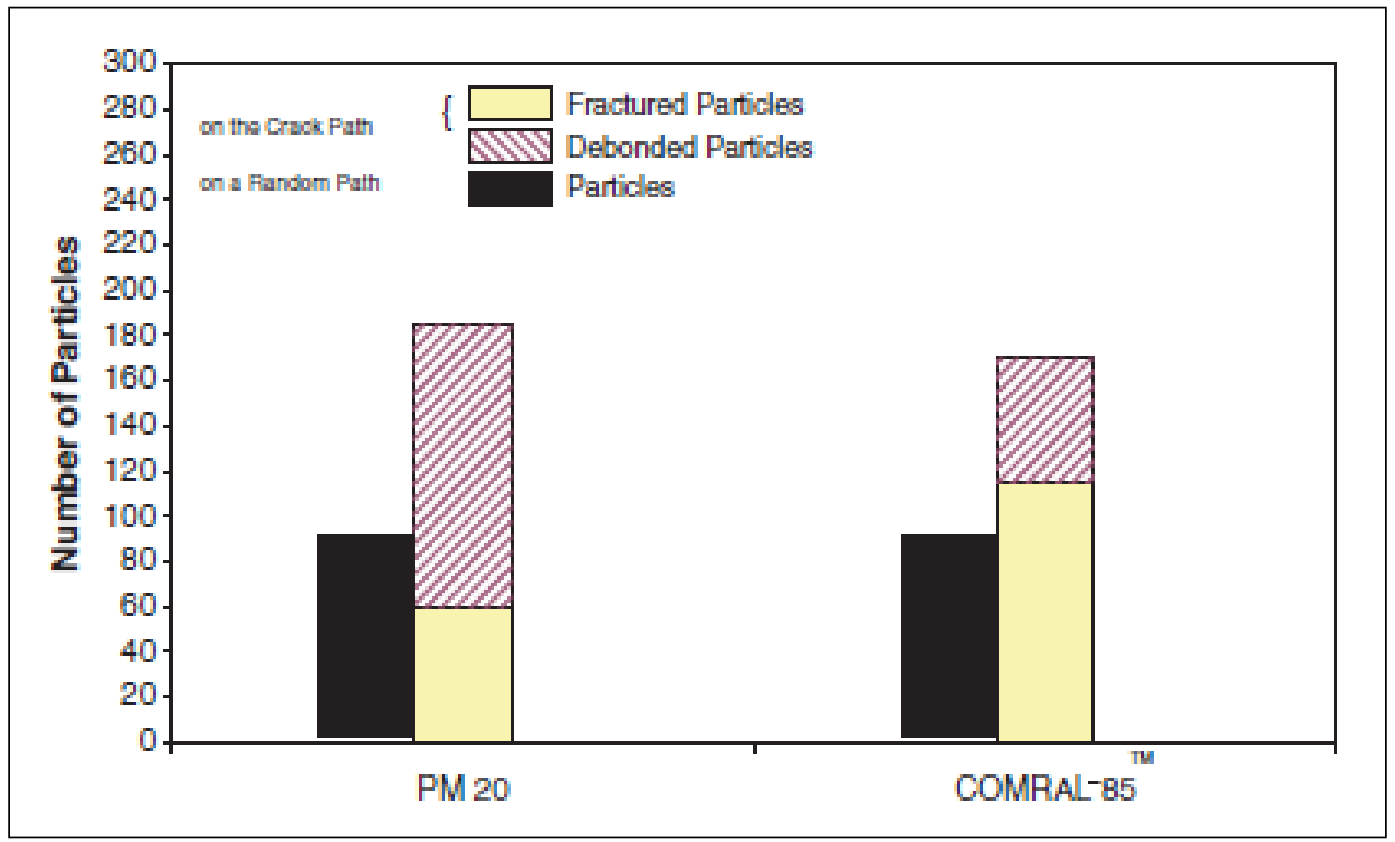

Most of the trends observed in the alumina particle-based MMC material were also observed in the case of the silicon carbide short fiber (SiC) MMC. An example of a silicon carbide short fiber is shown in Figure 9. The material showed a marked improvement in ultimate and yield strength in static conditions and experienced considerable hardening versus the unreinforced alloy. The SiC fibers were tested with vol\% ranging from 20 to 40 and, while the volume of $\mathrm{SiC}$ is indeed higher, the material's substantially lower density ( $3.2 \mathrm{~kg} / \mathrm{cm}^{3}$ versus $4 \mathrm{~kg} / \mathrm{cm}^{3}$ for $\mathrm{Al}_{2} \mathrm{O}_{3}$ ) has the advantage of decreasing the weight of the MMC (Lee et al. 2010; Peng and Chaki 1995).

One of the main evaluation criteria of the MMC for use in the AM2 is in regard to fatigue resistance. Overall, the fatigue resistance of the MMC is generally inferior to that of the unreinforced alloy. Figure 10 shows the stress-life results of both $\mathrm{Al}_{2} \mathrm{O}_{3}$ and $\mathrm{SiC}$ particle/ fiber reinforced MMCs. With the exception of vol\% $15 \mathrm{SiC}$ particles, the unreinforced alloy exhibited better fatigue performance. However, the one set of data that does show an improvement is over a small stress range and the trend may not extend through the full range of stress amplitudes. Since experimental results of fatigue of the AM2 show that failure is occurring in the low-cycle range in the presence of stress concentration, strain-life data is typically more applicable than stress-life. Figures 11 and 12 show the strain-life results of 
Figure 9. Micrograph of SiC particle reinforcement (Ding et al. 2002).

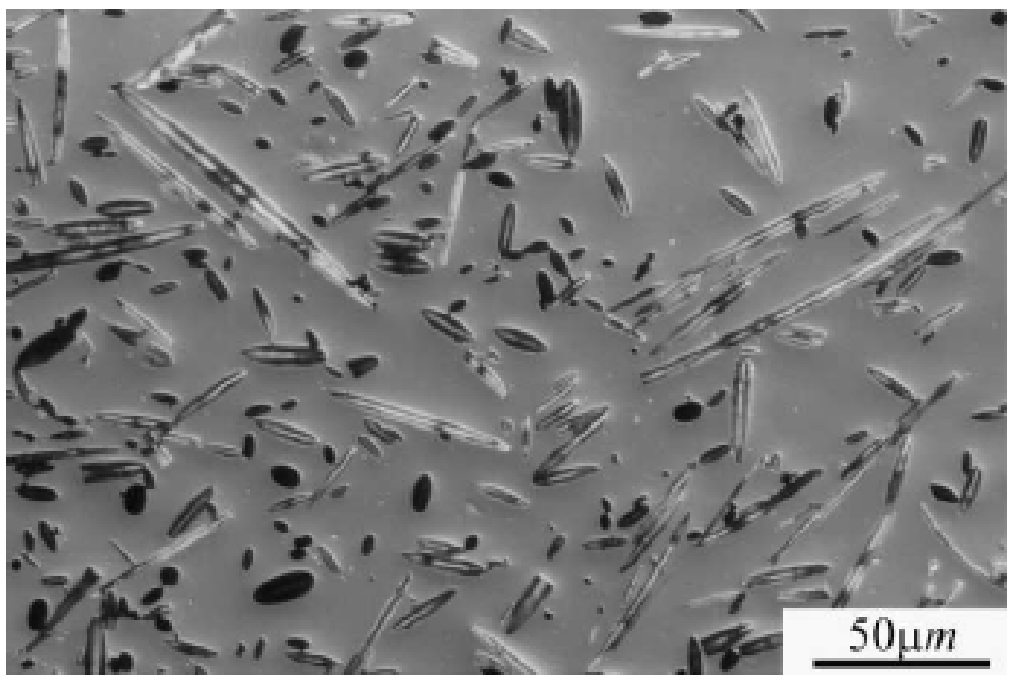

Figure 10. Fatigue stress life results at ambient temperature for alumina and silicon carbide reinforcements $(R=-1)$.

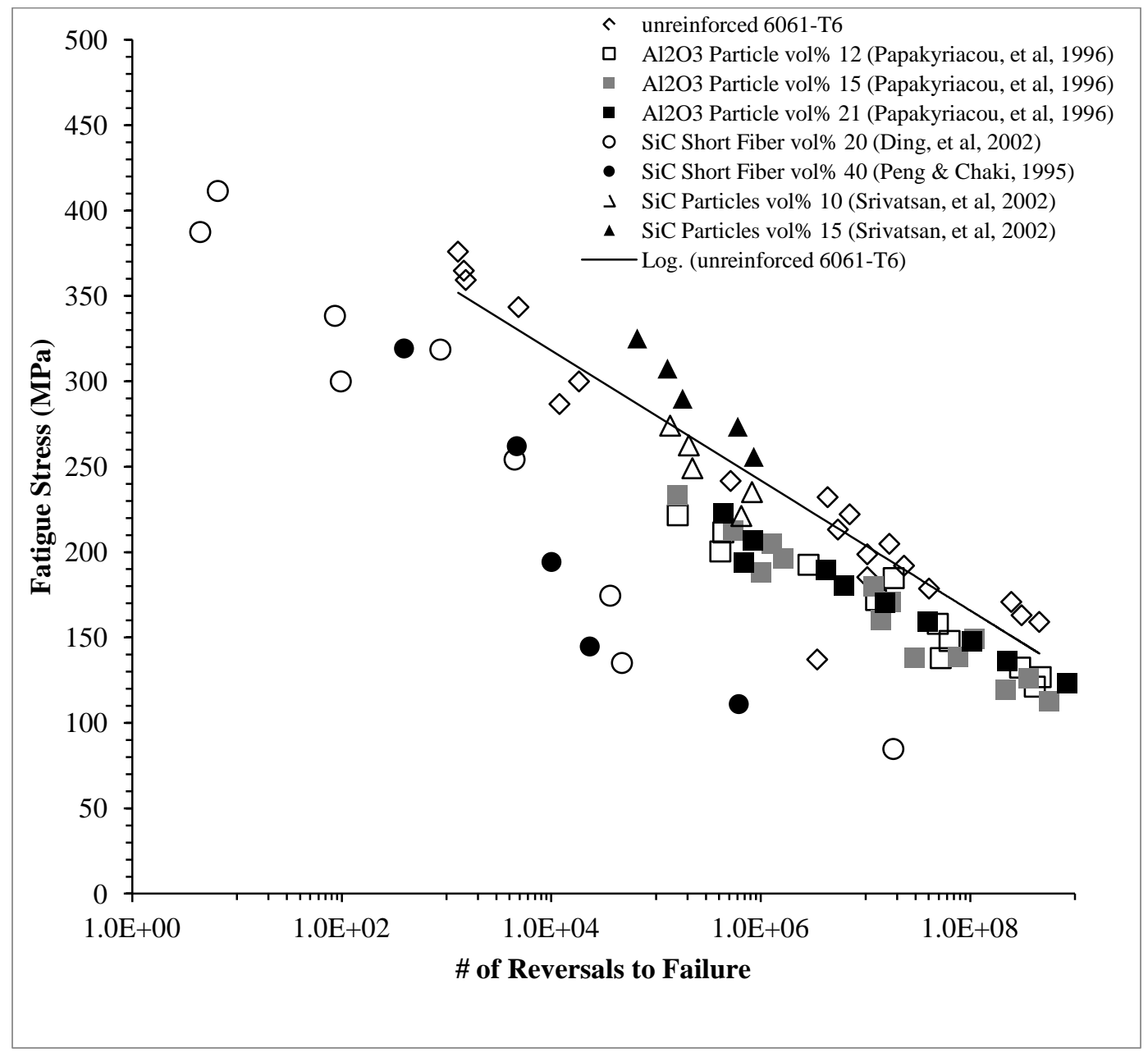


Figure 11. Constant strain fatigue life of MMCs and unreinforced alloy at ambient temperature between $25^{\circ} \mathrm{C}$ to $27^{\circ} \mathrm{C}(\mathrm{R}=-1)$.

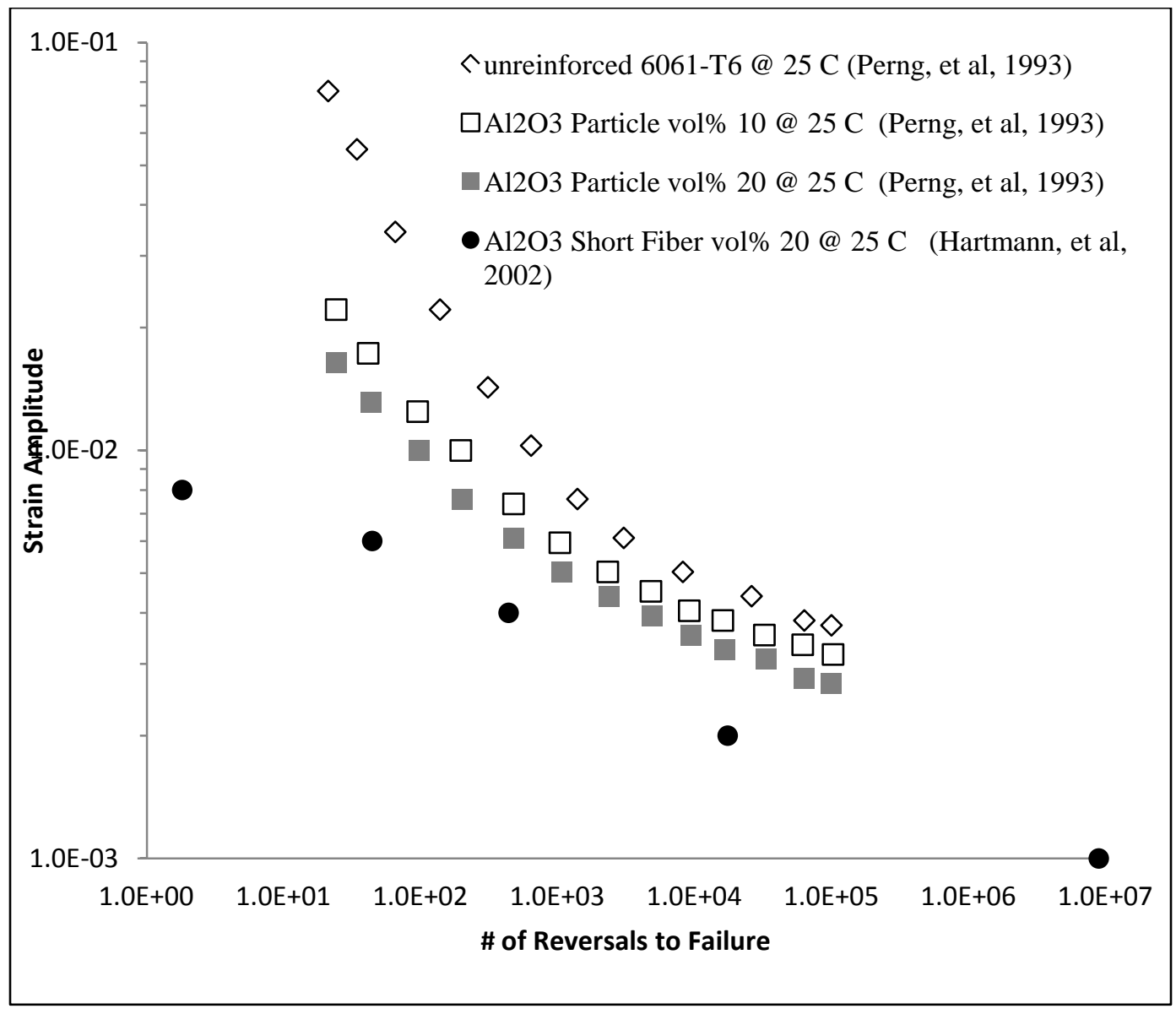

the $\mathrm{MMC}$ at ambient $\left(25^{\circ} \mathrm{C}\right)$ and elevated temperatures $\left(300^{\circ} \mathrm{C}\right)$, respectively. Here, the MMC performance under strain control followed a similar trend to that of the stress-life results. As shown in Figure 12, the MMC exhibited a significant drop in fatigue performance compared to ambient temperature. The presence of large temperature gradients in the material, especially when applied in a cyclic manner, were observed to decrease the fatigue life of the MMC significantly over that of very small temperature gradient conditions (Klaska et al. 2009). This trend was especially notable in short drawn fiber reinforcement MMCs (Figure 12). This is a substantial indicator of the development of internal stresses within the material due to differences in the thermal expansion coefficients of the various materials. These stresses could very likely have compounded the material further by producing shearing stresses in the matrix and, therefore, decreasing the material's performance. 
Figure 12. Constant strain fatigue life of MMCs and unreinforced alloy at elevated temperatures $\left(300^{\circ} \mathrm{C}\right)(\mathrm{R}=-1)$.

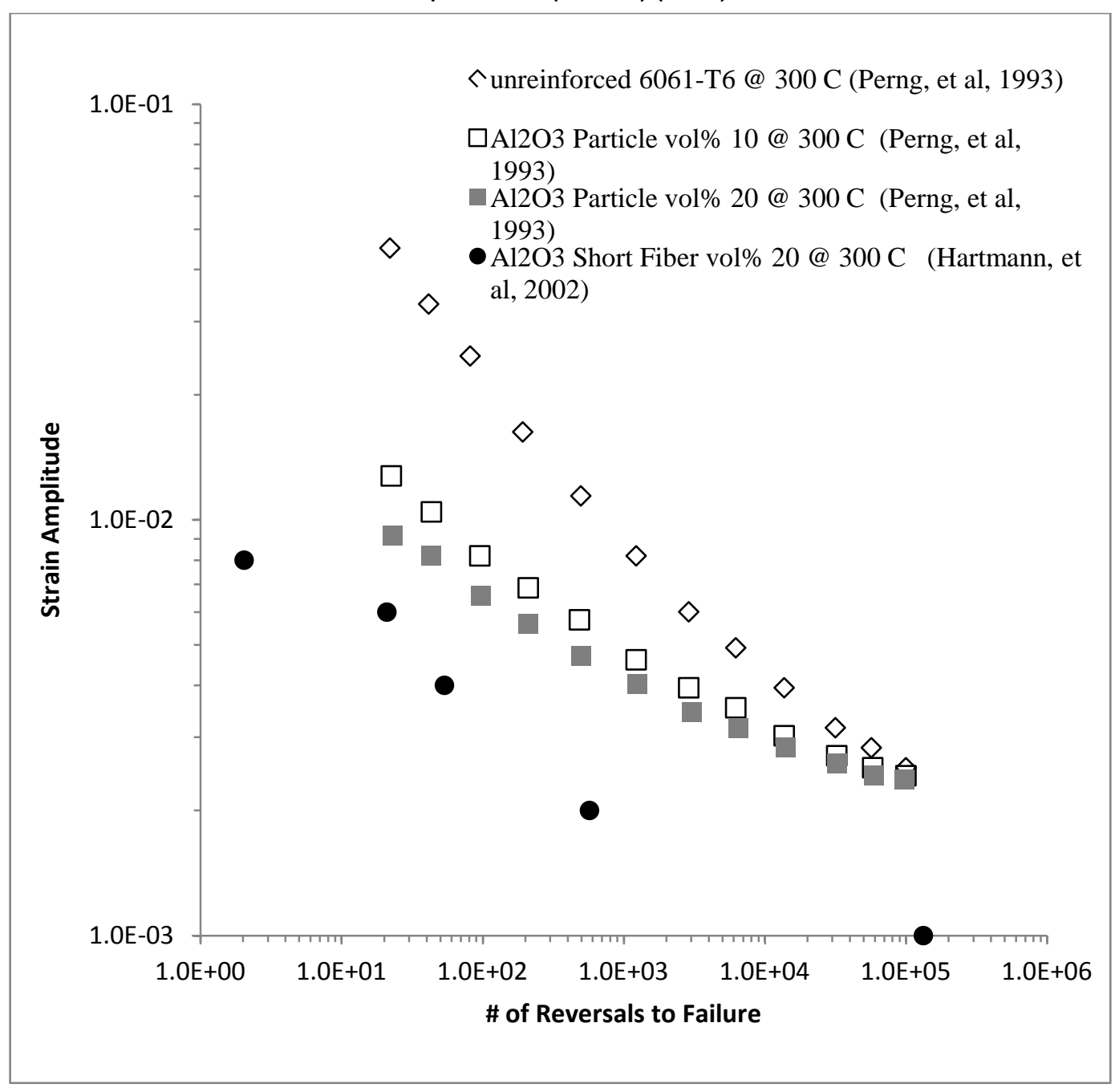

One significant solution for solving the fatigue life of the MMCs is addressed through the shape of the particle. It was observed that while all of the MMCs still underperformed compared to the 6061-T6 alloy in fatigue performance, the MMCs with smaller, smoother textured and/ or more asymmetrical particle reinforcement profiles were seen to have improved fatigue life than those with large, coarser textured and/ or simpler and symmetrical profiles and surfaces (Ding et al. 2002; Han et al. 1997).

The asymmetrical and smaller profile would allow for a much more solid interfacing between the particle and the matrix, greatly decreasing the debonding under cyclic fatigue, which was noted during several experiments. This debonding was stated as being in most cases the primary cause of crack development in the MMCs (Ding et al. 2002; Park et al. 2008). Examples of this debonding and particle cracking can be seen in Figures 13 
and 14, respectively. The smoother texturing would increase the fracture initiation resistance of the brittle ceramic reinforcement, while decreasing the rate of crack propagation in the metal matrix by targeting the cyclic fatigue life of the reinforcement itself. As shown in Figure 15, at a higher vol\% of reinforcement the primary mode of failure (debonding) moves from being the principal (up to 90\%) mode of failure to being almost equal to particle fracture in quantity of observed failures. As a higher loading is placed on the reinforcement, crack initiation of the particle reinforcement becomes more and more vital to the MMCs performance.

Figure 13. SiC particle debonding (Srivatsan et al. 2002).

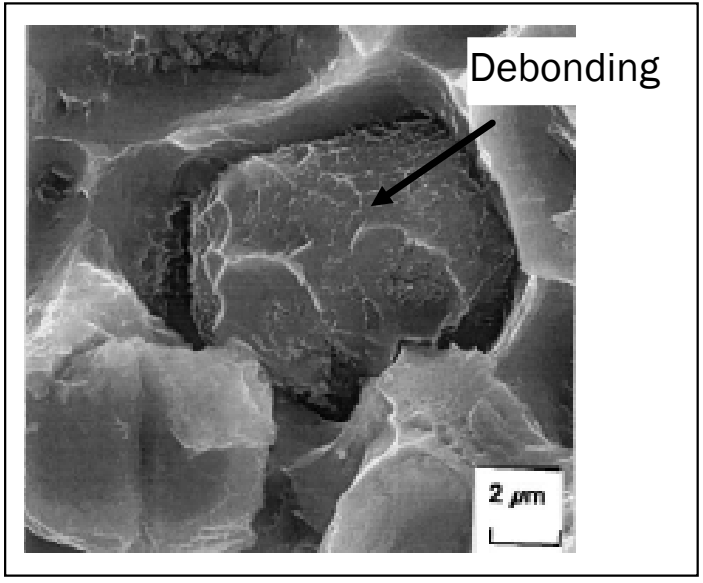

Figure 14. SiC particle cracking (Srivatsan et al. 2002).

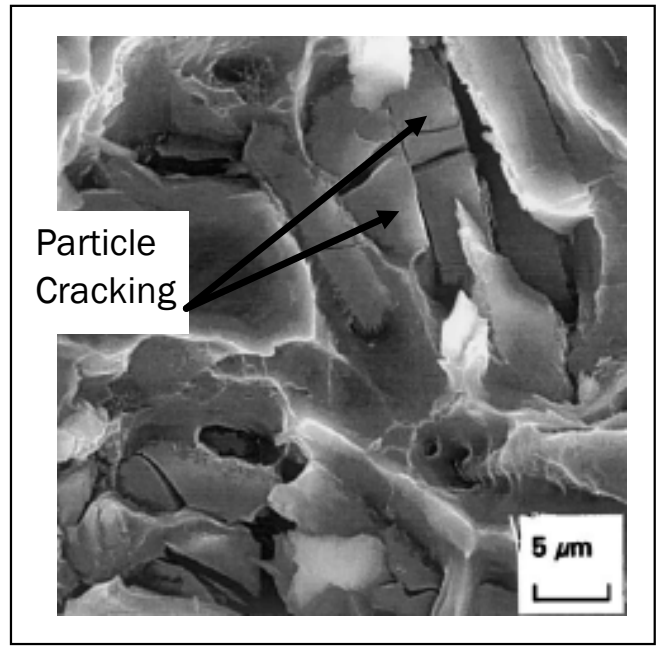


Figure 15. Particle failure dependence on vol\% (Park et al. 2008).

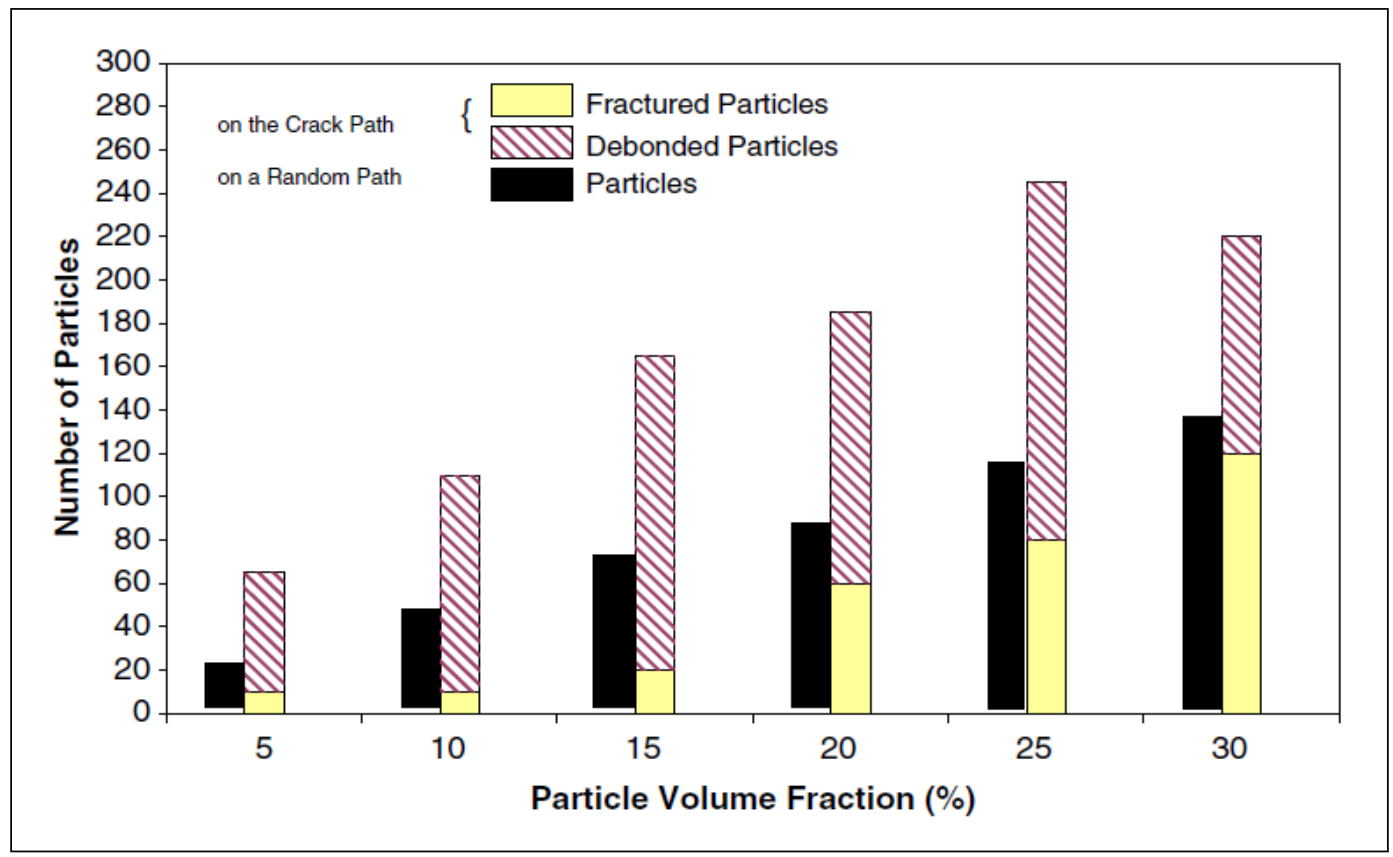

Further evidence concerning the relationship between MMC failure and particulate shape and texturing was found in computational results on the behavior of the particles with variances in these characteristics. Here, a 3D finite element analysis (Romanova et al. 2009) was performed to determine failure mode dependency on reinforcement shape. In this study, the focus was between the separation of the interface between the matrix and particulate debonding and fracturing of the particulate. The results showed that irregular particulate shapes decreased the chance of debonding, which was observed as being the primary mode of fracture in simple, common shapes (spheres, blocks etc.). This can be noted in Figure 16a where the failure in segment was clearly debonding and with a general increase in surface irregularity, a decreasing trend in debonding was observed (Figure 16b-e).

In addition to the observation concerning the decrease in debonding with the increase in the surface irregularity, as the surface became more distorted, particle cracking became more of an issue as shown in Figure 16d. The less agitated particulate surfaces were stated as decreasing the probability of inter-particulate fracturing. The drawn conclusion is that the performance of the material was very much dependent on the level of refinement seen in the particulate structure. An optimum shape and surface texture could be clearly identified in Figure 16. However, controlling particle characteristics could possibly mean a significant increase in manufacturing costs to achieve the desired particle product. 
Figure 16. Crack initiation in Sic particles (white areas denote debonding or volume cracking). (a)-(e) is under tension and (f)-(j) is under compression

(Romanova et al. 2009).

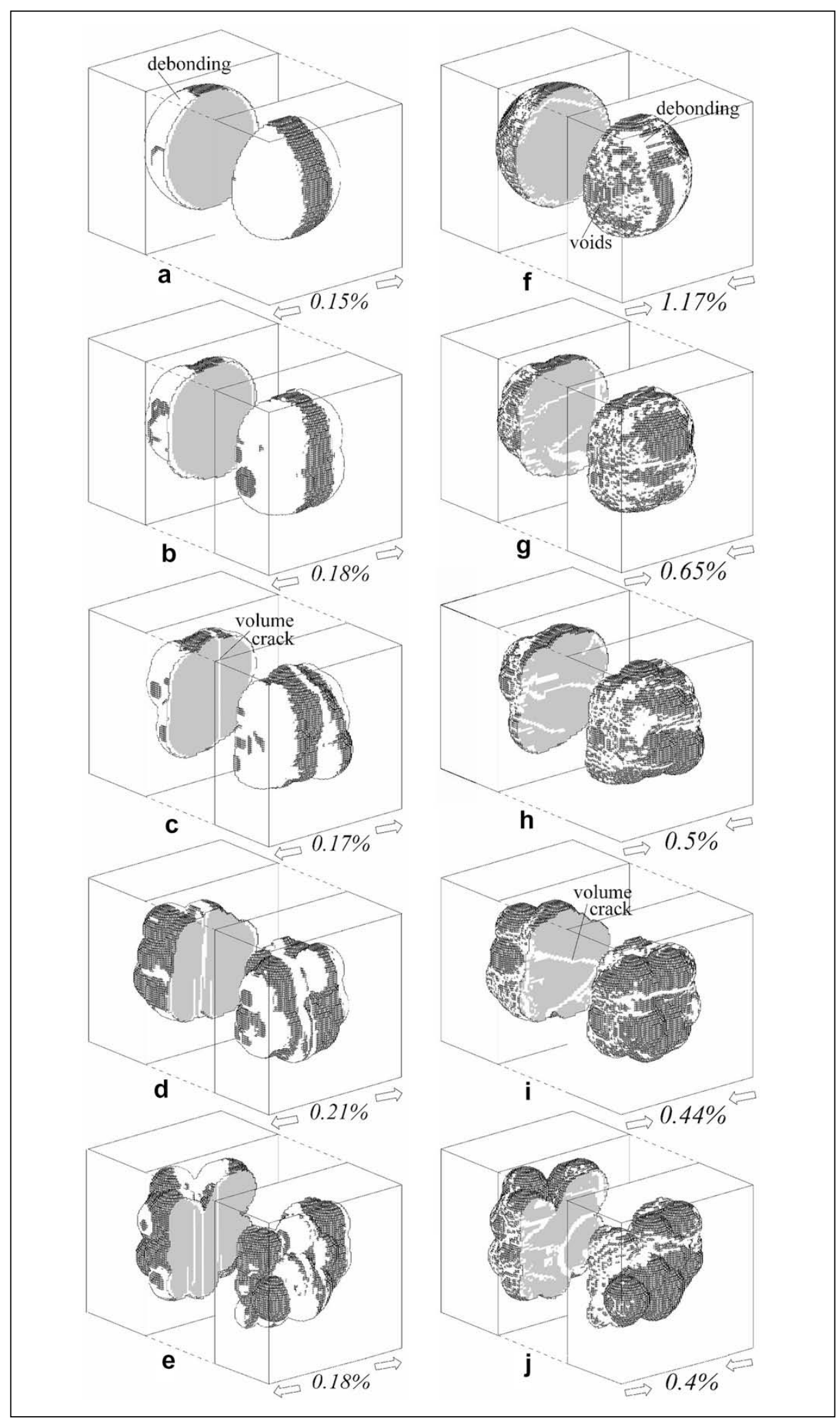


When analyzing the characteristics observed in MMCs, the trends point to very specific reinforcement and compatibility requirements necessary for achieving the benefit of the reinforcement for the matrix. The size, surface texture, and interface compatibility of the different materials used in both the reinforcement and matrix and manufacturing technique all play a part in the performance of the material. From the observed behavior of 6061 MMC, a thorough study of this MMC and others could produce a very beneficial material (Hochreiter et al. 1993). In other words, if a refined manufacturing technique was possible, with a high-quality output of engineered particles, it would greatly help to improve the fatigue performance of the MMC materials (Lee et al. 2010). This trend was notable in silicon carbide, where several specimens were observed to contain very high quality particulates with a minimum cross-sectional area and fairly smooth yet asymmetric surface characteristics. As shown by the best performing MMC in Figure 10, these qualities were noted as leading to higher fatigue behavior compared to that of the 6061-T6 alloy at ambient temperatures (Srivatsan et al. 2002).

In order to achieve better mechanical response at elevated temperatures, the thermal expansion of the matrix and reinforcement particulate should be similar. Thus, closely matching the thermal expansion characteristics of the matrix and reinforcement would help eliminate debonding or stress development at reinforcement interfaces during high-temperature loading and likely would lead to improved fatigue performance.

In summary, the conclusion of the analysis of MMC as a possible material replacement for AM2 strictly based on mechanical performance is not supported in literature. Based on fatigue performance and the initiation and fracture characteristics, MMC would provide little, if any, significant improvement for the purpose of light weighting the matting. While tensile yield and strength characteristic are shown to increase, ductility is reduced, which is critical in low-cycle fatigue behavior. In the end, while the MMCs have a large potential, they seem to be limited in their applications, especially in the area of structure members, due to poor fatigue performance. However, the MMCs have made some notable improvements in recent years and could eventually be developed into a very compatible solution for the AM2 system. 


\section{Nanoparticle reinforced metal matrix composites}

The scope of this review is to see if any significant improvement would be realized in the nanoscale MMCs, not only in the 6061-T6 alloy, but also for other readily available materials. A look at the manufacturability of these materials will also be made.

While there was a great deal of research in nanoscale composite materials as a whole, the research in metal matrix nanocomposites was very limited. Most of the research conducted in this area was focused on the manufacture and static stress/ strain properties of these materials; not much fatigue or elevated temperature characterization was performed. In fact, the bulk of this research was centered on nanometal matrix reinforcement synthesis and integration, a great deal of which was concentrated on carbon nanotube (CNT) reinforcements. The lack of research in this area of material science is clearly shown in Figure 17. From this figure, it can be seen that CNT reinforced polymer matrix materials are the predominantly researched materials.

Figure 17. Chart of number of publications on carbon nanotube reinforced materials per year (Bakshi et al. 2010).

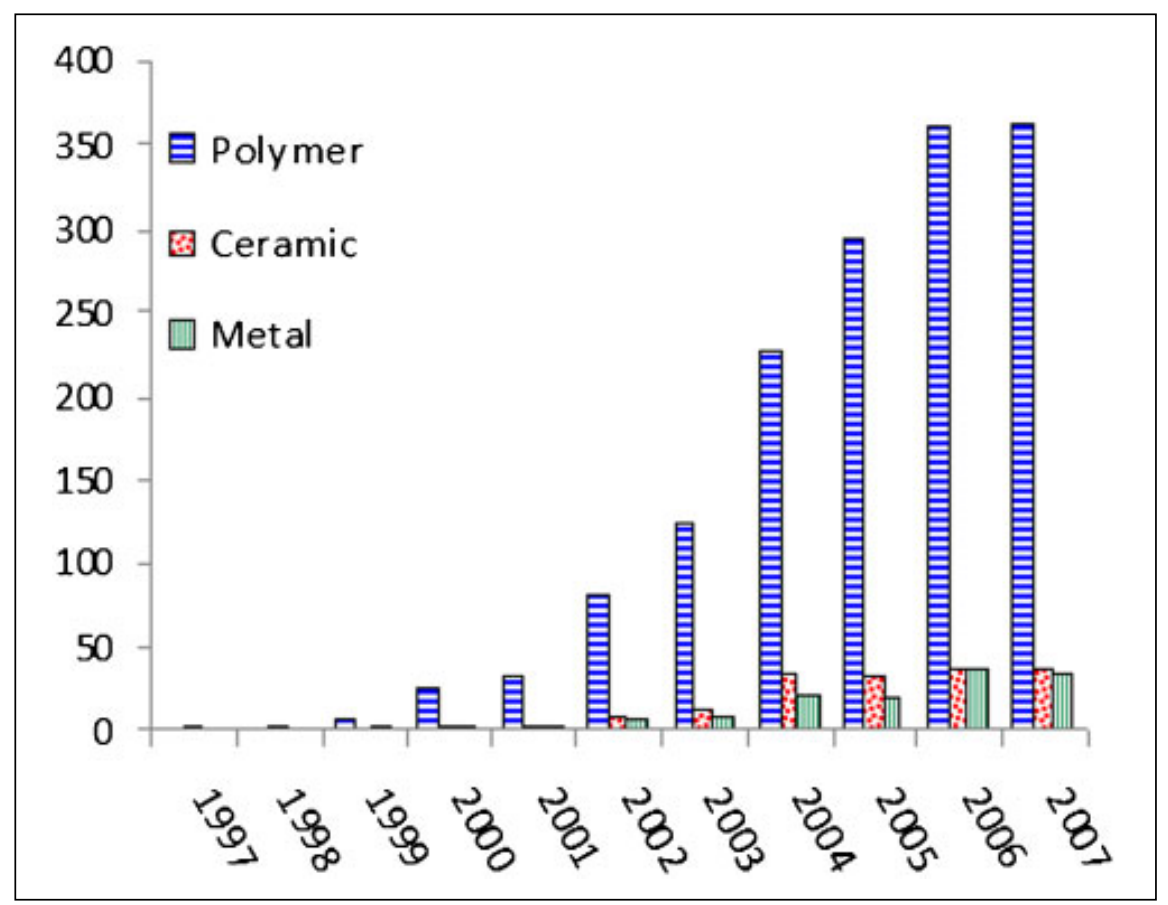

In the area of nanoparticle-based MMCs, there were several studies that analyzed and compared micro-MMCs to nano-MMCs. In the study by Tjong (2007), a comparison was made between the yield and tensile 
strength of a pure aluminum matrix micro-MMC vol\% $10 \mathrm{SiC}(10 \mu \mathrm{m})$ against a pure aluminum matrix nano- $\mathrm{MMC}$ vol\% $0-7 \mathrm{Al}_{2} \mathrm{O}_{3}(25 \mathrm{~nm})$, as shown in Figure 18. In both tensile and yield conditions, the nano-MMC performed better than the micro-MMC at ambient temperature and exhibited better hardness of the material (Tjong 2007).

Figure 18. Tensile properties of Al MMC with 0-7 vol\% $\mathrm{Al}_{2} \mathrm{O}_{3}(25 \mathrm{~nm})$ and $10 \%$ vol\% SiC (13 $\mu \mathrm{m})$ (Tjong 2007).

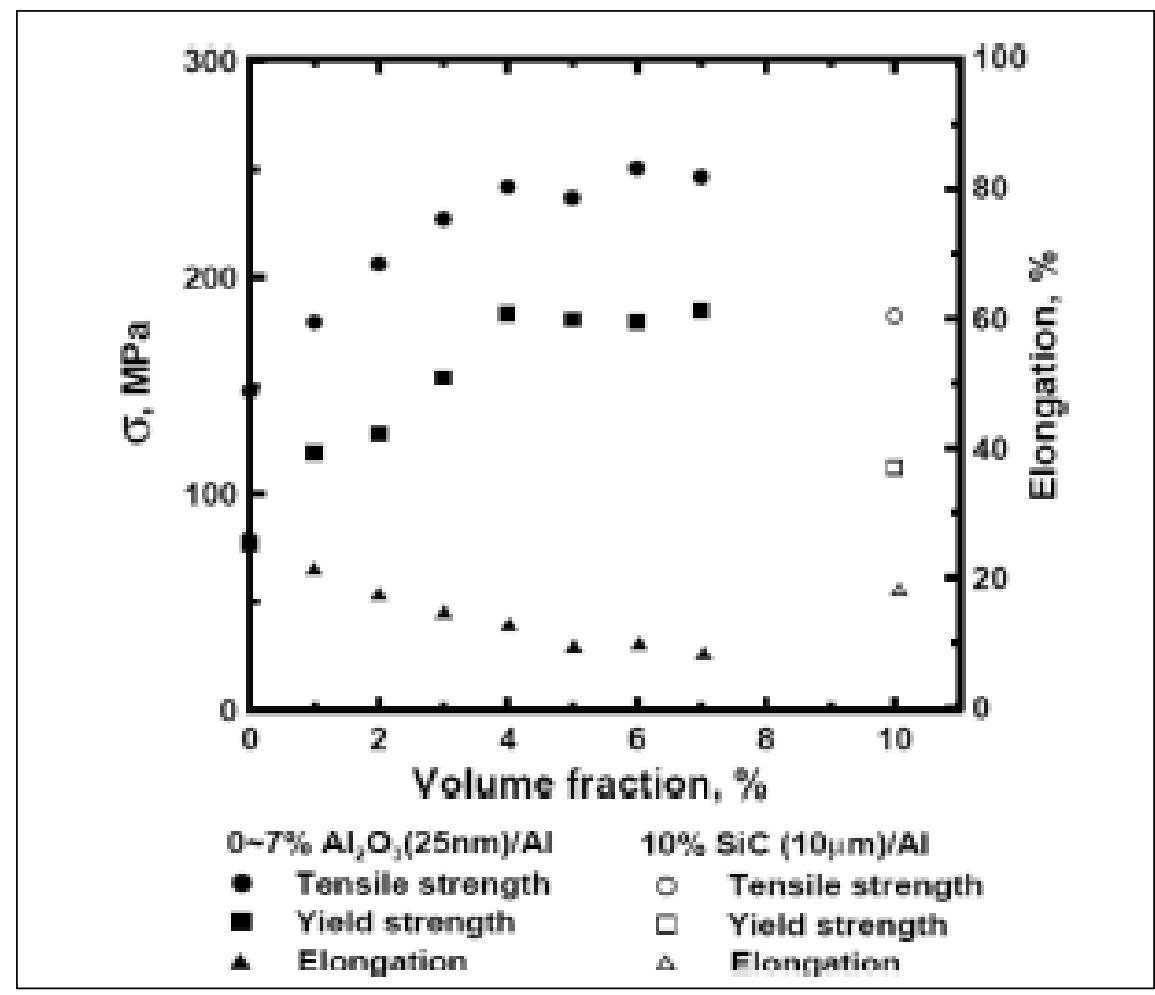

This study (Tjong 2007) also compared nanocomposite magnesium against its pure alloy at several temperatures $\left(23^{\circ} \mathrm{C}\right.$ to $\left.300^{\circ} \mathrm{C}\right)$. This analysis took into account the manufacturing technique for the nano-MMCs, with one set being ball-milled and the other being mechanically stir-blended; both were sintered at equal but unrecorded temperatures. As shown in Figure 19, the ball-milled magnesium nano-MMC was vastly superior to the mixed nanoMMCs and the pure compound. Interestingly, the data that is a blended metal was noted as having a larger grain size and asymmetrical particle distribution and, thus, had very little tensile and yield strength advantages over the pure metal. Also, the stir-blended metal exhibited severe decrease in elasticity (Tjong 2007). This observation confirms what had already been seen in $6061 \mathrm{MMCs}$-- that the quality and distribution of the matrix and reinforcement components was crucial to the overall performance of the material. 
Figure 19. Stress strain charts of pure magnesium and its nano-MMC peers at (a) ambient temperature, (b) $100^{\circ} \mathrm{C}$, (c) $200^{\circ} \mathrm{C}$, and (d) $300^{\circ} \mathrm{C}$ (Tjong 2007).
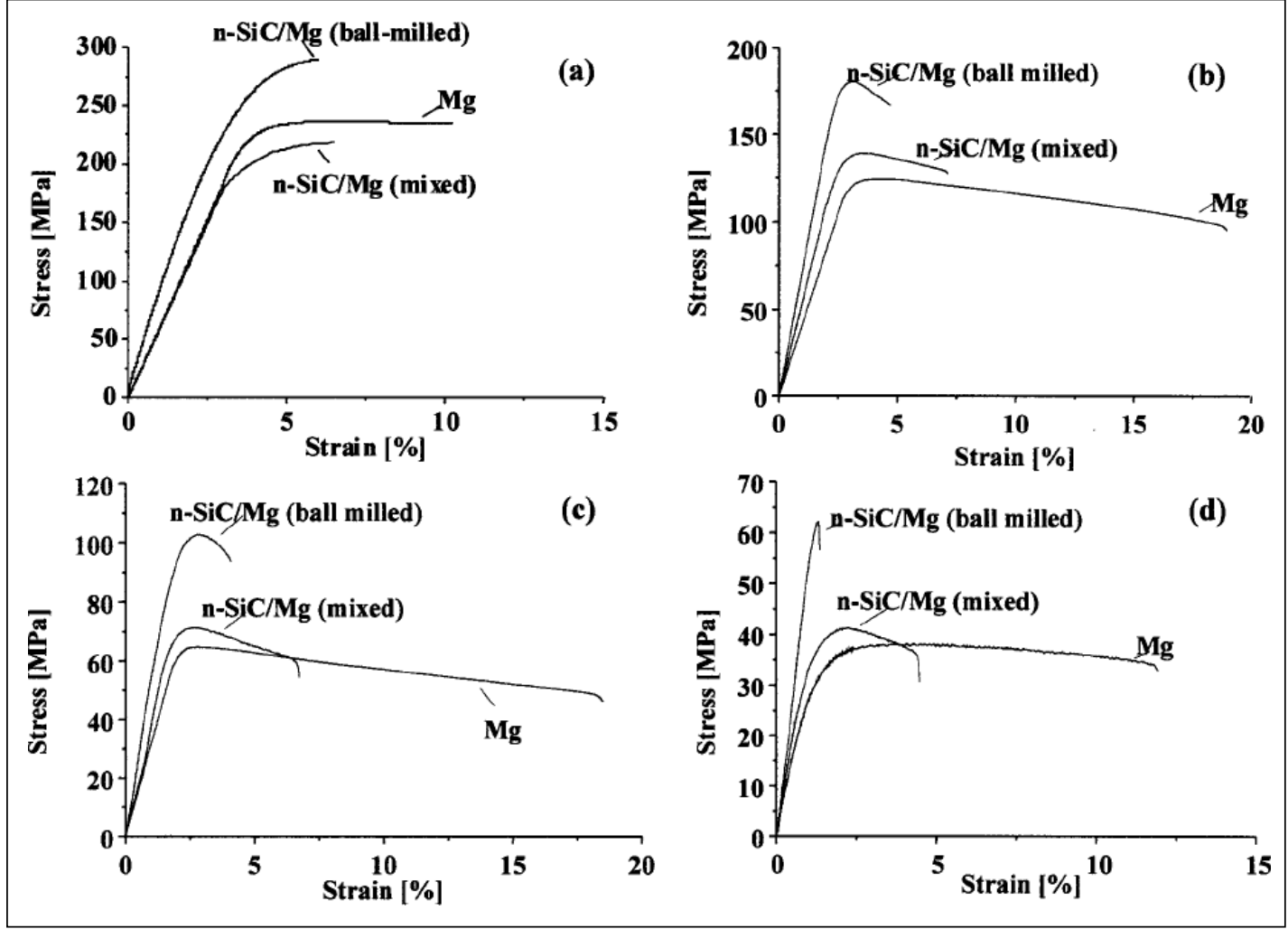

The ambient temperature trends observed in magnesium/ SiC nano-MMCs were also noted in $\mathrm{Al}_{2} \mathrm{O}_{3}$ reinforced nano-MMCs (Lim et al. 2005). In fact, the yield strength of the material was noted as increasing by as much as $50 \%$ versus the pure metal with as little as $0.22 \mathrm{vol}$. \% of $\mathrm{Al}_{2} \mathrm{O}_{3}$ for the reinforcement. Two main things were noted in both of the studies: with an increase in vol\% of the reinforcement particles, the rate of change in both the yield and tensile strength of the materials was seen to decrease to almost zero. This is interesting in that it is an indication of an optimum concentration for the reinforcement after which, in many cases, the strength advantage disappears. This trend is likely a result of the manufacturing technique or issues with material compatibility, which can cause the matrix material to no longer sustain the reinforcing particulate.

In micrograph studies of the $\mathrm{Al}_{2} \mathrm{O}_{3} \mathrm{MMCs}$ materials, with an increase in volume, especially in the nanometer range, a significant increase in agglomeration of the reinforcement within the aluminum matrix was observed (Figure 20). This was hypothesized as being an issue primarily with the manufacturing of the MMCs and, most likely, is greatly improved with a better control over the initial distribution of the reinforcement 
particles into the pre-processed matrix material. While the problems associated with reinforcement clustering will likely be improved, this characteristic of MMCs will most likely not be completely eliminated even with improvements in manufacturing, as the semi-fluid and fluid nature of many of the matrix materials during manufacture makes it very difficult to prevent the movement of the reinforcement within the matrix.

Figure 20. Increase in agglomeration that is seen in $1 \mathrm{vol} \%$ (a) to 4 vol\% (b) of $\mathrm{Al}_{2} \mathrm{O}_{3}$ (Tjong 2007).

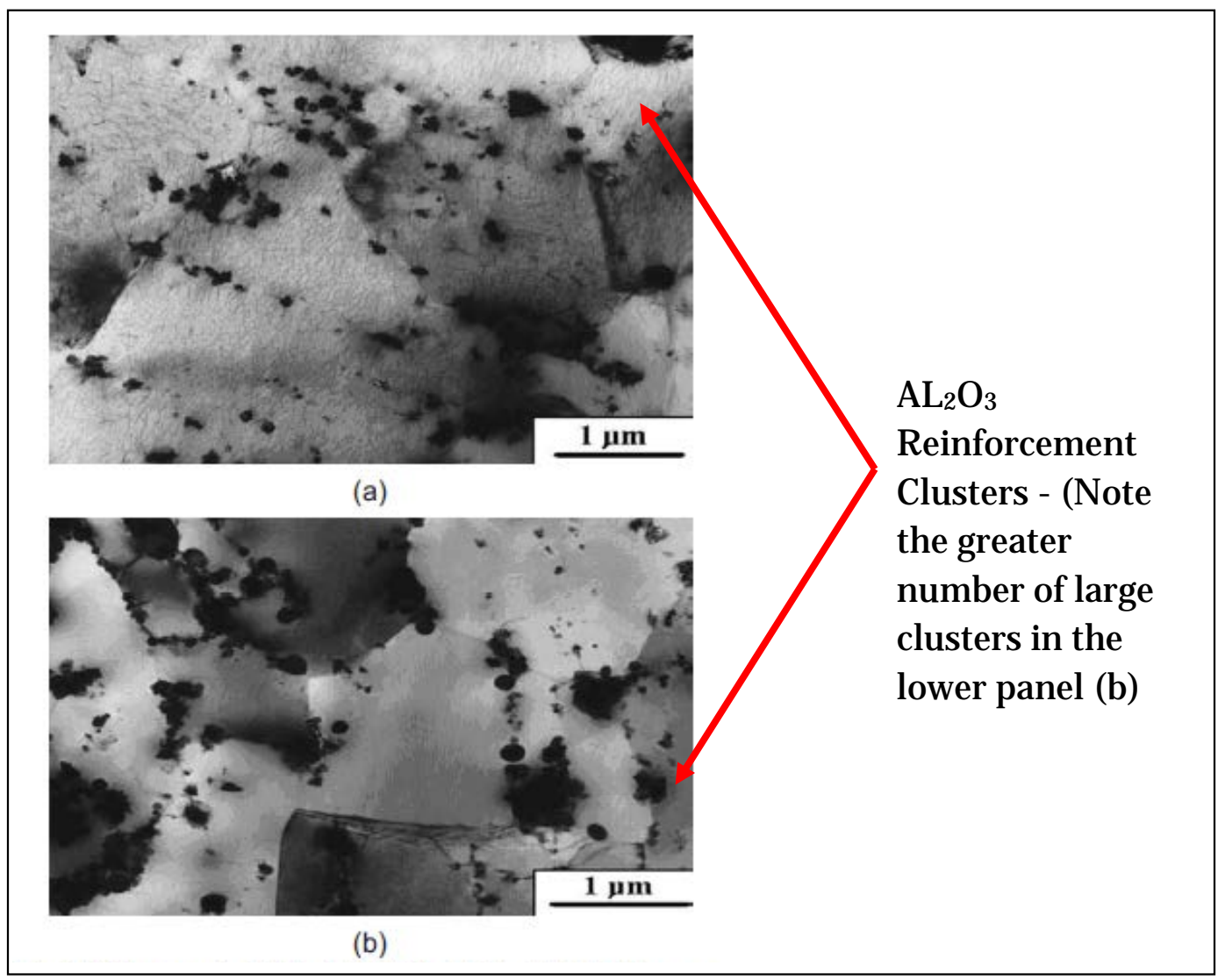

Other aluminum alloy MMCs were also identified that exhibit this same optimum concentration characteristic as the previous materials. One study (Ren 2007) showed that in $7075 \mathrm{MMC}$ materials with $50 \mathrm{~nm}$ SiC particles, the higher vol\% (5\%) of reinforcement decreased the yield and tensile strength of the material versus both the $1 \mathrm{vol} \%$ and unreinforced alloy 7075 materials. The results can be seen in Figure 21, which has experimental results at ambient temperature $\left(23^{\circ} \mathrm{C}\right)$. The $5 \mathrm{vol} \%$ reinforcement presented here was the best example of the reinforcement actually diminishing the performance of the material. From simply analyzing these experimental results, a hypothesis can be made that there are some matrix metals that will not be well-suited to the MMC concept as even the $1 \mathrm{vol} \%$ of the 7075 
MMC did not have a very large percentage increase in strength over the unreinforced alloy as seen in other MMC combinations, as shown in Figure 21. This, however, does not indicate that the $7075 \mathrm{MMC}$ was not a suitable alternative to the unreinforced alloy, as it did show an increase in strength and minimal decrease in ductility. However, it is suggested caution be used when implementing this nano-MMC as a detrimental material could be easily produced.

Figure 21. Stress-strain curve of 7075 aluminum and the $50 \mathrm{~nm} \mathrm{Al}_{2} \mathrm{O}_{3}$ reinforced MMC at 1 and 5 vol\%, (Ren 2007).

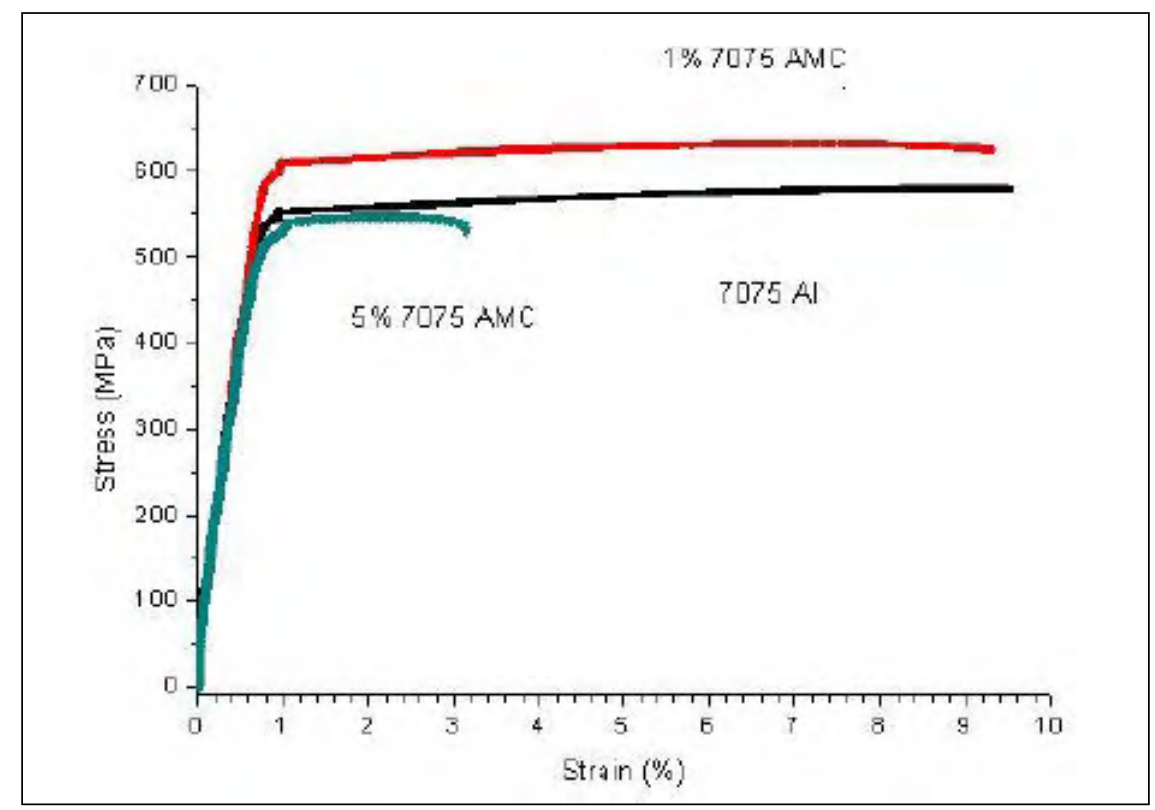

The implementation of nano-reinforced particles in 3xxx series alloys showed similar trends. A very thorough study was also performed (Mazahery et al. 2009) in the use of cast metal. A series of A356 cast aluminum MMCs was produced and tested with an $\mathrm{Al}_{2} \mathrm{O}_{3}$ nanoparticle reinforcement ranging between $0-6 \mathrm{vol} \%$. The test results were limited to static conditions as before but showed maximum increase in yield strength at $1.5 \mathrm{vol} \%$ of reinforcement of over $+20 \mathrm{MPa}$ from an initial strength of $93 \mathrm{MPa}$. This was in addition to a minimal decrease in ductility versus the unreinforced alloy " $<24 \%$ " (Mazahery et al. 2009). This is substantial, because it further opens up the manufacturing options for MMC to casting as a viable manufacturing technique for producing effective MMC materials.

One of the disadvantages of the integration of reinforcement particles such as $\mathrm{SiC}$ is that these particles can form extremely large clusters in cast metals, with very low interface bonding efficiency with the matrix material. 
The novel approach employed by Yang et al. (2004) to address this issue was to place the molten A356 alloy, after the integration of SiC nanoparticles, under an ultrasonic field. The use of ultrasonic technique produces a very solid material with strength advantages of over $50 \%$ versus pure A356 with only 2 wt\% of reinforcement. The ultrasonic produced microstructure versus unprocessed A356 MMC can be seen in Figure 22, where distinct differences are easily noted.

Figure 22. Examples of $A 356$ without Ultrasonic Dispersion with a 20 micro-meter rule (a) and $A 356$ with Ultrasonic dispersion with a 1 micrometer rule (b) (Yang et al. 2004).

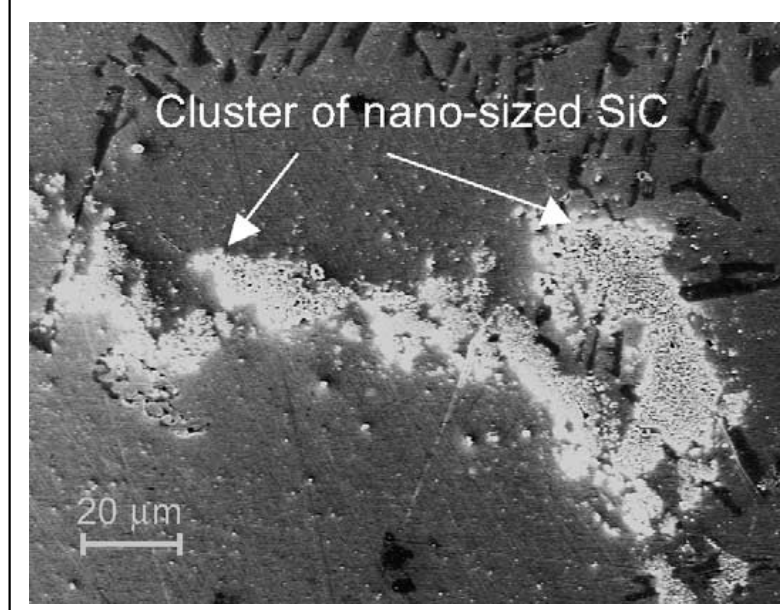

(a)

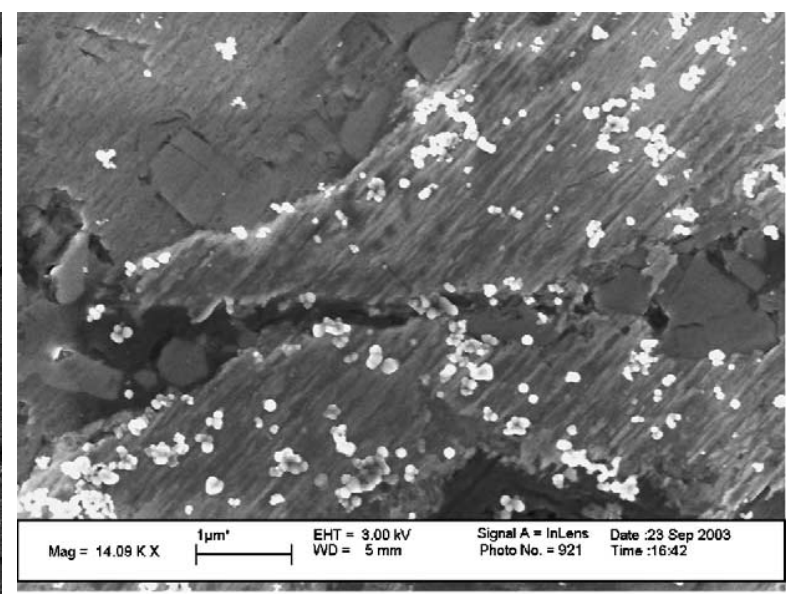

(b)

One interesting manufacturing technique that is promising in its capacity to produce high quality composite distribution in MMC both on the nanoand micro-scale is friction-stir processing, a technique that is basically a re-purposing of the friction-stir welding. Figure 23 shows the difference in microstructure of post-friction-stir processed materials compared to preprocessed, where distribution of particle reinforcement is improved and the size of the particles is significantly reduced. Figure 24 (Lee et al. 2011) displays the improved yield and tensile strengths after post-friction-stir processing. One of the major disadvantages is that this technique is extremely slow and limited in the amount of surface variations it can handle. These two factors limit it at the moment to very simple geometries such as bars and plates and, thus, is not applicable for AM2.

In conclusion, the potential of nanoscale MMCs is great; however, because of the lack of substantial research in this area, it becomes difficult to recommend MMCs that fully fit the requirements of the AM2 matting application. As can be seen in the microscale aluminum MMCs, which have been 
Figure 23. Micrographs of Pre-FSP 10 vol\% (Left) and Post-FSP 30 vol\% after 4 passes (Lee et al. 2011).
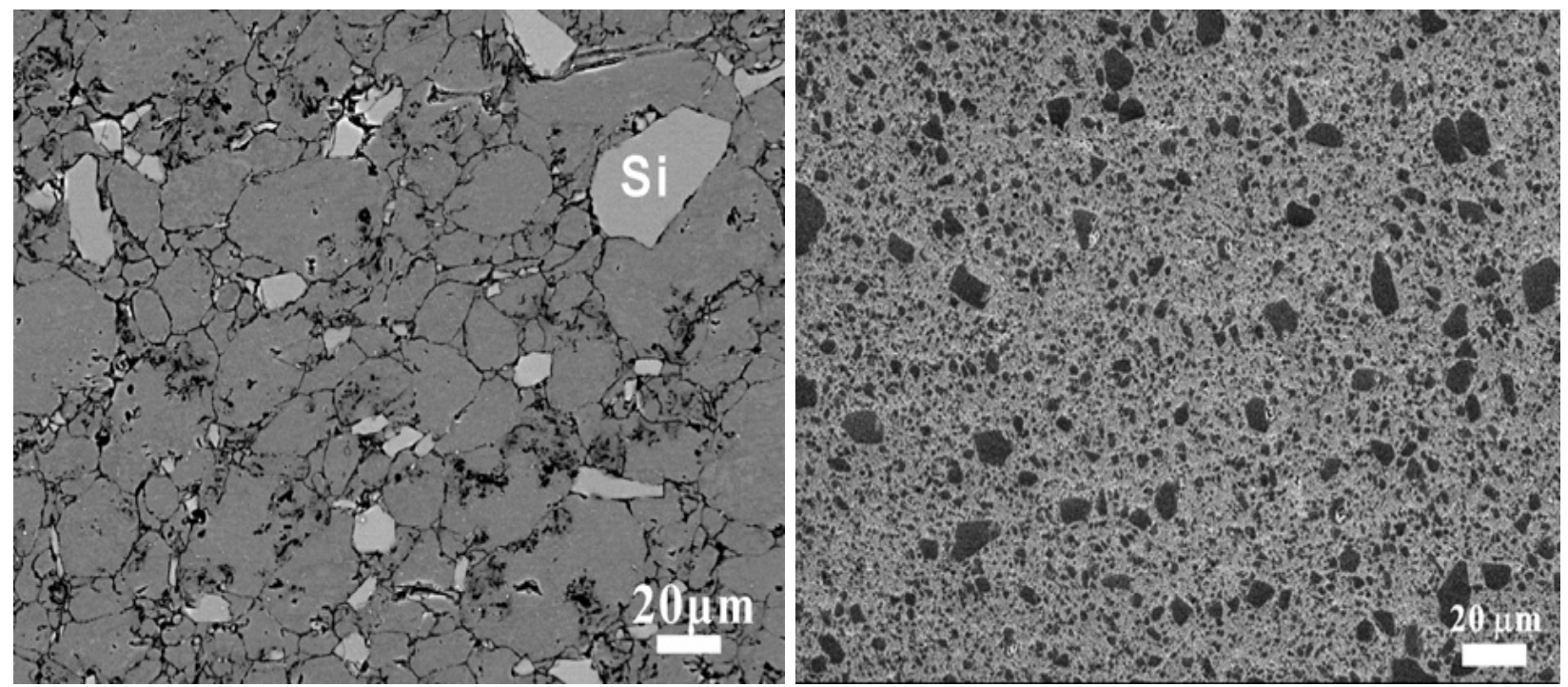

Figure 24. Tensile (T) and compressive (C) stress-strain curve of friction-stir processed MMCs versus pure aluminum (Lee et al. 2011).

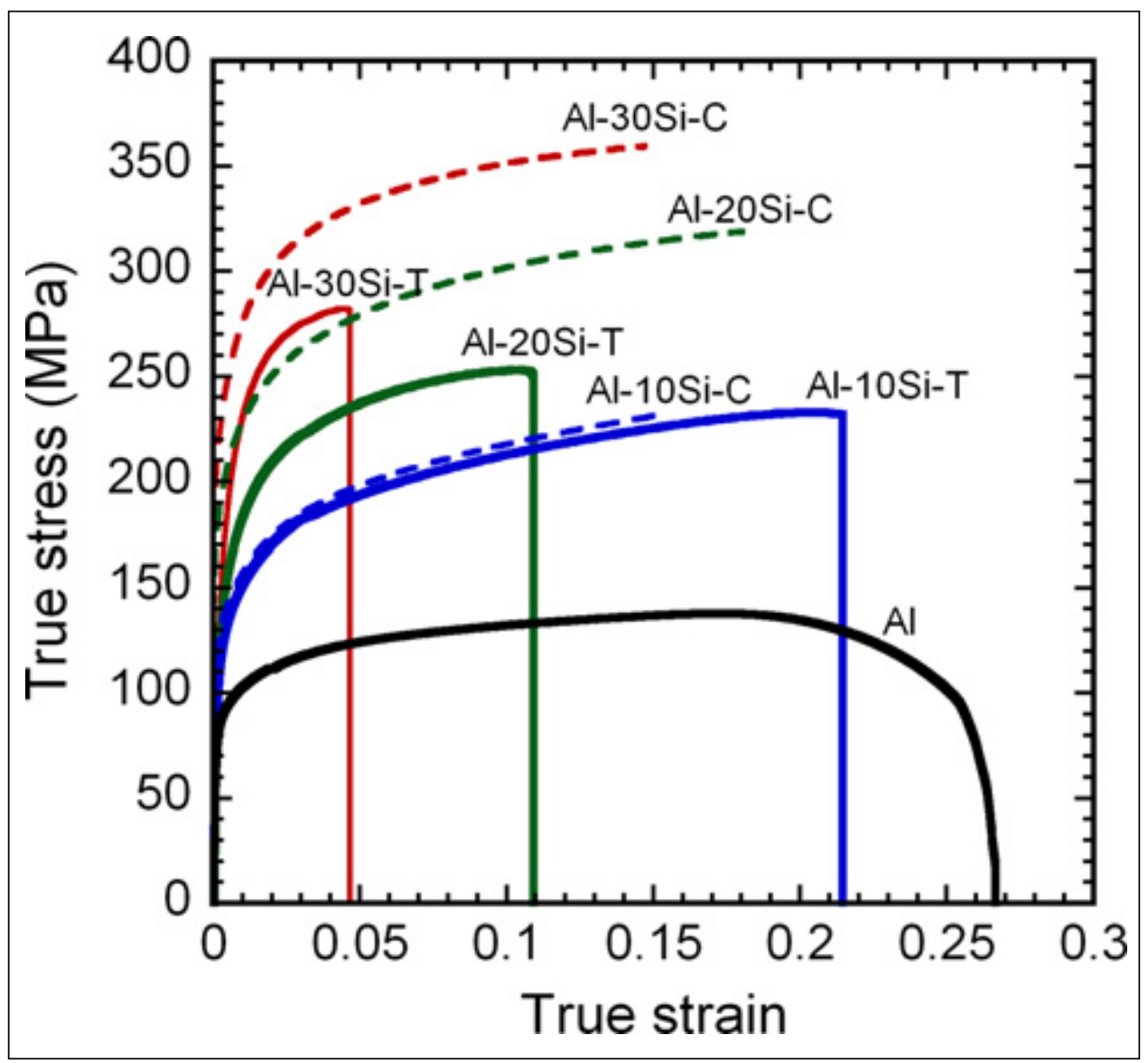

researched much more in depth by the engineering community, these materials need a great deal more refinement before they are completely 
reliable in both fatigue and high-temperature environments. Furthermore, additional research into the manufacturing techniques is needed before this material can be implemented at a large scale.

\section{Nanotube reinforcement}

Another area investigated in the nanoscale MMCs and one of the fastest growing areas of development in modern materials is carbon-nanotube (CNT)-reinforced systems. The extremely high modulus of elasticity of nanotubes makes them excellent candidates for increasing the strength, toughness, and rigidity of a wide variety of matrix materials, including members of all three primary material types: polymers, ceramics, and metals.

In analyzing nanotube MMCs for use in the AM2, several promising candidates were initially identified. One in particular is that of Magnesium CNT-reinforced MMCs. Unreinforced magnesium alloys have recently become attractive replacements for steel and aluminum alloys, mainly because of their comparable strength and elastic characteristics to these metals combined with a much lower density.

In one study (Goh et al. 2008), pure magnesium MMC was tested with CNTs that were $20 \mathrm{~nm}$ width and $100 \mu \mathrm{m}$ long at reinforcement concentrations ranging from 0.3 to $2 \mathrm{wt} \%$. This material was then placed under both static and cyclic loading. What was interesting about the mgCNT MMC was that at certain wt\%, the MMC showed a large increase in ductility, as shown in Figure 25. This was in addition to possessing similar if not superior fracture, tensile, and yield strengths to the base matrix material.

The most promising candidate was the 1.3 ut\% CNT MMCs, which showed improvements in yield, tensile, and failure strengths, as well as the large increases in ductility of all the magnesium MMCs, as shown in Figure 25. However, when the $1.3 \mathrm{wt} \% \mathrm{CNT}$ MMC was placed under full cyclic fatigue loadings, the static advantages of the material were not replicated. The pure magnesium specimens matched or outperformed the 1.3 wt\% MMC under constant stress plastic-strain loading.

While CNTs could possess an extremely high modulus of elasticity, up to 1.2 TPa, this number was heavily dependent on the manufacturing technique used in their production. Several manufacturing techniques were 
Figure 25. Stress strain chart of carbon nanotube reinforced magnesium MMCs, label numbers represent wt\% (Goh et al. 2008).

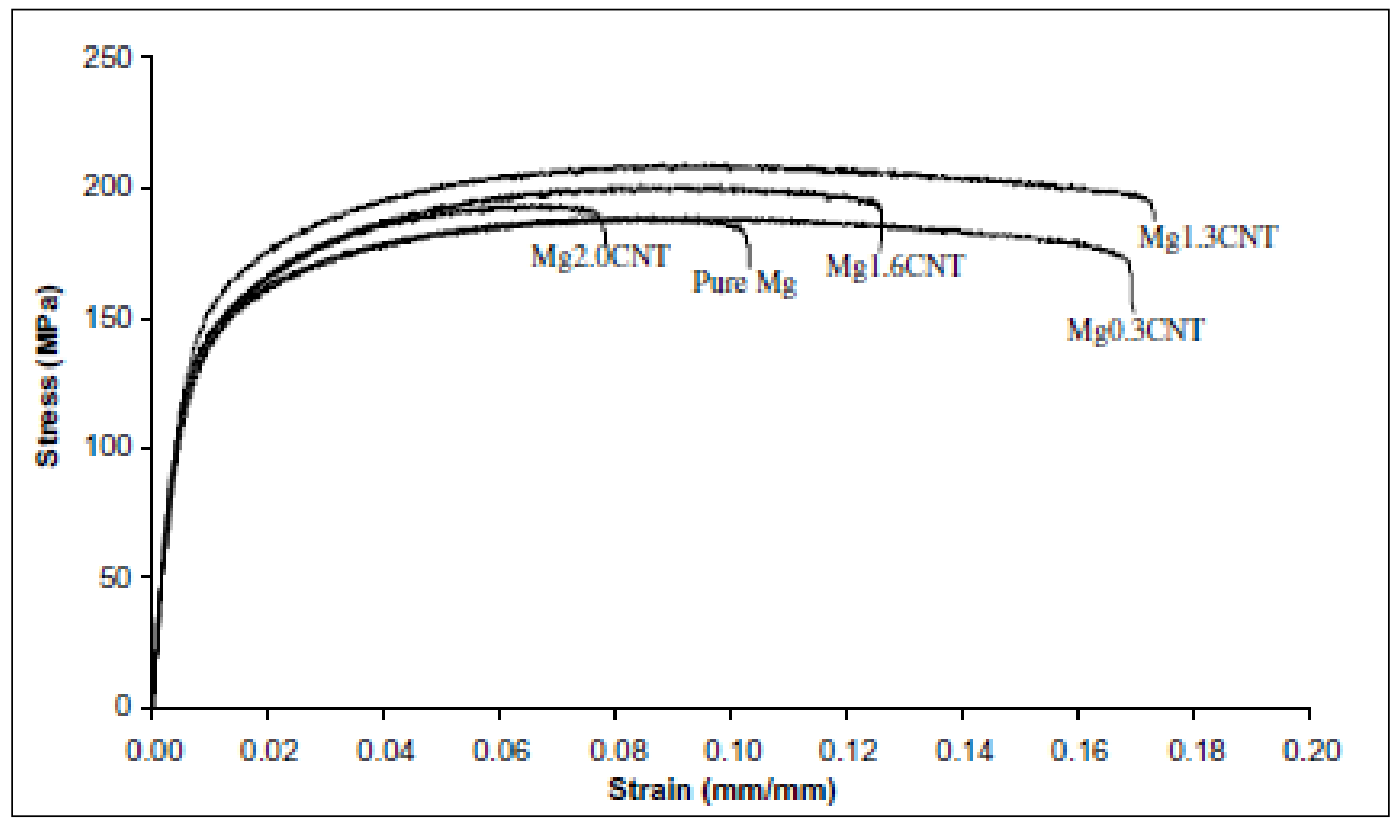

used for producing CNTs; however, so far, all of these techniques have proved to be very slow, costly, and/ or of low quality output. The most promising technique for mass producing CNTs is catalytic chemical vapor deposition, which has proven to be the quickest and most cost-effective of the techniques developed thus far. At the same time, however, this technique greatly decreases the CNT's overall quality, reducing the elastic modulus of the CNTs by more than one order of magnitude compared to the prime examples produced by techniques such as laser ablation (Sinha and Yeow 2005) from an average moduli of $870 \mathrm{GPa}$ to a moduli as low as $27 \mathrm{GPa}$.

Another CNT-reinforced MMC of great interest found in this study was that of pure titanium CNT-reinforced MMCs (Kondoh et al. 2009). These MMCs displayed good results as their performance in static loading was much greater than the pure alloy regarding the yield (400 MPa to $600 \mathrm{MPa}$ ) and tensile (590 MPa to $750 \mathrm{MPa}$ ) with almost identical ductility characteristics $(0.345 \mathrm{~mm} / \mathrm{mm}$ to fracture with the CNT, compared to $0.36 \mathrm{~mm} / \mathrm{mm})$ to that of the pure alloy, as shown in Figure 26 (Kondoh et al. 2009). However, the fatigue performance of this type of CNT is not currently known.

Several manufacturing factors were noted that were vital to maximizing the advantage of CNT materials. One study (Bakshi and Agarwal 2011) looked into the many factors that affected the strengthening of materials with CNT 
reinforcement. The primary observation made was that a certain vol\% range existed in which the strengthening advantage of CNT reinforcement is at its peak, a trend also observed in the particle- and fiber-reinforced micro-scale MMCs noted in the previous sections. A specific range was not isolated, but was stated as fluctuating with an increase in CNT quality, chemical bonding, and uniformity of reinforcement disperson in the matrix. High pressure ( $2 \mathrm{GPa}$ ) sintering at $2 \mathrm{hr}$ for $850 \mathrm{C}$ was shown to produce an exceptional aluminum MMC.

Figure 26. Stress-strain chart of CNT reinforced pure titanium (Kondoh et al. 2009).

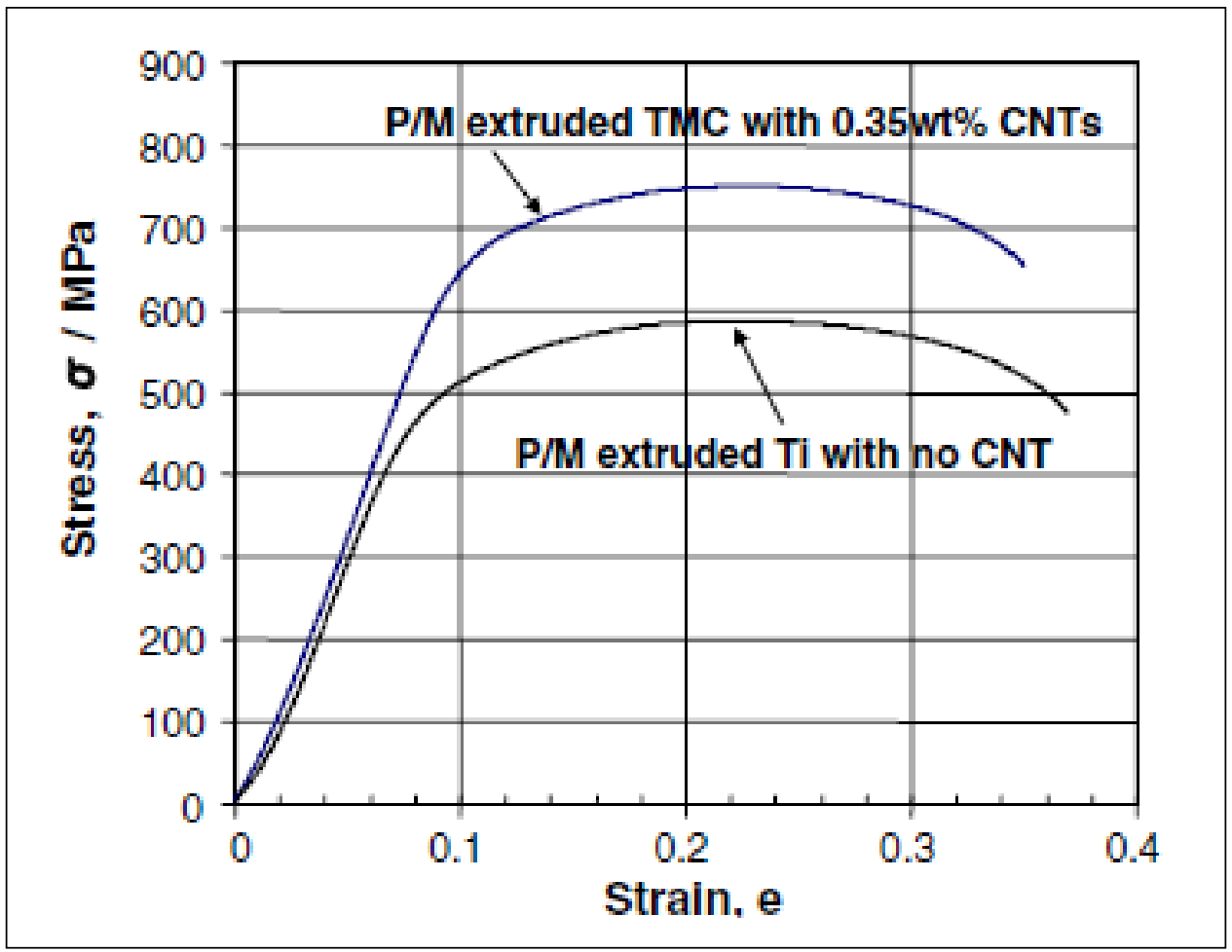

The grain size of the matrix material was seen to be strategic to the overall effect of the reinforcing CNT in the material. Researchers observed that with a decrease in the grain size of the unreinforced aluminum matrix, the strength characteristics of the MMC was altered significantly for any given vol\% of CNT reinforcement (Choi et al. 2011). Researchers also recorded that the different grain sizes tested were manufactured by subjecting a coarse powder to ball milling for 18 to $24 \mathrm{hr}$ (grain diameters of 250 to $150 \mathrm{~nm}$ ), and then sintering the powder into billets. An additional hot rolling of the sintered aluminum powder into sheets was used to achieve grain sizes below $150 \mathrm{~nm}$. By creating a finer grain structure, the maximum strengthening that the CNT reinforcement could offer decreased. 
An example of this was observed in pure aluminum MMCs. At $65 \mathrm{~nm}$, the material reached yield strengths of about $500 \mathrm{MPa}$ at only $3 \mathrm{vol} \%$ of reinforcement, with a very small amount of elongation till failure (0.022). In contrast at $250 \mathrm{~nm}$, the material only reached yield strengths of about $400 \mathrm{MPa}$ at the same volume percent. However, the results did not necessarily favor the smaller grain matrix materials. At higher vol\% ( $4.5 \mathrm{vol} \%$ to 9 vol\%), the 250 -nm grain material was able to achieve yield strengths in excess of $700 \mathrm{MPa}$ before a decrease in strengthening was observed. The 65-nm material reached only slightly above $500 \mathrm{MPa}$ before the rate of strengthening saturated.

Researchers hypothesized the cause of this observation was that the smaller grain size placed less tensile stress on the CNT fiber and increased the shear stress loaded perpendicular to the fiber's length, as shown in Figure 27 (Choi et al. 2008). Therefore, as the material became more dependent on the integrity of the CNT for its strength, the small grain structure began to fracture the CNT fibers. The lower percentage of reinforcement required in the small grain MMCs still gives it a substantial advantage over the large grain. The manufacturing of CNTs is still very difficult and, in most techniques, exhibits a low production volume, which is not very applicable for manufacturing of the AM2.

Figure 27. Plastic strain fields in ultra-fine grain (a) and nanoscale grain (b) aluminum MMC. Tensile (top chart) and Shear Stress (bottom chart) for ultra-fine grain (c) and nanoscale grain (d) aluminum MMC (Choi et al. 2008).

(a)

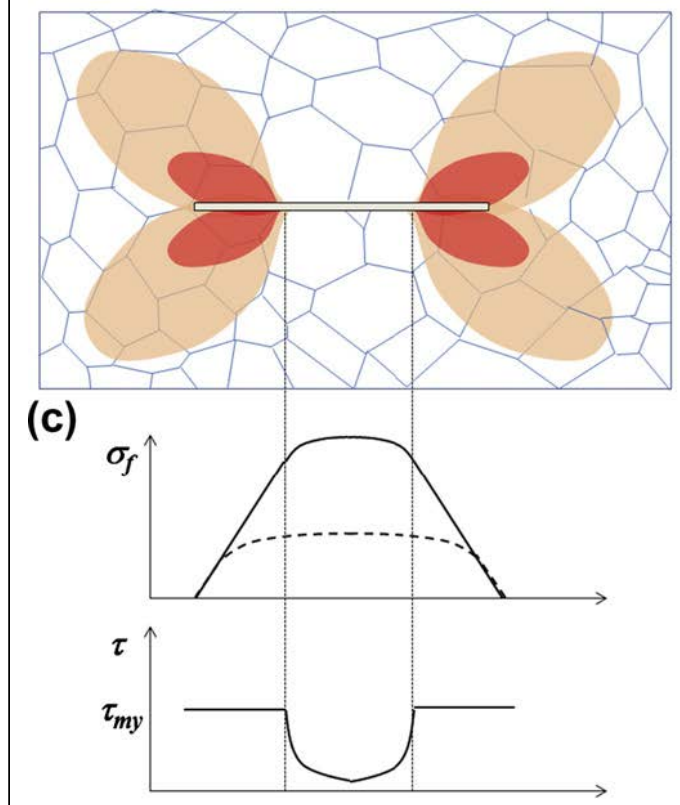

(b)

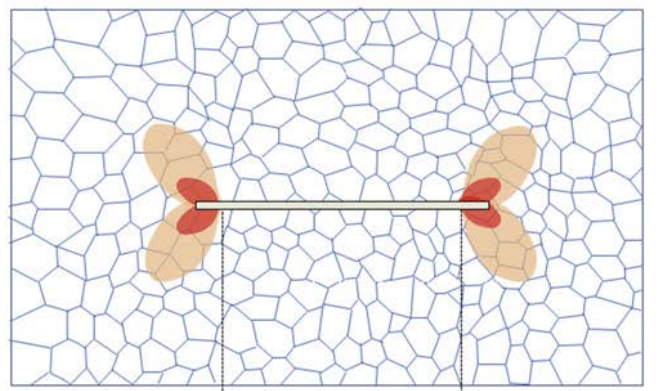

(d)

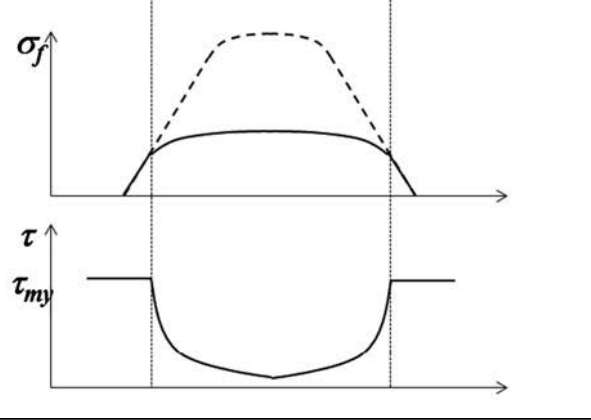


In the end, the nanoscale MMCs investigated here exhibited potential for use as high-strength alloy, similar to microscale MMC. However, much like the micro-scale MMC, they suffer from manufacturing shortcomings and material compatibility. A lack of substantial research in the areas of fatigue and temperature endurance limits the ability to fully analyze the application of these nano-MMCs into a system such as AM2 airfield matting. Based on the performance of the microscale MMCs systems versus their pure alloy counterparts, these nanoscale systems most likely will have only a limited advantage in either fatigue or elevated temperature scenarios versus the unreinforced matrix metal and, thus, provide no significant lightweighting advantage.

\section{Manufacturing}

In analyzing the MMC for use in the AM2 airfield matting, the question of manufacturing is a significant issue. The manufacturing issues/techniques are presented irrespective of any advantage, considering that MCCs largely do not provide much, if any, improvement in fatigue resistance.

\section{Extrusion}

The logical approach for manufacturing the MMC is extruding a billet into final form for the AM2 cross-section. However, because of the increase in tensile strength caused by the particulate reinforcement, the extrusion forces required to extrude an MMC billet into an AM2 full-scale crosssection would easily exceed the capacity of the extrusion press if identical extrusion conditions for the unreinforced 6061 were used. The current extrusion press used to produce the AM2 is the largest press in North America and, thus, extrusion of the MMC into full-scale cross-section is not possible. However, one possible solution is to extrude at elevated and/ or high temperatures. Here MMCs were shown to maintain mechanical performance when extruded at high temperatures $\left(350\right.$ to $500^{\circ} \mathrm{C}$ ) (Schauder et al. 1992). Another possible solution to extruding a high-strength alloy like an MMC is to extrude smaller cross-sections, which would reduce the required extrusion force. The smaller sections then could be welded together to reach full cross-section width of the AM2. A joining technique like friction-stir welding (FSW) could possibly be employed because of high joint efficiency. Other joining techniques like spot welding, bolted fasteners, and self-piece riveting (SPR) could also be employed; however, durability of the joints are a significant issue and would require an in-depth analysis and 
experimental testing to determine suitability for any of the above joining methods.

\section{Spray atomization}

Another possible manufacturing technique would be the use of a spray atomization and co-deposition, as shown in Figure 28. This system is very reminiscent of carbon fiber systems in that it greatly increased the stiffness of the material, especially in the plastic region, during tensile testing (Xu et al. 1999). This trend was shown to increase, along with the material's strength, as the layer thickness decreased. While the material was not stated as being tested under high-temperature environments $\left(\mathrm{t}>100^{\circ} \mathrm{C}\right.$ ), the concept is very interesting in that the use of spray-based application allows for possible final form fabrication and a high degree of composite customization (particle reinforcement), which could offer the ability to adjust the performance of the material to account for hotspots.

Figure 28. Example of Spray Atomization (Srivatsan et al. 2002).

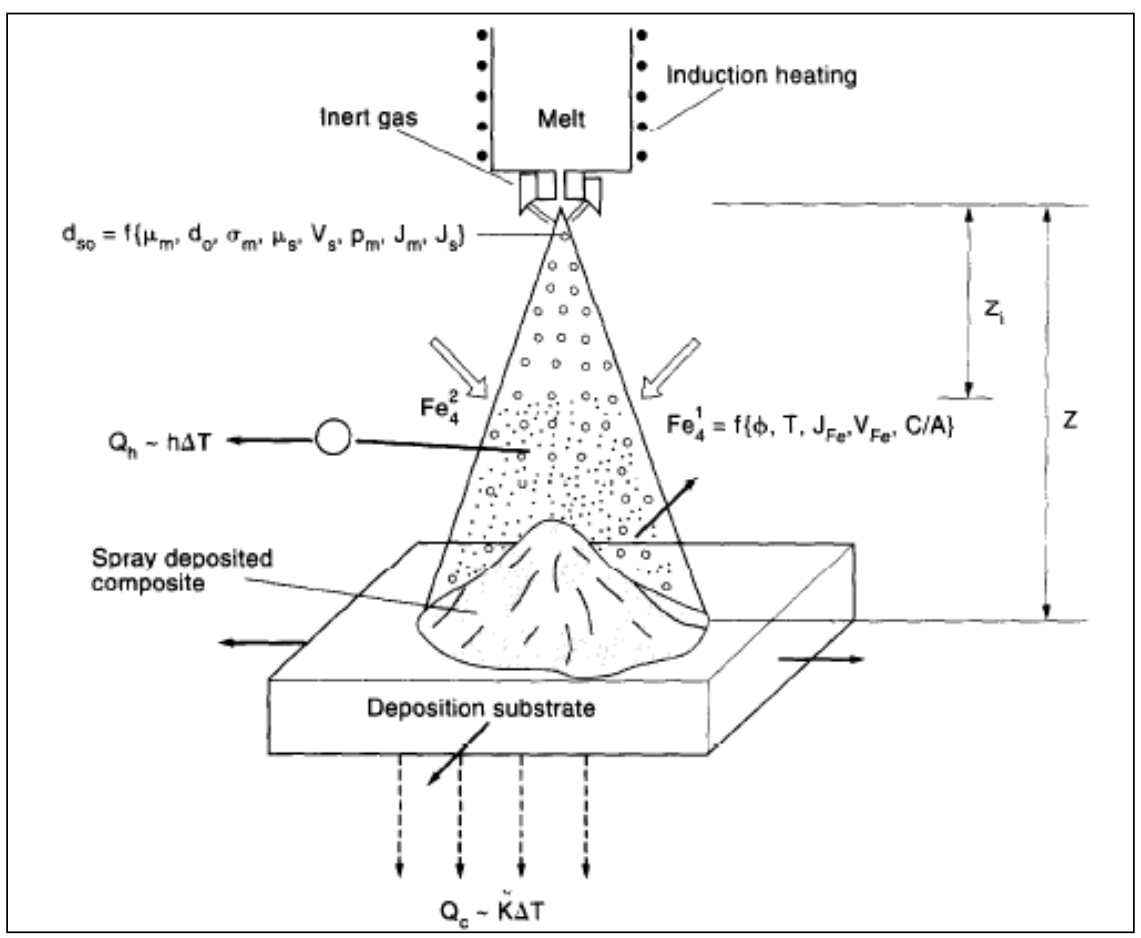

\section{Joining}

One of the issues facing the implementation of MMCs into many of these environments is the area of joining. In particular, the main issue in joining MMCs is maintaining high joint efficiency and fatigue resistance, which in 
most cases is already diminished compared to the unreinforced alloy's typical performance. Of the different existing welding techniques, friction stir typically maintains the highest joint efficiency compared to other joining techniques. In this review, a look into the implementation and effect of friction-stir welding on the various characteristic of MMCs is presented and its practicality for implementation in the manufacture of an AM2 airfield matting system.

FSW has a large potential in producing seam welds and can be implemented commercially using industrial concepts very similar to today's CNC machining systems, making its implementation very straight-forward. An example of friction-stir butt-welded MMC material is shown in Figure 29.

Figure 29. Friction-stir welded 7005 particle reinforced $\mathrm{Al}_{2} \mathrm{O}_{3}$ (Ceschini et al. 2007).

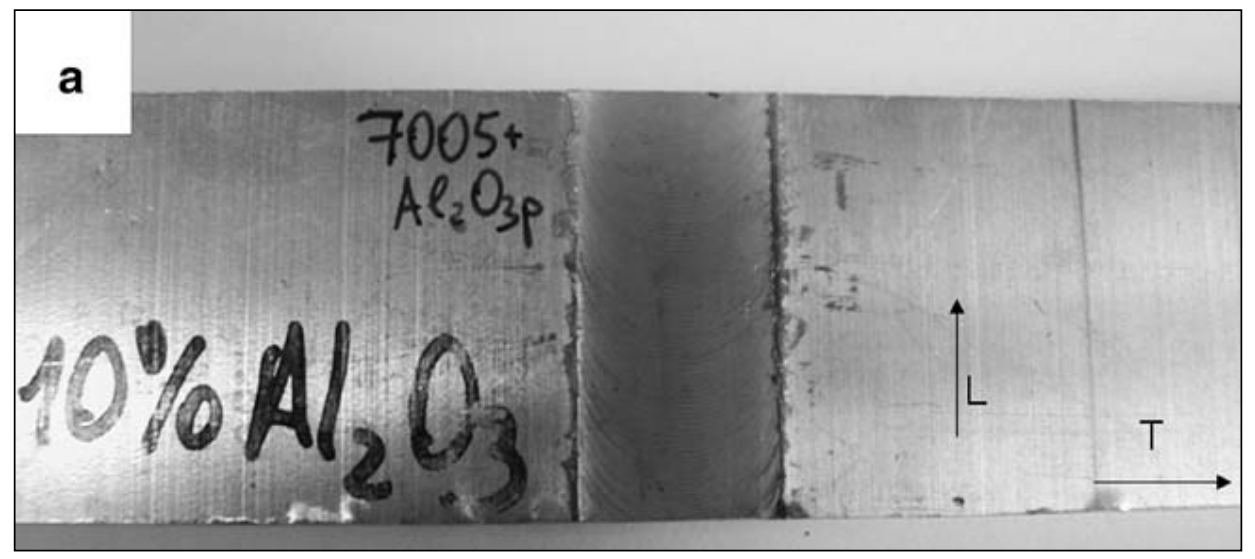

In review, the AM2 runway system is primarily a three-component system, with the primary runway matting surface being made of an extruded segment of 6061-T6. A welded two-rail flange is bonded to each end of the panel and a locking key is used to hold two matting segments together. In previous studies of MMCs, especially those based around 6061 aluminum alloy, there was a notable degree of improvement in the areas of fracture toughness, yield strength, and surface hardness over standard 6061-T6. However, these MMCs were shown to have lower fatigue strength in most cases compared to the base 6061 material. This was also noted as being an issue that increased with extreme temperature environments, in this case up to $300^{\circ} \mathrm{C}$. Despite the obvious impracticality of the MMCs use in the flange, the primary identified region of failure in the AM2 system (Rushing and Mason 2008), could the material still be a viable replacement for the 6061-T6 in the primary matting surface? To make this work, the fatigue strength of the MMC material needs to be maintained at the joint between 
the matting and flange, not transferring the primary failure point from the flange rails to this joint.

The minimally intrusive characteristics of FSW make it a good candidate for welding MMC materials since it does not create the amount of heat that causes the formation of voids and cracks at the reinforcement interface, which is the result of thermal expansion and dramatic altering of the grain structure of the base material far away from the joint. Like the material itself, research into the field of friction-stir welding in MMCs is fairly limited. However, in recent years, several studies have been published on this topic and provide insight on the effect of FSW on MMCs. One such study (Storjahann et al. 2005) discussed the practicality of arc, laser beam, electron-beam welding and FSW in $6061 \mathrm{SiC}$ whiskers $20 \mathrm{vol} \%$ and $\mathrm{Al}_{2} \mathrm{O}_{3}$ particles $20 \mathrm{vol} \%$ reinforced MMCs. Here, Storjahann et al. found that joints formed by the various fusion welding techniques exhibited increases in brittleness. Additionally, it was noted the high temperatures produced in the joints using fusion welding allowed for the formation of reinforcement clusters. These clusters have been previously observed as being major components of crack initiation in the non-welded MMC material.

In the case of FSW, high-fidelity welds were produced with superior mechanical performance. In fact, the effect of the welding was noted as being almost non-existent, where the melding of the materials was virtually seamless in relationship to the base material characteristics with only a slight drop in hardness being noted in the joint. Alongside the $\mathrm{Al}_{2} \mathrm{O}_{3} \mathrm{MMC}$, a $20 \mathrm{vol} \% \mathrm{SiC}$ whisker reinforced 2124 Aluminum MMC was also tested in identical scenarios. This MMC did not have as spectacular results as its $\mathrm{Al}_{2} \mathrm{O}_{3}$ peer, with the whiskers becoming aligned in such a way that the hardness of the joint was decreased considerably compared to the base material.

In the stir zone, the particle reinforcement was observed to have homogenous distributions, which likely explains the lack of detrimental effects due to the FSW process. Researchers (Storjahann et al. 2005) noted that the $\mathrm{Al}_{2} \mathrm{O}_{3}$ reinforcement was seen to be affected physically by the welding process in that the $\mathrm{Al}_{2} \mathrm{O}_{3}$ particles were broken down to much smaller sizes, as shown in Figure 30. This, however, could be an advantage for the welding as smaller particle-reinforced MMCs have been seen as performing progressively better than the larger length scale MMCs (Storjahann et al. 2005; Marzoli et al. 2006). 
Figure 30. Micrograph of a FSW 6061 Al203 sample. BM - Base Metal, TMAZ -Thermallyand mechanically affected region (Outer Ring), and DXZ - Directional Recrystallized Region (Center of the Weld) (Storjahann et al. 2005).

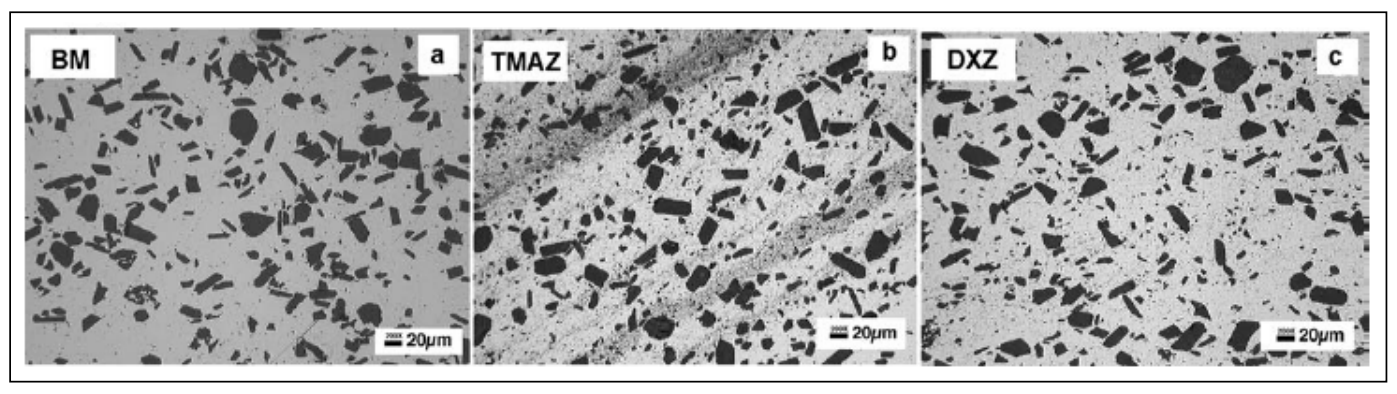

In cyclic fatigue, two distinct studies concerning the reinforcement of 6061 MMCs with $\mathrm{Al}_{2} \mathrm{O}_{3}$ reinforcement were found. Earlier, the base $6061 \mathrm{MMC}$ material was noted to have inferior fatigue life compared to its matrix alloy; therefore, this should translate directly into the weld joint. If the fatigue life was further decreased by the structural integrity of the weld, this could significantly hamper the integration of this joining technique into structural systems. In the experiments, several different rotational and linear speeds were used to produce several different weld sets. Each set was placed under a series of different constant stress, full-cycle loadings. The results of the tests did show a decrease in fatigue life of as much as one full order of magnitude from the performance of the unwelded MMC material (Minak et al. 2010).

Similar fatigue characteristics were noted in 7005 aluminum reinforced with $10 \mathrm{vol} \% \mathrm{SiC}$ particles (Ceschini et al. 2007). Here, researchers noted that at constant strain-amplitude fatigue loadings, the weld performed similar to the base metal. However, under high strain amplitudes, the fatigue life was approximately 66\% lower compared to the base MMC. This degradation in fatigue life may be contributed to the processing effect on $\mathrm{SiC}$ particles. In addition, a decrease of about $20 \%$ occurred in the tensile and yield strength at the joint versus the base (Ceschini et al. 2007). This was a greater decrease than was seen in the $6061 \mathrm{Al}_{2} \mathrm{O}_{3} \mathrm{MMC}$ studied earlier (approximately 6.5\% less). One possible explanation for this could be that the $\mathrm{SiC}$ fibers did not rebond with the matrix material as effectively as the $\mathrm{Al}_{2} \mathrm{O}_{3}$ particle reinforcement and, therefore, allowed for a more rapid degrading of the material's performance due to fundamental defects associated with MMCs.

Researchers noted that a majority of the failures recorded with FSW joints were outside of the physical stir region and more within the base material 
and/ or the transitional region. This could be an indication of an adverse reaction to the heat produced by the welding that is negated in the actual weld material by the physical processing. The shape of the weld joint was also investigated, and the welding was overall very symmetrical with neither the retreating nor advancing sides of the welding joint being noted as failing more than the other, and the hardness of the weld was symmetrically distributed across the weld-joint profile.

The main drawback of using FSW to join MMCs is the issue of tool wear. While several reports have shown that the wearing and deformation of the tooling actually produced a shape that was advantageous for the weld quality, the tooling became ineffective after only one use, since it could no longer be utilized to tap into the material at the beginning of the process. Examples of the wear observed in the FSW tooling are shown in Figure 31. The significant wear observed in the tooling was expected when considering the increase in the material's hardness caused by the particulate reinforcement (Femandez and Murr 2004).

Advantageous or not, in the end the FSW technique did demonstrate a decrease in material characteristics that were beneficial to the MMCs, especially in 6061 aluminum alloys. In fact, this welding technique was effective in producing welded joints with efficiencies as high as $90 \%$, with an average of $75 \%$. FSW could be a very viable joining process for MMCs; however, the issue of tool wear presents a significant barrier to FSW large linear seam welds needed for large-scale production of the AM2 airfield matting system.

\section{Polymer matrix composites}

For the past two decades, the US military has been researching the possibility of developing a replacement airfield matting system to upgrade its existing AM2 portable runway platform. The need for an upgrade has been identified as stemming from four distinct points. First, the AM2 matting surface was initially designed for military aircraft that were comparatively lighter than now in service. Therefore, the landing gear loadings have become much higher than originally envisioned. The theatres of deployment such as the Vietnam War have changed significantly since its inception. Target environments that the matting was designed for have changed considerably, moving from the damp, clay-based valleys of Southeast Asia to dry, sandy plains of the Middle East. 
Figure 31. Wear of a FSW Pin tool at various rotational speeds and transverse distances at a constant transverse speed of $6 \mathrm{~mm} / \mathrm{s}$. (a) $\mathrm{R}=500 \mathrm{rpm}$, (b) $\mathrm{R}=750 \mathrm{rpm}$, and (c) $\mathrm{R}=1000 \mathrm{rpm}$ (Femandez and Murr 2004).

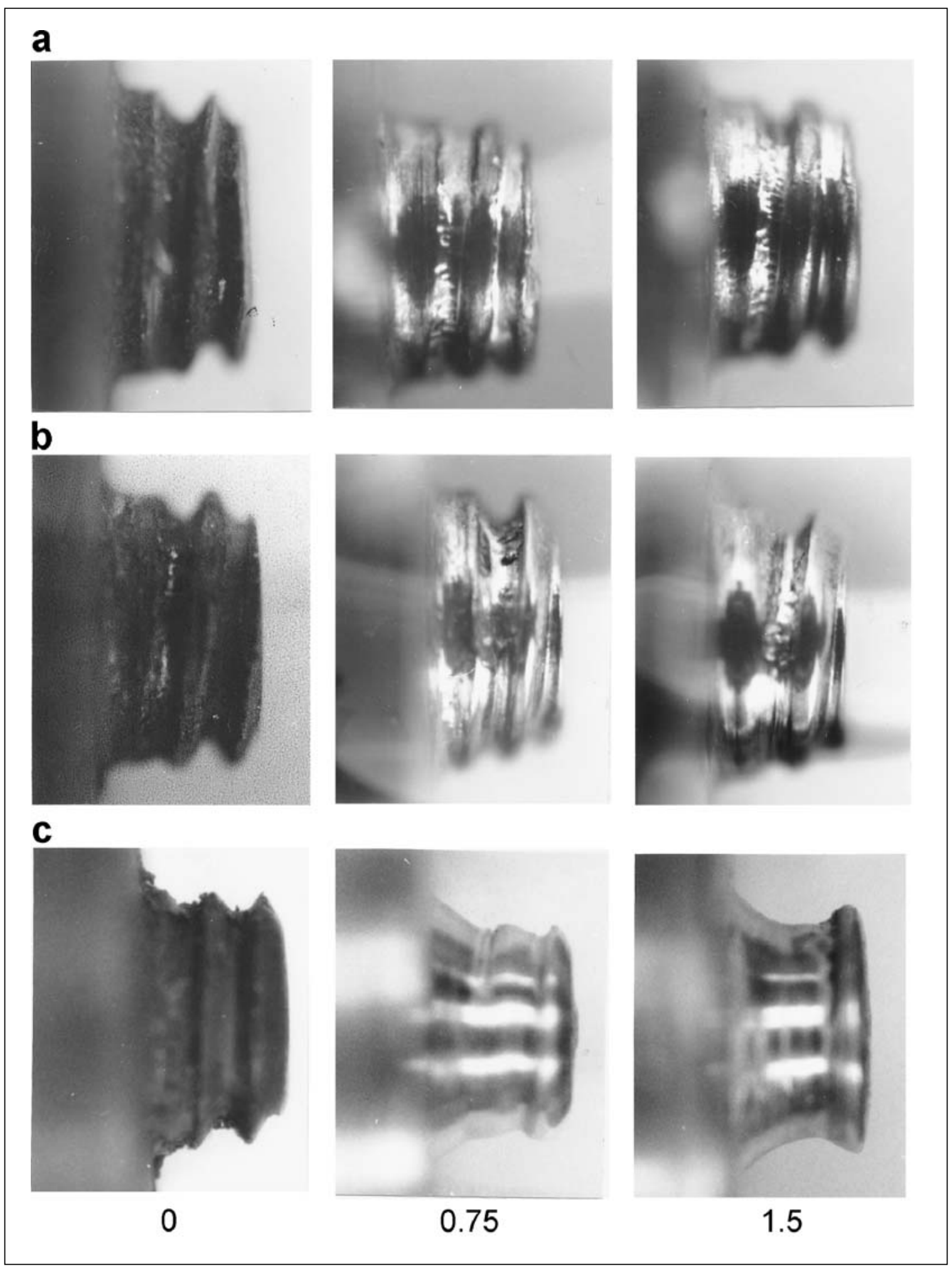


Besides the changing deployment conditions, it was realized that the matting was significantly heavier than the volumetric carrying capacity of the available heavy-lift aircraft. This creates a very inefficient logistic situation for the military's often burdened supply distribution infrastructure. Another issue that has emerged in the past decade concerns improvements in the high temperature endurance of the AM2 matting, mainly due to the development and deployment of vertical takeoff tactical fighter platforms such as the F-35J oint Strike Fighter. The F-35 will be equipped with a new vertical lift technology, which will require directing the full exhaust stream of the Pratt and Whitney F135 turbofan engine against the runway surface (Gertler 2011). This exposes the runway surfaces to very intense thermal gradients, creating a potential for stressing and localized material softening because of high-temperature exhaust.

The application of these high temperature gradients pose a significant issue in metal matrix composites because of several factors. However, the most significant issues were caused by debonding between the ceramic reinforcement particles or fibers and the metal matrix material produced by differences in material thermal expansions and lower material yield strengths at these elevated thermal conditions (Lincoln et al. 2001). This issue is even more pronounced since the F-35 will be one of the heaviest joint strike fighters ever deployed, weighing almost twice as much as a conventional F-16. This makes for higher landing gear loadings and a need for the most powerful jet engine ever placed in generation tactical joint strike fighters (Gertler 2011).

After observing this debonding in MMCs, researchers hypothesized that a more ductile material might perform better under these conditions than a stiff, high-strength material. Polymer-based materials were investigated because of their toughness and ability to experience a large amount of elastic deformation with lower levels of detrimental effects. However, most polymers are susceptible to significant degradation in high-temperature applications, presenting a major problem for integration into the AM2 system. The large loadings and high temperatures to which the matting will be subjected could severely damage components made with these materials. Another issue is that polymers are susceptible to long-term ultraviolet light exposure, which breaks down the polymer chains and weakens the material, posing a significant issue in long-term desert deployment. 
After reviewing literature on high-temperature polymer materials, a wide range of materials and approaches were found. In the past two decades, a great deal of time and energy has been spent in trying to find polymers that can withstand the types of thermal loadings subjected to when implemented in the runway matting. However, few polymers have been found to have the thermal loading capabilities needed for implementation into a portable runway system. Some of the most prominent materials isolated were Nylon 6, phenylethnyl terminated imide oligomer (PETI), and PMR-15 (Lee et al. 2011). PMR-15 is the foundational resin for many of the composites being used by the aerospace industry and has received a good deal of attention in recent years for its implementation into the Boeing 787 Dreamliner. However, it is an older polymer and has a maximum temperature limit of about $200^{\circ} \mathrm{C}$, making it an insufficient candidate for the matting system for use in high-temperature applications.

Researchers quickly showed that none of the identified polymers exhibited performance matching that of PETI-5 resin. This resin was created in 1999 by NASA's Langley Research Center as a direct result of NASA's attempt to find lightweight yet sturdy materials as the main structural and surface component for the primary aerodynamic surfaces of the High Speed Transport System under development in the 1990s and early 2000s (Lee et al. 2011). What makes this material so unique is its ability to withstand high temperature environment -- as high as $450^{\circ} \mathrm{C}$ for up to $5 \mathrm{hr}$ without losing any of its characteristic properties through thermal degradation (Cho and Drzal 1999).

While the material is known to be very stable under thermal loadings, it was still noted as having mechanical characteristics very similar to those seen in other polymers, such as low yield and tensile strengths, especially when compared to metals; low modulus of elasticity; and an extreme vulnerability to compressive loadings.

When compared to standard 6061-T6 aluminum, the pure PETI-5 resins exhibited much lower tensile yield strengths (116.4 MPa versus $310 \mathrm{MPa}$ ) as well as significantly lower elastic moduli (3.25 GPa versus $69 \mathrm{GPa}$ ) (Lee et al. 2010; ASM 1991). Here, the performance of PETI- 5 was compared to the performance of a 3900 series polymer resin produced by Hexcel, the primary supplier of polymer resin to Boeing for their 787 Dreamliner aircraft. In the comparison it was noted that PETI-5 performed significantly better than 3900 in all tests. 
Literature showed that PETI-5, with only a minimal increase in density ( $1234 \mathrm{~kg} / \mathrm{m}^{3}$ to $1335 \mathrm{~kg} / \mathrm{m}^{3}$ ), displayed a $35 \%$ increase in its elastic modulus, an $80.4 \%$ increase in its ultimate strength and was seen to be much more ductile at equal strain rates compared to 3900 (Lincoln et al. 2001). Researchers also noted that PETI- 5 was able to remain fairly ductile at much higher strain rates compared to the 3900. However, the PETI-5 displayed brittle material characteristics at strain rates of 2,000 $(\mathrm{mm} / \mathrm{mm}) / \mathrm{s}$, failing immediately at its maximum recorded stress, which was much higher than observed in the lower strain rate samples, reaching $174 \mathrm{MPa}$ versus 3900's $65 \mathrm{MPa}$ recorded at a strain rate of 1,600 $(\mathrm{mm} / \mathrm{mm}) / \mathrm{s}$ (Lee et al. 2011).

Another point of note was that PETI- 5 showed considerably improved crack initiation toughness when subjected to three point bending loadings and observing mode 1 crack initiation and growth. The PETI-5 produced stress intensity coefficients in the range of $5.1 \mathrm{MPa}^{*} \mathrm{~m}^{1 / 2}$, maintaining a 4.5 $\mathrm{MPa}^{*} \mathrm{~m}^{1 / 2}$ factor post-initiation, both of which were substantial increases compared to maximum 3900 factor of $2.5 \mathrm{MPa}^{*} \mathrm{~m}^{1 / 2}$. The PETI- 5 crack formation also started 50 micro-seconds after crack formation in 3900 (Lee et al. 2011).

Several studies made note of the material's exceptional ability to maintain its base characteristics under thermal loading. [With PETI-5 samples that were cured at temperatures between $100^{\circ} \mathrm{C}$ to $400^{\circ} \mathrm{C}$, an optimum curing temperature of $220^{\circ} \mathrm{C}$ could be identified (Cho and Drzal 1999)]. At $220^{\circ} \mathrm{C}$ all of the samples cured at or above this temperature were found to have exhibited no molecular degradation with up to $5 \mathrm{hr}$ of continuous exposure to environmental temperatures up to $500^{\circ} \mathrm{C}$.

Along with curing temperature, research also showed that PETI-5's properties were very dependent on the cooling rate of curing process (Cho and Drzal 1999). This fact is very important in that solid control of the cooling process established a stable set of mechanical properties. Cooling rates of $1.1^{\circ} \mathrm{C} / \mathrm{m}$ (Lincoln et al. 2001) were shown to produce a more ductile polymer matrix with the highest recorded glass transition temperature and, therefore, the best thermal stability of all of the samples.

In study of the thermal characteristics of the PETI-5, while the material maintained its properties exceptionally well under high thermal loadings of up to $500^{\circ} \mathrm{C}$, one aspect of the material did change within that range. The 
glass transition temperature for samples cured at $350^{\circ} \mathrm{C}$ was found to be around $271^{\circ} \mathrm{C}$ (Cho and Drzal 1999). The issue with this is that the elastic properties of PETI- 5 were mainly recorded at ambient temperature where the material is more brittle. When the material temperature passes over this transition temperature, being a thermoset, the molecular bonding will not reset if it plastically deforms. Therefore, even though the material will maintain its shape, the material's tensile strength will decrease and a weak segment in the structure will develop (Lincoln et al. 2001).

Another area of concern and one that was not addressed at length in literature is the compressive strength of the material. The overall development concentration for this material was under tensile and shear loadings conditions. How PETI-5 will perform when acting as a load support member like the vertical struts in the current matting design cannot be confidently determined. If the material trends closely to what is observed in other polymer compounds, then its bearing strength might only be half of its tensile strength. This is probably the defining limitation in using the PETI-5 neat resin as a primary structural material.

In terms of composite structural materials, several polymer matrix composites (PMC) using the PETI- 5 were identified as being excellent candidates for implementation into an AM2-type matting system. Two primary types of matrix composites were identified in the research paper found. The first was the integration of nanoparticles into a matrix made of the PETI-5. The addition of up to $20 \mathrm{wt} \%$ in graphite platelets led to an increase of up to $1000 \%$ for the storage modulus of the PETI- 5 matrix in regions above the material's glass transition temperature, indicating the formation of a much stiffer material (Cho et al. 2005). The second PMC type, and by far the more prevalent of the two, was the continuous fiber reinforced composite systems. For this study a specific carbon fiber was able to be isolated as the reinforcement material of choice in almost all of the composites studied. This fiber is typically identified as IM7 and is primarily produced by Hexcel Corporation under the name HexTow as individual fiber spools of 6,000 or 12,000 thread counts implemented into a large variety of woven fabrics (Hexcel Corporation 2011).

Carbon fiber-reinforced PMC as a whole has proved to be very effective in higher temperature and loading environments and are being used for engine cowlings and compressor blades (the inlet segment of the jet turbine) in many modern aircraft. One of the most prevalent PMC is the 
HexPly M36 prepreg, which has been noted to withstand tensile loadings as high as $2.1 \mathrm{GPa}$ at ambient temperature and with a unidirectional fiber orientation (Hexcel Corporation 2011). This material uses an epoxy resin that is cured along with a Tenax HTS (Multidirectional) or HTA (Unidirectional) fiber at a final temperature of $180^{\circ} \mathrm{C}$ for $5 \mathrm{hr}$. The specific resin used was not mentioned in the supplied information, other than it is unique to the M36 prepreg. The Tenax fibers were found to have very similar performance to the IM5 fiber, although it is a weaker version of the IM7 fiber.

From manufacture data, the M36 fabric was shown to be able to endure multidirectional tensile loadings at ambient temperature as high as $568 \mathrm{MPa}$ and possessed compression strength of $587 \mathrm{MPa}$. This makes a large tensile/ compression ratio improvement over the performance shown in the PETI-5 neat resin discussed earlier (Hexcel Corporation 2011). The design of the composite for multi-axial loading was seen to decrease the strength of the material in tension by almost $75 \%$, and the material's elastic modulus decreased by about $60 \%$. However, the multi-axial loading increased the material's compressive and open-hole loading performance. In open-hole loading, the increase was as high as 74\% (273 MPa to $474 \mathrm{MPa}$ ) in compression, from $273 \mathrm{MPa}$ to $474 \mathrm{MPa}$ with the fiber orientation change (Hexcel Corporation 2011).

While the M36 prepreg performed exceptionally well under ambient temperature environments as seen above, its thermal performance was limited to a maximum of $180^{\circ} \mathrm{C}$ and, therefore, would be an insufficient candidate for the matting application. As such, the IM7/ PETI- 5 composite noted earlier appears to be more promising, since it can be cured at much higher temperatures $\left(>=350^{\circ} \mathrm{C}\right.$ ) and could potentially be compatible with the $300^{\circ} \mathrm{C}$ thermal endurance requirement of the matting for the F-35 strike fighter. However, the analysis of these composites are limited, like the neat resin, by a very small quantity of research regarding the structural properties of the material, especially in cyclic fatigue.

Since these high-temperature polymers were highly sought during NASA's high-speed transport program, a concentration was noted in the study of the open-hole bearing strength of the material at elevated temperatures $\left(177^{\circ} \mathrm{C}\right)$. This is a vital characteristic when assembling the material using rivets or removable fasteners such as bolts or screws. In long-term loading, the bearing strength of the material was seen to reach up to $358 \mathrm{MPa}$ with over $6,000 \mathrm{hr}$ of continuous loading before failing. The material was 
actually noted as reaching $409 \mathrm{MPa}$ of loading before failure, but it was recorded that the duration of loading reached just only $100 \mathrm{hr}$ (Ahmad et al. 2003). Researchers also observed that the material could reach tensile open-hole bearing strengths as high as $461 \mathrm{MPa}$ under quasi-static loading at the ambient operating temperature of $177^{\circ} \mathrm{C}$ (Counts and J ohnson 2002).

One of the major concerns expressed in the work by Ahmad et al. (2003) regarding the IM7/ PETI-5 was the rapid failure of the material once it began to elongate. Researchers noted that the material experienced only a $4 \%$ total elongation in the final 33\% of the loading period. Of this 33\%, almost $84 \%$ of the total elongation occurred rapidly at failure. This makes it very difficult to determine when the material is close to failure and increases the risk of damaged components being missed during equipment checks.

Counts and J ohnson (2002) also studied the effects of load cycling on the fatigue life of IM7/ PETI-5. Their tests were run at $177 \mathrm{oC}$, with an R-ratio of 0.1 in four different configurations. The first test strictly studied the effects of the above conditions on the material's tensile bearing strength. The material was able to sustain loadings in excess of $375 \mathrm{MPa}$ for a minimum of one million cycles (Counts and J ohnson 2002) as shown in Figure 32.

One area of concern found in the PETI- was the effect that oxidation had on the resin at high temperatures reported elsewhere (Upadhyaya et al. 2011). In this work, the effect of long-term aging $(+2000 \mathrm{hr})$ at $300^{\circ} \mathrm{C}$ on unidirectional IM7/ PETI- 5 specimens was studied and a finite element model was developed to predict its effects on composite performance. What was found in the study was that the load-carrying capacity of an aged specimen was over half of that seen in an un-aged specimen of similar dimensions.

The decrease in loading performance was more than $61 \%$ from $775 \mathrm{~N}$ to $300 \mathrm{~N}$ (Upadhyaya et al. 2011). However, this decrease could be caused by the means of processing used in the manufacture of the resin. If the matting was impregnated with the resin but was not cured long enough, the required carbon bonding in the PETI- 5 would not form completely, creating a weak matrix structure that would produce a faster degradation of the material under thermal loading (Cho and Drzal 1999). This could account for the low tensile strength of 43.7 MPa for the resin reported by Upadhyaya et al. (2011). 
Figure 32. Fatigue life comparison between IM7/PETI-5 and IM7/K3B materials (Counts and Johnson 2002).

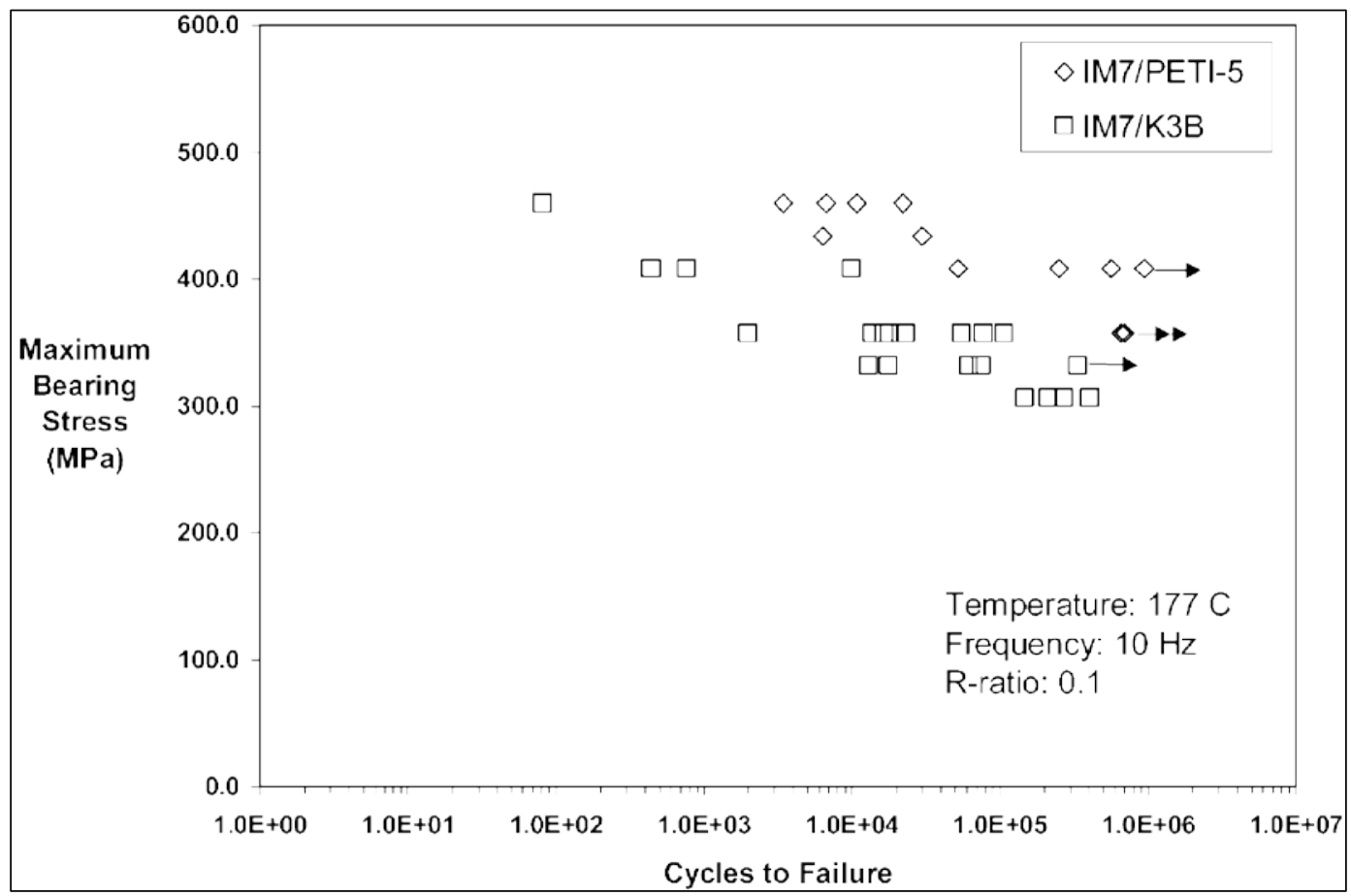

In conclusion, while the PETI-5 resin did show substantial performance in high-temperature application, it is almost impossible to confidently predict its performance under high mechanical and thermal loading environments. It is noted that among the items left out of this survey of polymer composite research, the endurance of the material under cyclic thermal loading, fully reversing cyclic mechanical loading, high impact durability, ultraviolet and infrared radiation degradation, and the effects of different carbon reinforcement weaves on the performance of the material is not completely known. In addition, many of the applications that the composite were shown to be placed in the aerospace applications were not operating beyond $200^{\circ} \mathrm{C}$, which is well below the glass transition temperature of the PETI-5. Before PETI- 5 composite can be implemented, a great deal of research still needs to be conducted to fully understand the limits of this material at high temperatures.

\section{Magnesium alloys}

As a lightweight metal, magnesium is being intensively sought to be integrated in large mechanical structures for more energy savings and greenhouse emission reductions. This industrial renaissance is reviving wide attention to the complex fundamentals of the effect of materials 
processing on the fatigue resistance of magnesium alloys. In fact, wrought magnesium alloys present generally higher mechanical strength and fatigue resistance than cast magnesium alloys due to their ability to have smaller inclusion sizes and essentially no porosity, and their precipitation hardening after the severe deformation during the processing conditions. Wrought magnesium alloys, however, present sharper textures over cast magnesium alloys and thus are more anisotropic by nature. Texture has indeed a profound effect on the mechanical response because of the low symmetry of the hexagonal close-packed (HCP) crystal structure. In fact, the closepacked planes in HCP magnesium reduce only to the basal planes, which cannot accommodate deformation along the c-axis. Slip that could mediate strain along the c-axis corresponds only to pyramidal planes. Pyramidal slip is at least five times harder than the basal slip. As such, $\{1012\}$ tensile twinning is readily activated to provide strain along the c-axis with intermediate strength between those of basal and pyramidal slips. \{1012\} twinning, however, rotates the basal poles structure by almost 90 deg around a $<1120>$ direction toward the loading direction, which results in a very rapid hardening and a strong nonlinear behavior in the mechanical response that have never been reported to occur in face-centered cubic (FCC) and body-centered cubic (BCC) structures. Furthermore, the twins could be systemically removed by a detwinning mechanism through any stress reversal. Therefore, mechanisms of fatigue crack propagation in magnesium under negative values of $\mathrm{R}$ were reported to be extremely complex. Armstrong and Horne (1962) showed complex mechanisms of slip in regions ahead of the fatigue crack where the material twins and detwins.

Some cyclic tests were recently performed on extruded AM30 (Bernard et al. 2010; Begum et al. 2008) and AZ31 (Begum et al. 2009a; Begum et al. 2009b; Lin and Chen 2008a; Lin and Chen 2008b; Hasegawa et al. 2007, J ordon et al. 2011) alloys in an effort to understand the mechanisms underlying fatigue in wrought magnesium alloys. These materials were found to have marked cyclic hardening characteristics. Plastic strain amplitudes and mean stresses increased as the total strain amplitude increased and were typical observation for these alloys. Regarding traditional fatigue modeling methods, the conventional Coffin-Manson law and Basquin's equation were found to correlate with the experimental fatigue results of these alloys (Begum et al. 2008; Begum et al. 2009a; Begum et al. 2009b; Lin and Chen 2008a; Lin and Chen 2008b; Hasegawa et al. 2007). Furthermore, analysis of the current body of literature on fatigue of wrought magnesium alloys suggests that a multistage fatigue approach, which is based in part on 
Suresh's (1998) classification of fatigue damage of metals and originally developed for FCC structures such as aluminum and austenitic steels, could be extended to capture the fatigue behavior of magnesium alloys.

Much like in wrought aluminum alloys, inclusions (generally intermetallic particles) have a major effect on the mechanisms controlling the cause of fatigue crack incubation in extruded magnesium alloys (Bernard et al. 2010). Other studies (Begum et al. 2008; Begum et al. 2009a; Begum et al. 2009b; Lin and Chen 2008a; Lin and Chen 2008b; Hasegawa et al. 2007) on fatigue of wrought magnesium alloys did not explicitly report on the sources of fatigue incubation. However, persistent slip bands and grain boundaries sliding are also thought to be a source of fatigue crack initiation in magnesium alloys (Begum et al. 2008; Begum et al. 2009a; Begum et al. 2009b; Lin and Chen 2008a; Gall et al. 2004a).

A level of interest has been recently given to the issue of small fatigue cracks in wrought magnesium alloys. The inapplicability of the conventional linear elastic fracture mechanics (LEFM) parameters (i.e., stress intensity factors) to characterize the growth of fatigue cracks on the order of microns in length was evidenced in wrought magnesium alloys (Tokaji et al. 2004; Sajuri et al. 2006). On the other hand, fatigue cracks on the order of millimeters or greater in length and larger could be satisfactorily characterized by LEFM parameters. However, all of these models are semiempirical, disregard the main mechanisms of fatigue damage in magnesium, and have no microstructural relationships. The transition from the Microstructurally Small Crack (MSC) propagation to long crack propagation has not been clearly established yet for wrought magnesium alloys. However, the small crack regime in cast magnesium alloys appears to be in the range of 60 to $100 \mu \mathrm{m}$ (Gall et al. 2004b) of crack length, which is six to ten times the grain size for wrought alloys (or dendrite cell size for cast alloys).

As stated above, the mechanisms controlling the effects of twin-slip interaction on the fatigue crack growth including crack incubation are still unclear, but this is an area of ongoing research. Recent work has shown the important influence of texture on fatigue life in magnesium alloys (Bernard et al. 2010, Sajuri et al. 2006; Chamos et al. 2008). Similar conclusions were drawn for other HCP metals like titanium alloys (Bache et al. 1998; Whittaker et al. 2009). However, the relative importance of the anisotropy from the texture compared to the inclusion (defect) size is still an open issue. 
In addition to the high strength-to-weight ratio, magnesium alloys are readily extrudable, having comparable extrusion speeds to that of aluminum alloys. In fact, the extruded magnesium alloys can typically be extruded at speeds similar to 6061 aluminum alloy (Bernard et al. 2010; J ordon et al. 2011), while maintaining superior fatigue behavior. One of the drawbacks to extruded magnesium alloys, however, is the strong texture formation that develops during processing. This strong texturing can lead to anisotropic mechanical behavior (Agnew et al. 2005). However, the extent of texturing can be reduced through manipulation of extrusion speeds and temperatures (Shahzad et al. 2007), but is highly dependent on the crystallographic orientation (Uematsu et al. 2006). In any case, extruded magnesium generally shows good fatigue resistance. Three of the most common (AM30; AZ31; AZ61) and most frequently studied magnesium alloys are compared to 6061 aluminum alloy (Wong et al. 1984) in Figure 33. All three magnesium alloys displayed comparable, if not slightly better, fatigue resistance to the 6061 aluminum alloy. As such, the use of magnesium alloys could provide significant weight savings over the 6061 AM2 design while maintaining mechanical performance.

Figure 33. Comparison of common extruded magnesium alloys to 6061 aluminum alloy.

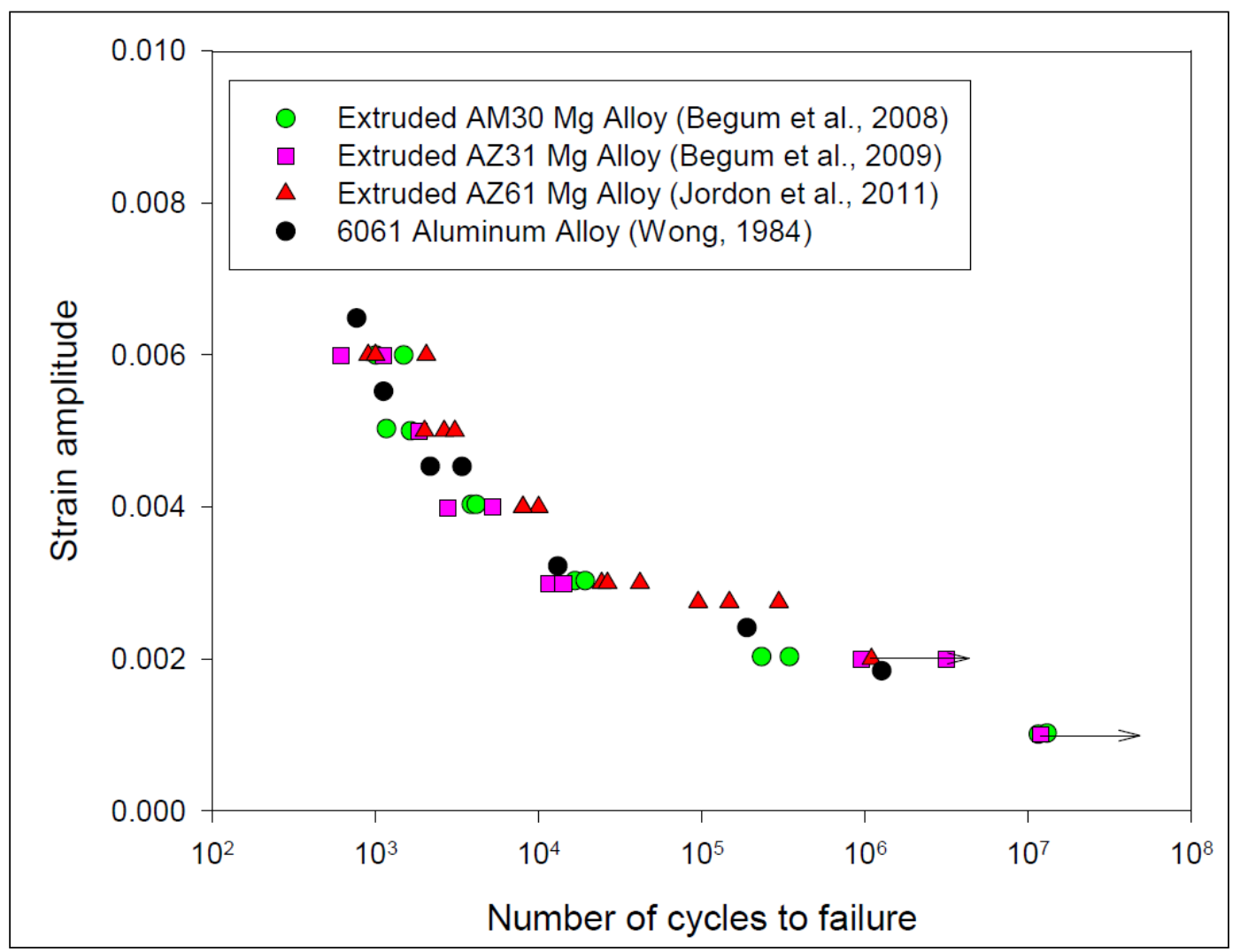


The issue of elevated temperature during cyclic loading is an area of sparse documentation. Because of its relatively low melting point, magnesium alloys show significant reduction in fatigue strength at elevated temperatures (Sajuri et al. 2005). However, extensive fatigue data on the quantitative reduction in strain-life behavior due to elevated temperatures does not exist for other common extruded magnesium alloys. Figure 34 shows the results of the effect of elevated temperature on fatigue lifetimes for an extruded AZ61 magnesium alloy. Here, the fatigue resistance is significantly reduced in the high-cycle regime. However, in the lower-cycle regime, the detrimental effect due to elevated temperature is less severe. Thus, additional experimental testing is needed to explicitly determine this for other alloys such as AM30 and AZ31.

Figure 34. Influence of temperature on fatigue properties of extruded AZ61 magnesium alloy (Sajuri et al. 2005).

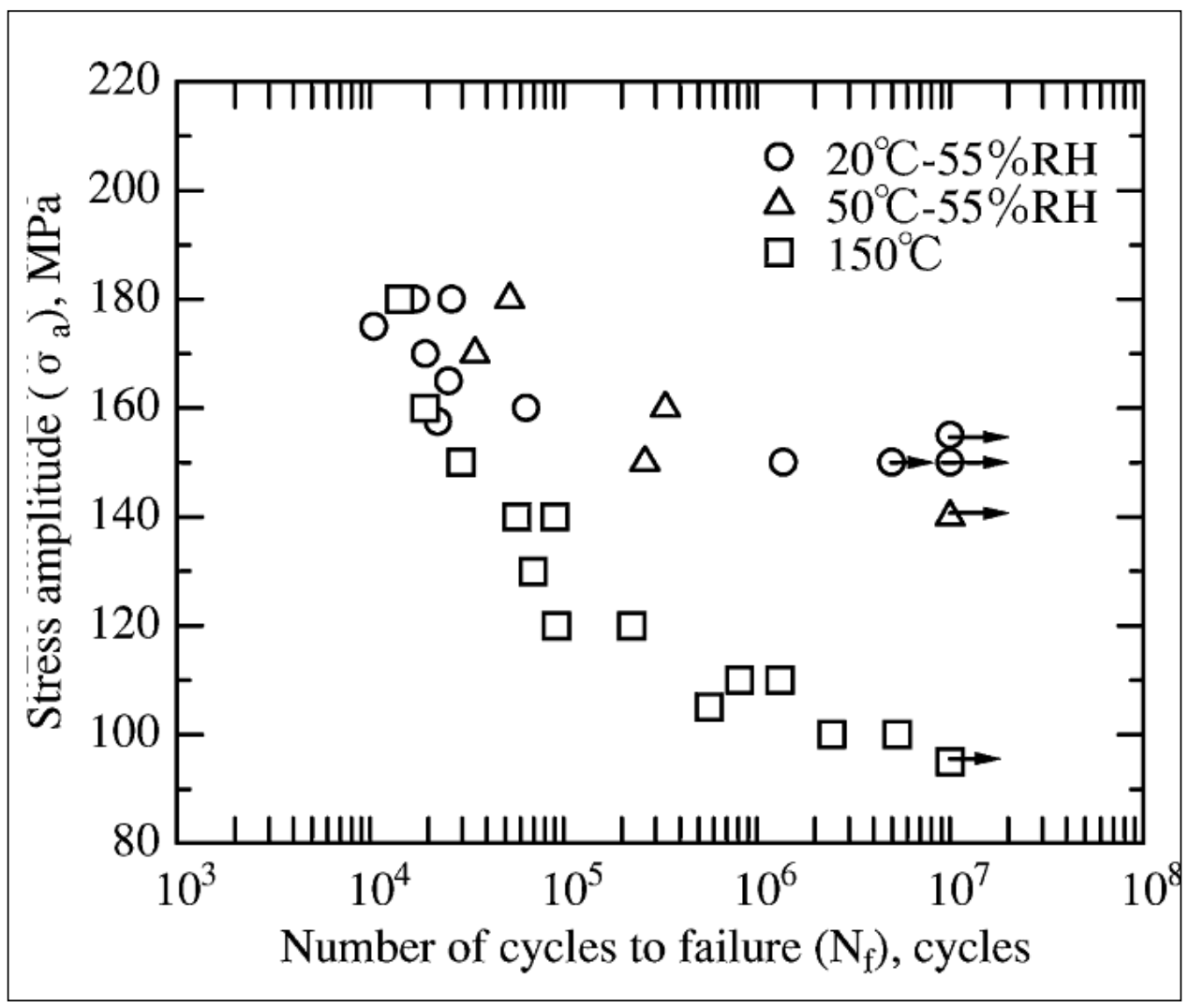

To address the reduction in strength as well as creep at elevated temperatures, rare earth (RE) elements have been shown to improve the mechanical properties. Figure 35 shows the effect of adding rare earth elements on tensile strength AZ91 magnesium alloy at elevated temperatures $\left(150^{\circ} \mathrm{C}\right)$. Additional strength is achieved by the replacement of the $\mathrm{Mg}_{17} \mathrm{Al}_{12}$ 
intermetallic compound with RE-containing compounds. The RE compound is thermally and metallurigically more stable than the $\mathrm{Mg}_{17} \mathrm{Al}_{12}$ intermetallic. In addition, the RE reduces grain-boundary migration during elevated temperature (Khomamizadeh et al. 2005). The addition of RE beyond $3 \%$ is noted to having negative effect on tensile strength and ductility ( Li et al. 2000; Khomamizadeh et al. 2005). However, the effect of RE on fatigue resistance in extruded magnesium alloys is not currently known.

Figure 35. Tensile properties of magnesium alloy AZ91 tested at 150C. Note that $1 \mathrm{RE}$ represents addition of $1 \%$ rare earth, $2 \mathrm{RE}$ represents addition of $2 \%$ rare earth; $3 \mathrm{RE}$ represents addition of $3 \%$ rare earth (Li et al. 2000).

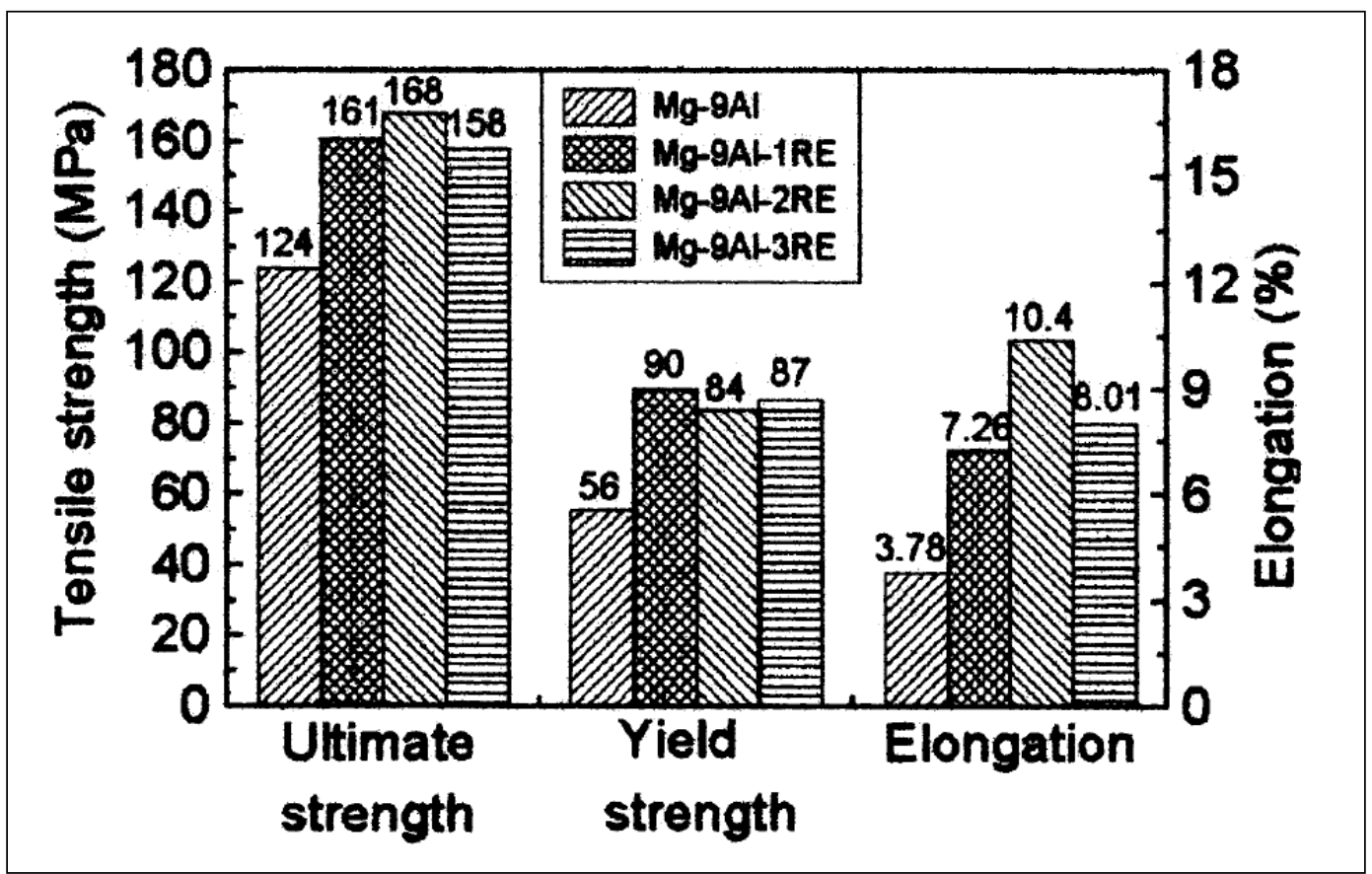

\section{Corrosion}

Several papers have been published concerning the corrosion resistance of the AZ31-, AZ61-, and ZK60-Mg alloys. Unigovski et al. (2003) investigated the effects of exposure of AZ31, AM50, and ZK60 to $3.5 \mathrm{wt} \% \mathrm{NaCl}$ solution saturated with $\mathrm{Mg}(\mathrm{OH}) \neg 2$. They found that the increase in concentration of aluminum alloying elements greatly affected the corrosion resistance of the various alloys. Fatigue performance was seen to be greatly affected by corrosion. In both air and $\mathrm{NaCl}$-saturated conditions, a trend was found in which ZK60 Mg alloy consistently exhibited superior performance over AM50 and AZ31 Mg alloys under fully reversing stress-controlled fatigue testing. AZ31 experienced substantially smaller levels of degradation with $\mathrm{NaCl}$ exposure compared to AM50-Mg alloy, as shown in Figure 36. The 
corrosion rate of AZ31-Mg alloy was seen to be more than double of that seen in ZK60-Mg alloy and half of that in the AM50-Mg alloy (Unigovski et al. 2003). These results were further confirmed by Cheng et al. (2009) with the added analysis of AZ61. The results of Cheng's analysis using $1 \mathrm{~mol} / \mathrm{L}$ of $\mathrm{NaCl}$ showed that the corrosion resistance of the magnesium alloys from greatest to poorest is: ZK60>AM60>AZ31>AZ91

Figure 36. $\sigma-\mathrm{N}$ curves for extruded ZK60, AM50 and AZ31 alloys in air (a) and in $3.5 \% \mathrm{NaCl}$ solution saturated with $\mathrm{Mg}(\mathrm{OH}) 2$ (b) (Unigovski et al. 2003).

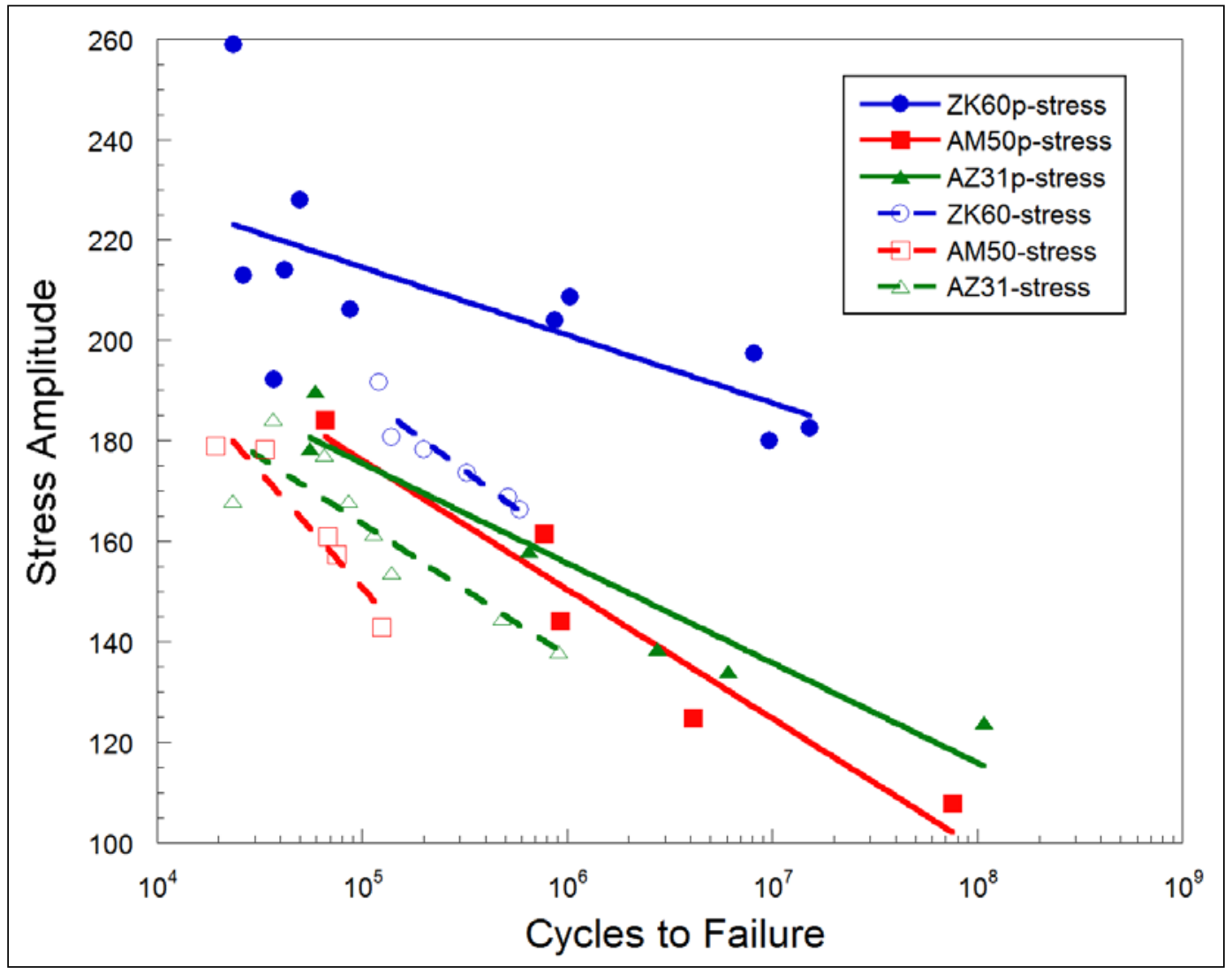

Interestingly, the trend in corrosion resistance in Mg alloys was found to be inconsistent with industry experience. Magnesium Elektron stated that ZK60 typically underperformed AZ series magnesium alloys in corrosion performance-based scenarios. Also, while the previous reports showed a trend towards a decrease in corrosion resistance with an increase in aluminum concentration, Song et al. (1998) noted that AZ91 Mg alloy appeared to exhibit superior corrosion resistance over AZ501 Mg alloy, which in turn was superior to AZ21 Mg alloy. Similarly, Zhao et al. (2008) demonstrated the dependence of corrosion resistance on the microstructure of the magnesium alloy. $\beta$-phases were found in all four studies to be very susceptible to corrosion. These studies also noted that the presence of 
corrosion resistant $\beta$-phases could either act as a barrier to corrosion or, if in the presence of an electrolyte for a galvanic cell with the $\beta$-phase, accelerate the rate of $\beta$-phase corrosion. The size, distribution, and orientation of these $\beta$-phases determined the effect they have of the material's corrosion performance (Zhao et al. 2008; Unigovski et al. 2003; Cheng et al. 2009; Song et al. 1998).

Since magnesium alloys are known for being highly susceptible to corrosion, much effort has focused on determining appropriate protective coatings for magnesium alloys. Some of these techniques include: electrochemical, plating, conversion coatings, anodizing, hydride coatings, organic coatings and vapor-phase processes (Gray and Laun 2001). Unfortunately, many of these techniques do not adequately protect against harsh environments. Recently, however, industry has adapted to this problem by applying protective coatings with good success. In fact, the engine cradle on GM's Corvette Z06 is a magnesium AE44 alloy (Magnesium Showcase 2011) with a protective coating and aluminum bushing to reduce galvanic corrosion. As such, specific research into appropriate coatings to provide corrosion prevention and vehicle traction for the AM2 is needed.

\section{Manufacturability}

In 2008, Taber conducted a test of the extrusion feasibility of magnesium alloys using the AM2 matting profile. This investigation was conducted in parallel with the Army Corps' on-going program to optimize the AM2 runway platform. Taber stated that the company was able to successfully extrude the AZ31 alloy into the AM2 profile. This was accomplished utilizing the porthole-type extrusion die originally designed for the 6061 material. Using this die, Taber was able to successfully produce a set of stable extrusion profiles during the production run. Preheating was applied to the billet, which was optimized for magnesium chemistry and was noted as being lower than that used on a typical 6061 aluminum alloy extrusion procedure (Brown et al. 2006).

For the Magnesium feasibility study, Taber procured and tested a derivative of the AZ31 Mg alloy identified as AZ31PE Mg alloy. The AZ31PE was smelted and cast by the Timminco Corporation. This alloy is very similar to AZ31B Mg alloy in most aspects with the exception of an optimized chemistry with a focus on optimization for electro-chemical etching to form engraving plates for the publication and graphic industry. However, the material was noted as having similar mechanical characteristics to AZ31B Mg alloy and, therefore, was determined to be an acceptable performance gauge. The results of the testing are displayed in Tables 3 and 4 . 
Table 3. AM2 Matting Extrusion Profile Mechanical Properties (Brown et al. 2006)

\begin{tabular}{|l|l|l|l|l|l|l|l|l|l|}
\hline & $\begin{array}{l}\text { Tensile Ult. } \\
\text { Strength, } \\
\text { Die (Alloy) }\end{array}$ & $\begin{array}{l}\text { Tensile } \\
\text { Yield } \\
\text { Strength, } \\
\text { ksi }\end{array}$ & $\begin{array}{l}\text { Tensile } \\
\text { Elongation }\end{array}$ & $\begin{array}{l}\text { Barcol } \\
\text { Hardness }\end{array}$ & $\begin{array}{l}\text { Compress } \\
\text { Modulus, } \\
\text { Msi }\end{array}$ & $\begin{array}{l}\text { Compress } \\
\text { Yield, ksi }\end{array}$ & $\begin{array}{l}\text { Swage } \\
\text { Load, lb }\end{array}$ & $\begin{array}{l}\text { Linear } \\
\text { Weight,a } \\
\text { lb/ft }\end{array}$ & $\begin{array}{l}\text { \% Wt. } \\
\text { Savings }\end{array}$ \\
\hline $\begin{array}{l}11809 \\
\text { (AZ31pe) }\end{array}$ & 30.7 & 12.6 & $21 \%$ & 62 & 6.1 & 6.4 & 3,200 & 7.740 & $32 \%$ \\
\hline $\begin{array}{l}11809 \\
(6061-T 6)\end{array}$ & 44 & 41 & $11 \%$ & 80 & 10.3 & 43.5 & 14,600 & $11.455 \mathrm{lb} / \mathrm{ft}$ & - \\
\hline $\begin{array}{l}11219 \\
(6061-T 6)\end{array}$ & 44 & 41 & $11 \%$ & 80 & 10.3 & 43.5 & N/A & $8.998 \mathrm{lb} / \mathrm{ft}$ & $21 \%$ \\
\hline $\begin{array}{l}13304 \\
\text { (6061-T6) }\end{array}$ & 44 & 41 & $11 \%$ & 80 & 10.3 & 43.5 & N/A & $8.183 \mathrm{lb} / \mathrm{ft}$ & $33 \%$ \\
\hline
\end{tabular}

a Actual measured linear weight. In many cases it differed significantly from what was listed on the print.

b The percentage lighter a given profile and/or alloy is than standard 11809 die in 6061-T6.

Table 4. Static deflection test results (Brown et al. 2006).

\begin{tabular}{|l|l|l|l|l|l|}
\hline Alloy & Die & $\begin{array}{l}\text { Deflection } \\
\text { Capability }\end{array}$ & $\begin{array}{l}\text { Deflection } \\
\text { Pressure }\end{array}$ & $\begin{array}{l}\text { Permanent Set } \\
\text { at 3-in. Input }\end{array}$ & $\begin{array}{l}\text { Pressure at } \\
\text { 3-in. Input }\end{array}$ \\
\hline AZ31PE & 11809 & $0.5 \mathrm{in}$. & $165 \mathrm{psi}$ & $1.75 \mathrm{in.}$ & $260 \mathrm{psi}$ \\
\hline $6061-\mathrm{T} 6$ & 11809 & $2 \mathrm{in}$. & $1180 \mathrm{psi}$ & $0.688 \mathrm{in}$. & $1400 \mathrm{psi}$ \\
\hline $6061-\mathrm{T} 6$ & 11219 & $2.375 \mathrm{in}$. & $1010 \mathrm{psi}$ & $0.516 \mathrm{in}$. & $1200 \mathrm{psi}$ \\
\hline $6061-\mathrm{T} 6$ & 13304 & $2 \mathrm{in}$ & $1005 \mathrm{psi}$ & $0.625 \mathrm{in}$. & $1170 \mathrm{psi}$ \\
\hline $6061-\mathrm{T} 6$ & 13631 & $2.125 \mathrm{in}$ & $990 \mathrm{psi}$ & $0.531 \mathrm{in}$. & $1100 \mathrm{psi}$ \\
\hline $\begin{array}{l}13631 \\
\text { Assembly }\end{array}$ & 13631 & $2.25 \mathrm{in}$ & $1700 \mathrm{psi}$ & N/A & N/A \\
\hline
\end{tabular}

a Deflection capability is the amount of elasticity before permanent set occurs (the higher the amount, the better).

b The assembly consisted of two mat sections ( $2 \mathrm{ft}$ ' $\times 7 \mathrm{ft}$ ') locked together length-wise with a QD bar. The deflection apparatus was unable to supply sufficient force to provide $3 \mathrm{in}$. of total deflection on the assembly.

As can be seen clearly in Table 3, the extruded magnesium performed substantially worse than the 6061 aluminum in static testing. The material displayed a high level of softening due to the extrusion process. This is especially noticeable in the swage test and deflection beam test seen in Table 4. The material showed a 75\% decrease in deflection depth input due to permanent deflection set with an $86 \%$ decrease in vertical loading. This shows a significant decrease in material stiffness. These results were also further supported by the swage results. This test was done to verify weldzone integrity, but also indicates welding bearing load capacity. The AZ31PE Mg alloy, however, did display acceptable weld performance, but showed a substantial decrease in bearing strength versus the 6061-T6 
aluminum alloy. A special heat treatment was attempted on some of the extrusion products, but the results were unsuccessful. No details of the exact nature of the heat treatment were given.

The final extrusion product of the AZ31PE Mg alloy was evaluated in its asfabricated state, with no post-processing heat treatments. This alloy did not satisfactorily meet the structural property requirements to act as a creditable replacement for 6061-T6 aluminum alloy in the AM2 design. Also, based on the current industrial understanding of magnesium's extrusion properties, it was Taber's opinion that an optimized die made specifically for magnesium would only slightly improve the characteristics of the final product above that of a 6061 aluminum die set. However, due to limited industry experience in closed hollow-void extruding of higherstrength magnesium alloys other than ZM21 and AZ31, determining extrusion feasibility, quality, post-mandrel seam weld integrity, and overall extrusion speed of any other alloy with current industry knowledge would be difficult. Taber has stated that it will not guarantee the successful extrusion of any of the magnesium alloys, including its mechanical properties, dimensional tolerance, or any quantifiable property of the alloy or structure.

In view of this, the mechanical properties of the extruded AZ31PE Mg alloy results not being in agreement with known published results is important to note. Published results in archival journals identified many magnesium alloys that are viable extrusion materials options. Table 5 shows a collection of monotonic data comparing 6061 and 7075 aluminum alloys to the target magnesium alloys. This table shows that magnesium alloys are comparable to 6xxx series aluminum alloys. In fact, Gupta and Sharon (2011) and Hilditch, T. et al. (2009) found that the extrusion of AZ31, AZ61, and ZK60 produced monotonic properties superior to those noted for 6061-T6 aluminum alloy. Furthermore, extruded AZ31 Mg alloy tubing under threepoint bending and tensile testing possessed comparable performance to 6063-T6 extruded alloy extrusions as can be noted in Figure 37. The AZ31 Mg alloy extrusions were performed using identical extrusion rates, reduced billet temperatures $\left(500^{\circ} \mathrm{C}\right.$ to $\left.400^{\circ} \mathrm{C}\right)$, and no post-production heat treatments (Hilditch et al. 2009).

In literature a sizeable amount of work exists on the quantification of the forming limits, crystallographic behavior, and thermo-mechanical behavior of Mg alloys. Specifically, Yang et al. (2003) and Galiyev et al. (2001) 
showed that AZ31 and ZK60 experience substantial amounts of dynamic grain recrystallization during hot forming, which was shown to be tied directly to the fluctuation of processing temperature and strain rates. Yang also noted that AZ31 showed a large degree of basal slip plane reorientation away from the hard slip direction to the soft slip direction, defined as the extrusion direction. This was hypothesized as being a primary source of work softening during the deformation process.

Figure 37. (a) Peak load versus peak displacement for AZ31, 6063-T6 and 7075-T6 (D/t = 15) and AZ31 (D/t $=10$ ) at different indenter diameters and (b) Load versus indenter displacement plot using a displacement rate of $1 \mathrm{~mm} / \mathrm{s}$. An indenter diameter of $15 \mathrm{~mm}$ was used with a lower support separation of $100 \mathrm{~mm}$ (Jämsä, Jalovaara, and Peng 1998).

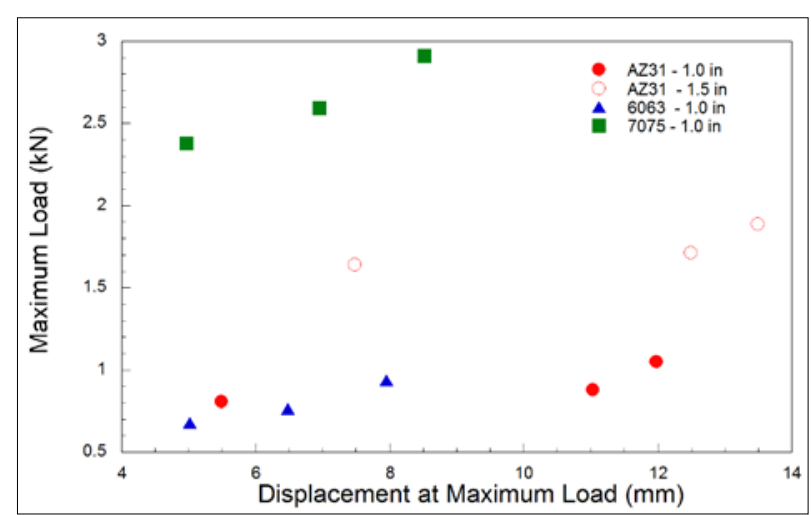

(a)

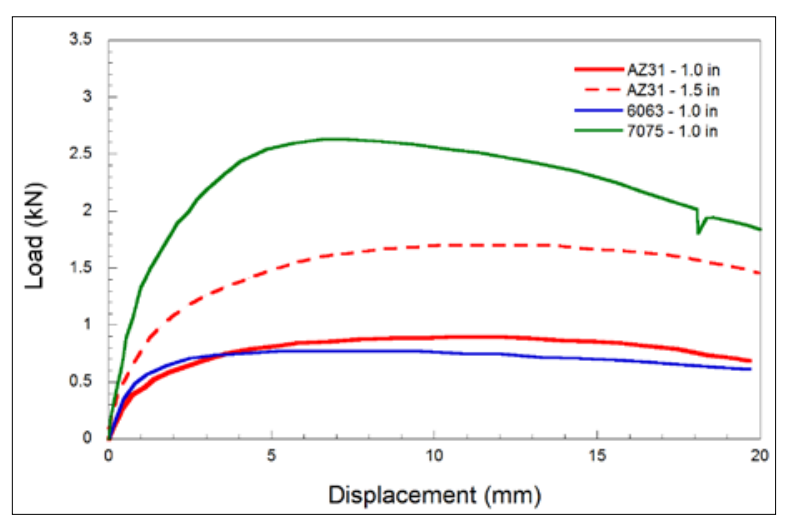

(b)

In fact, Az31 magnesium alloy can be readily hot deformed at temperatures above $150^{\circ} \mathrm{C}$ dynamic recrystallization (DRX) and dynamic grain recovery is activated during hot deformation of $175^{\circ} \mathrm{C}$ through deformation-based mechanisms. Yu et al. (2009) demonstrated that room temperature extrusion of AZ31 Mg alloy resulted in a refined grain structure and improved mechanical properties from 300 microns in the initial billet to 2 to 3 microns in the extruded product through activation of re-crystallization mechanisms (Chandrasekaran and J ohn 2004).

Spigarelli and Mehtedi (2005) investigated the occurrence of DRX and grain recovery in magnesium alloys and found that grain formation is highly dependent on the temperature at which plastic deformation occurs within AZ31 Mg alloy. They noted that DRX occurred readily at temperatures between 250 and $350^{\circ} \mathrm{C}$, increasing in intensity with increasing temperature. Deformation in temperature ranges at $400^{\circ} \mathrm{C}$ resulted in fully developed DRX and grain growth. They also demonstrated that heat treatment $\left(500^{\circ} \mathrm{C}\right.$ for $2 \mathrm{hr}$ ) on AZ31 Mg alloys produces large, homogenously- 
distributed grain structure versus the as-extruded microstructure, which was shown to have a much finer grain structure interspersed with large, elongated grains.

Murai et al. (2003) found that homogenizing the billet before extrusion improved the elongation performance of the AZ31 Mg alloy-extruded product. They found that an optimum billet extrusion temperature exists that provides a refined uniform grain structure, with maximum tensile and elongation properties. Ogawa et al. (2002) demonstrated that ZK60-Mg alloy can be extruded with high extrusion ratios as high as 10.3 with extrusion temperatures higher than $300^{\circ} \mathrm{C}$. An upper limit for the extrusion temperature range was established through the observation of the formation of significant oxidation on the billet surface.

Chino et al. (2008) demonstrated that grain size played an important role in determining the mode of relaxation of stress concentrations within the magnesium. For coarse grains, twinning was noted as playing an important role in the relieving of stress concentrations in compression. While with fine grains, sliding grain boundaries served to relax the stress concentrations, during compression and tension. The fine grain microstructure was noted as improving the tensile strength and elongation performance of the AZ31 alloy.

Several investigations studied the effects of billet temperature on the extrusion limits of magnesium and found that the limit is directly related to the magnesium-alloying components (Atwell and Barnett 2007; Davies and Barnett 2004). Furthermore, the increase in extrusion speed and load was inversely proportional to the increase in aluminum content and applied extrusion pressure and directly proportional to zinc content (Davies and Barnett 2004). This study also showed that magnesium alloys in general possess inferior extrusion production speed versus the aluminum 6063 alloy, as can be noted in Figure 38, which shows the trend of the extrusion speed versus temperature going from greatest to poorest performance: AA6063>AZ31>ZK60>AZ61>7075 (Davies and Barnett 2004).

As can be seen in literature, magnesium responds well to extrusion-type forming techniques, and there is an established precedence in the extrusion of these alloys. However, because of the HCP crystalline structure of this metal, a wide range of factors that can cause anisotropic performance within the material is observed. The test run by Taber confirms this and 
demonstrates that further research is required in order to better understand and characterize the microstructure and extrusion behavior of magnesium to allow for effective implementation into the AM2 runway matting profile.

Figure 38. Aluminum and Magnesium Alloy Extrusion Limit (Atwell and Barnett 2007; Davies and Barnett 2004).

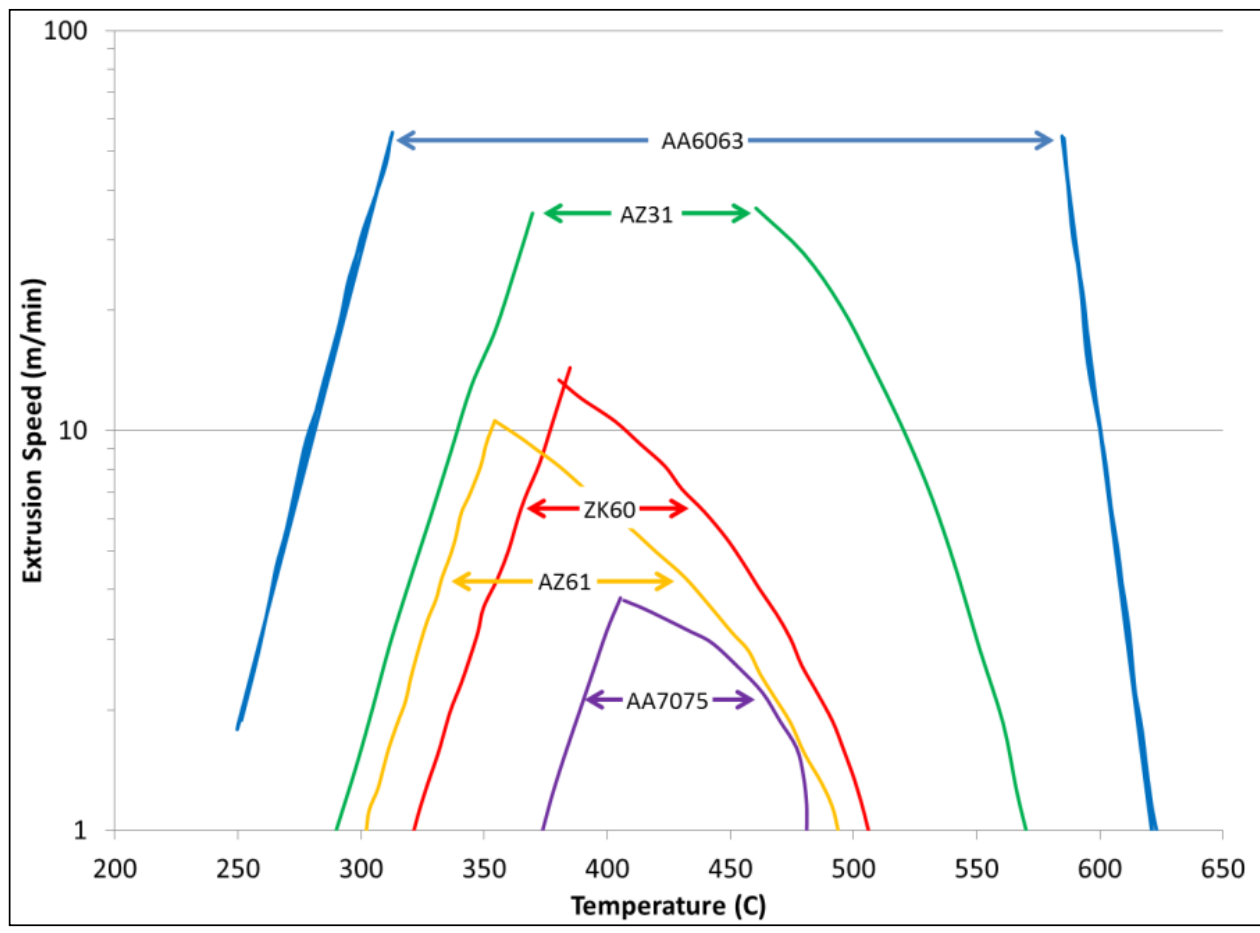

In summary, magnesium alloys could potentially provide weight savings of 30 to $40 \%$ while maintaining current performance. Additionally, magnesium alloys are extrudable with comparable flow stresses to the 6061 aluminum alloy. As such, the magnesium alloys could likely be extruded into the full cross-section of the AM2.

\section{Aluminum alloys}

This section summarizes aluminum alloys that could potentially be substituted for the 6061 aluminum alloy currently used in the AM2 matting. The analysis contained here focuses on mechanical performance under static and cyclic loading. For brevity's sake, an in-depth discussion regarding the performance of these common alloys is not presented, since all of these high-strength aluminum alloys have been widely documented. 


\section{XXX SERIES}

The $1 \mathrm{xxx}$ series aluminum alloys consist of at least $99.000 \%$ aluminum and are sometimes referred to as pure aluminum (MMPDS 2011). The ultimate tensile strength (UTS) of these alloys falls between $10 \mathrm{ksi}$ and $27 \mathrm{ksi}$, significantly lower than the 6061-T6 currently used in the AM2. Lower strength combined with a lower melting point excludes $1 \mathrm{xxx}$ series alloys from further consideration.

\section{XXX SERIES}

Overview

The $2 x x x$ series aluminum alloys have a primary addition of copper, which leads to a high-strength, heat-treatable alloy. Many of these alloys are used in aerospace applications, but are typically not used in the fully hardened condition because of the decrease in ductility compared with other alloys (Kaufman 2000). The UTS for 2xxx series alloys typically falls between $27 \mathrm{ksi}$ and $62 \mathrm{ksi}$, with 2024-T3 being the most common (ASM 1993). 2xxx series alloys are noteworthy for excellent strength at elevated and cryogenic temperatures, and creep-resistance at high temperatures. Aluminum alloy 2024 is the most researched member of this series as well as one of the strongest. Because of the amount of information available on it compared to the other alloys, it will be explored in more detail.

2024 aluminum alloy

The composition of 2024-T3 is given in Table 6. The nominal values for material strength and strain are given for the T3 and T81 tempers in Table 7. The major difference between these tempers is 2024-T3 exhibits ductile failure, whereas the 2024-T81 fails in a brittle mode.

Table 5. Chemical composition of AA2024 (Wt. \%) (Wang 2011).

\begin{tabular}{|c|c|c|c|c|c|c|c|c|c|c|c|c|}
\hline \multirow[b]{2}{*}{ Element } & \multirow[b]{2}{*}{$\mathrm{Cu}$} & \multirow[b]{2}{*}{$\mathrm{Mg}$} & \multirow[b]{2}{*}{$\mathrm{Si}$} & \multirow[b]{2}{*}{$\mathrm{Fe}$} & \multirow[b]{2}{*}{$\mathrm{Mn}$} & \multirow[b]{2}{*}{$Z n$} & \multirow[b]{2}{*}{$\mathrm{Ti}$} & \multirow[b]{2}{*}{ Ti-Zr } & \multirow[b]{2}{*}{$\mathrm{Cr}$} & \multicolumn{2}{|c|}{ Others } & \multirow[b]{2}{*}{ Al } \\
\hline & & & & & & & & & & Each & Total & \\
\hline Min. & 3.8 & 1.2 & - & - & 0.30 & - & - & - & - & - & - & Rem \\
\hline Max. & 4.9 & 1.8 & 0.5 & 0.5 & 0.90 & 0.25 & 0.15 & 0.20 & 0.10 & 0.05 & 0.15 & \\
\hline
\end{tabular}


Table 6. Tensile properties of the alloys AA2024 or the T3 and T81 temper designations (Kuo et al. 2005).

\begin{tabular}{|l|l|l|l|}
\hline Alloy & $\begin{array}{l}\text { Yield Strength }(\mathbf{0 . 2} \%) \\
(\mathrm{MPa})\end{array}$ & $\begin{array}{l}\text { Tensile Strength } \\
(\mathrm{MPa})\end{array}$ & $\begin{array}{l}\text { Elongation } \\
(\%)\end{array}$ \\
\hline AA2024-T3 & 354 & 485 & 17 \\
\hline AA2024-T81 & 450 & 485 & 7 \\
\hline
\end{tabular}

Because of the exposure to elevated temperatures in the AM2 application, the issue of overaging is addressed. In general, overaging of 2024 is not advantageous for fatigue life applications and over-refining grain size also has a detrimental effect (Bray et al. 2001; Kamp et al. 2007; Rodopoulos and Kermanidis 2007; Sarioglu and Orhaner 1998; Mohamed et al. 2005). The O-temper alloy of 2024 shows precipitate-free zones near grain boundaries that do not appear in the T6 temper. Needle-like precipitates form in two orientations in the O-temper alloy that are not present in the T6 temper (Mohamed et al. 2005). Sarioglu and Orhaner (1998) found that cyclic softening occurred after prolonged heating at $130^{\circ} \mathrm{C}$ and propose the following explanations: over-aging of the components, resolutionizing the alloy, microstructural inhomogeneities in the alloy, or dissolution due to ripening. The T3 temper has better high-cycle fatigue (HCF) life than the T6 temper for 2024, due to higher yield strength. The HCF performance can be further improved through the use of surface hardening such as shot-peening (Ludian and Wagner 2007).

Ductility of 2024 is highest at $450^{\circ} \mathrm{C}$ and experiences a sharp decrease between $450^{\circ} \mathrm{C}$ and $493^{\circ} \mathrm{C}$. Fracture conditions were found to vary based on the temperature at which forming occurred. From $350^{\circ} \mathrm{C}$ to $450^{\circ} \mathrm{C}$, a ductile fracture due to debonding or fracture of second-phase particles was the dominant failure mode (Wang et al. 2011). In the range from $450^{\circ} \mathrm{C}$ to $480^{\circ} \mathrm{C}$, solute enrichment of grain boundaries educed boundary cohesion and softened the matrix leading to a mixed ductile and intergranular fracture. From $480^{\circ} \mathrm{C}$ to $493^{\circ} \mathrm{C}$, intergranular fracture was the primary failure mode (Wang et al. 2011).

During fatigue loading, small amplitude cycles on the order of 50 to $100 \%$ of the endurance limit have been shown to play a significant role in both lowcycle fatigue (LCF) and HCF (Ngiau and Kujawski 2001). Surface hardening also occurs during those and even the more significant amplitude cycles on the nano- to meso-scale (Pantelakis et al. 2007). Using von Mises stress to compare torsional fatigue loads to tension-compression loading, torsion 
tests could go 2 to 10 times more cycles than the tension-compression samples (Mayer 2006).

Localized peaks in thermoelastic source amplitude, the center of the biaxial stress states, and constituent particles have all been found to be probable locations for crack initiation (Merati 2005; Morabito et al. 2007; Bellett et al. 2011). As cracks propagate, the effect of interstitial particles was found to depend on the state of the particle, with a well-bonded particle effectively decreasing the crack growth rate by rerouting the crack tip around itself, and a poorly bonded one effectively speeding it up by allowing a better path (DeBartolo and Hillberry 1998). Furthermore, the crack growth rate was found to decrease for small cracks as crack length and $\Delta \mathrm{K}$ increased (Halliday et al. 2003). Assuming the same maximum principle stress and strain energy density, tensile specimens and mixed mode specimen cracks follow essentially the same predicted path trajectory (J eong 2004). At the flat-to-slant fracture mode transition regime, a separation of the $\Delta \mathrm{K}_{\text {eff }}$ occurs (Lacy et al. 2007). Poly-crystal 2024-T351 alloys have been shown to have continuous crack growth along a single shear band even when multiple, mutually perpendicular shear bands originated at the crack tip and far beyond the length typical of the stage I regime (Zhang et al. 2002). The T3 temper of 2024 exhibited thermoelastic cooling, followed by thermoplastic heating, with signs of necking before fracture, whereas the T81 temper showed signs of a cleavage-type fracture (Kuo et al. 2005). Systematic path changes due to loading sequences result in the formation of ridges and depressions. Local fracture plane orientation is an important variable in determining ridge geometry and crack extension mode (Krkoska et al. 2010).

As shown in Figure 39, the 2024 aluminum alloy shows a significant increase in fatigue performance versus the 6061 aluminum alloy. However, the fatigue performance of 2024 can be altered significantly with more focus on controlling impurities. For the 2024, EDX was used to determine that the primary crack initiation sites were constituent particles, primarily iron particles (Merati 2005). The 2324 and 2524 alloys are variations of 2024-T3, where the focus is on controlling iron and silicon impurities in the alloys (Kaufman 2000). The 2324 alloy is designed for extrusions with high elongation and fracture toughness compared to 2024-T3 alloy (Kaufman 2000). In the 2324-T39 alloy, some crack branching was observed as the low load truncation was increased to certain levels, below which no branching was observed (Bao and Zhang 2010). The 2524 alloy is currently 
used for formed structural aircraft parts that require higher crack-arrest properties and higher toughness while presenting similar monotonic behavior to 2024 alloy (MMPDS 2011).

Figure 39. S-N comparison of peak-aged 2024 versus peak-aged 6061 (Wang 2010).

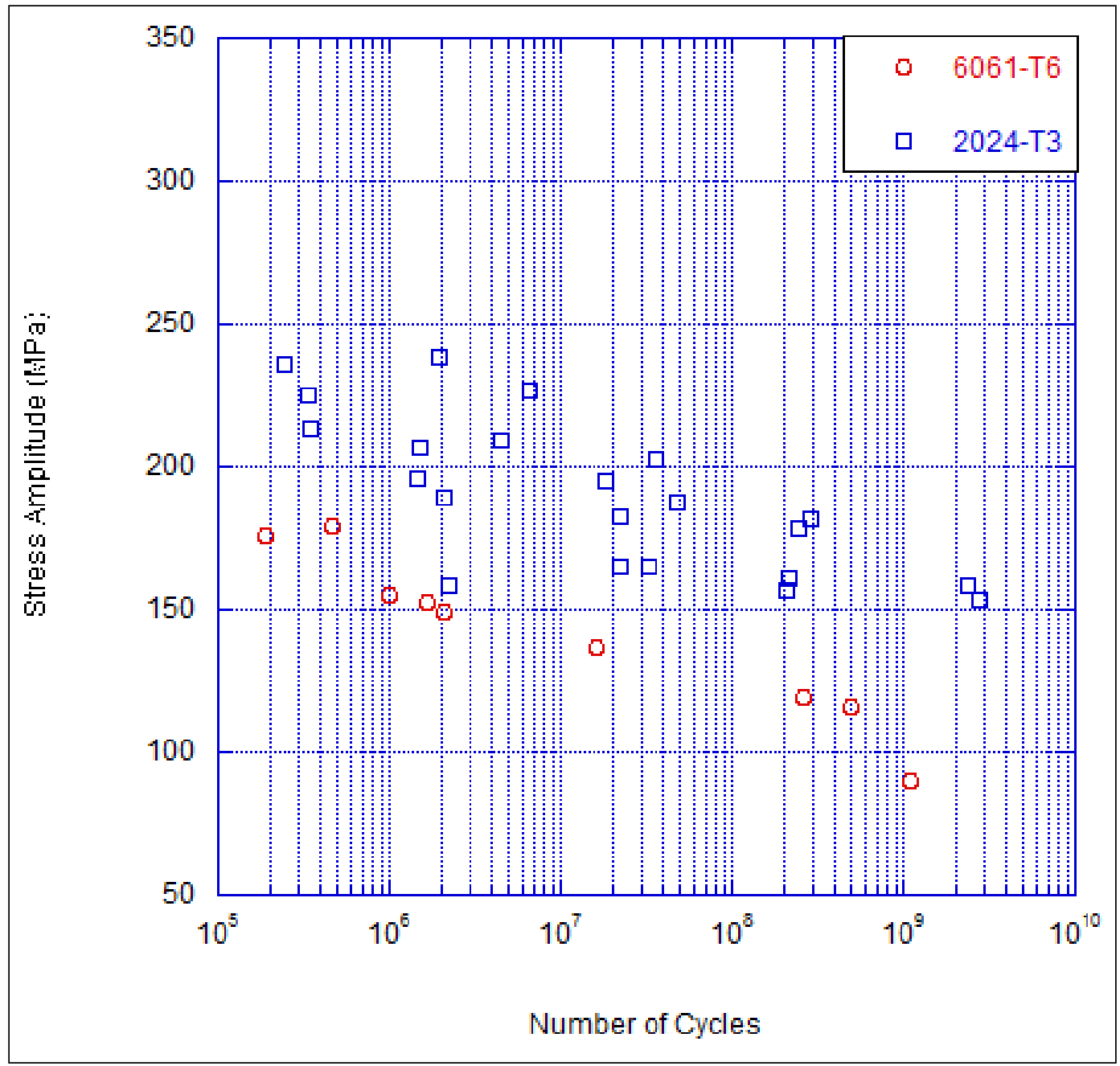

2026 aluminum alloy

The 2026 alloy is an Al-Cu-Mg-Mn alloy that is typically used for extrusions, especially for parts that tend toward cracking during formation. This alloy has high strength and damage tolerance compared to 6061 alloy, but typically is not used in situations involving welding (MMPDS 2011). Figure 40 shows that regardless of cross-section, the 2026 alloy has approximately twice the bending fatigue performance of 2024 alloy. Also 2026 offers improvements over 2024 in monotonic loading as well as in the extruded form (MMPDS 2011). 
Figure 40. S-N curve comparing 2026 against 2024 in four-point bending (Li et al. 2005).

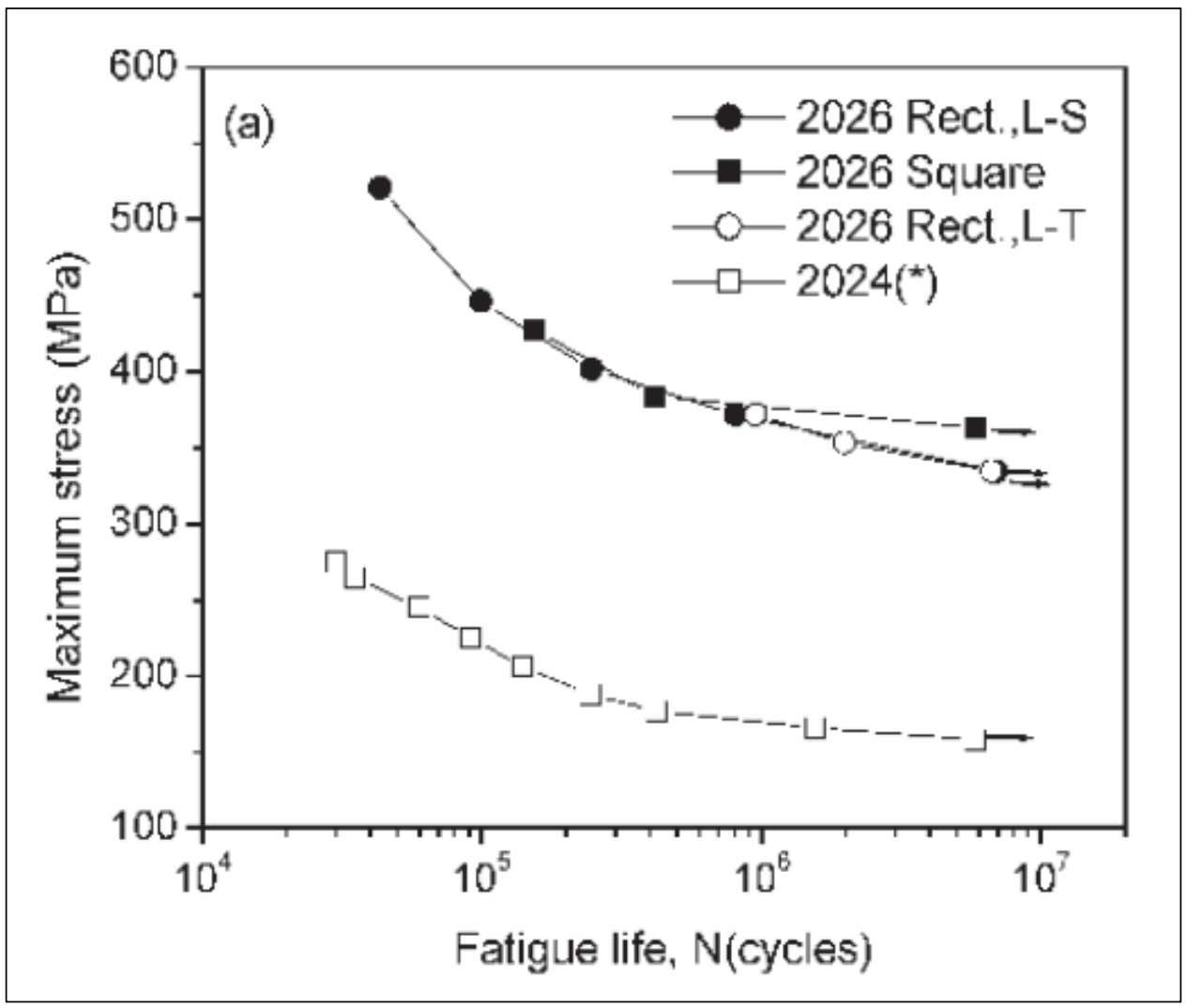

2090 aluminum alloy

The 2090 alloy is an Al-Cu-Li alloy that offers strength comparable to the 7075 alloy. Additionally, it has an elastic modulus approximately 10\% higher and it is about $8 \%$ less dense. Similar to other $2 \mathrm{xxx}$ series alloys, the 2090 alloy experiences a decrease in both overall strength and toughness from over-aging (Venkateswara Rao et al. 1988). Table 8 shows a comparison of ambient temperature properties of 2090 Alloys in the peak aged (T8) temper compared to the lightly over-aged (LOA) and over-aged (OA) conditions as well (Venkateswara Rao et al. 1988).

The peak-aged 2090 specimens had highly anisotropic microstructure and large pancake-shaped grains (Venkateswara Rao et al. 1988). The high strengths are due to coherent, ordered precipitates distributed homogenously within the grains and not on the grain boundaries (Venkateswara Rao et al. 1988). Furthermore, the small crack ( $>1000 \mu \mathrm{m}$ ) growth was found to be up to four orders of magnitude faster than the long crack growth for aluminum lithium alloys with the short crack-growth phase being comparable to typical contemporary alloys like 2124 and 7150 
(Venkateswara Rao et al. 1988). Even with the degradation in strength and toughness after being over-aged for $1000 \mathrm{hr}$ at around $325^{\circ} \mathrm{F}$, Venkateswara Rao et al. (1988) found that the 2090 alloy was still comparable or preferable to similarly over-aged 2124 as well as 2124-T351, 7150-T651, and 7150-T751 commercially available alloys.

Table 7. Comparison of aging conditions in 2090 alloy (Venkateswara et al. 1988).

\begin{tabular}{|l|l|l|l|l|}
\hline Alloy & $\begin{array}{l}\text { Yield Strength } \\
(\mathrm{MPa})\end{array}$ & $\begin{array}{l}\text { Tensile Strength } \\
(\mathrm{MPa})\end{array}$ & $\begin{array}{l}\text { Elongation in } \\
\mathbf{2 5} \mathrm{mm}(\%)\end{array}$ & $\begin{array}{l}\text { Fracture Toughness } \\
\left(\mathrm{MPa}^{*} \mathrm{~m}^{1 / 2}\right)\end{array}$ \\
\hline $2090-\mathrm{T} 8$ & 548 & 579 & 9.3 & 24 \\
\hline 2090-LOA & 545 & 566 & 12 & - \\
\hline 2090-OA & 466 & 527 & 10 & 20 \\
\hline
\end{tabular}

\section{XXX SERIES}

The 3xxx series alloys use manganese as the primary additive, which gives them favorable characteristics with regard to elevated temperature and high corrosion resistance (ESAB 2011). Manganese only allows for a modest strength gain, but does boast improved formability and ductility to other aluminum alloys. These alloys are non-heat-treatable and are typically used for both consumer products like pots and pans, as well as heat exchangers in automotive and industrial settings. However, the UTS for these alloys ranges from $16 \mathrm{ksi}$ to $41 \mathrm{ksi}$ (ASM 1993), which is significantly less than the $45 \mathrm{ksi}$ UTS of 6061-T6 alloy. Because of the low tensile strengths and because they are non-heat-treatable, 3xxx series alloys should not be considered for use in the AM2 matting system.

\section{XXX SERIES}

Silicon is the primary additive to $4 \mathrm{xxx}$ series aluminum alloys. The excess silicon decreases the melting temperature and improves the flow characteristics of the molten alloy (Kaufman 2000). This alloy is almost exclusively used as a filler material in welding applications (Kaufman 2000). Because of its low melting point and lower strength, $4 \mathrm{xxx}$ series alloys can reasonably be excluded from use in the AM2 matting.

\section{XXX SERIES}

The principle alloying elements for $5 \mathrm{xxx}$ series alloys is magnesium. This series of alloys is typically used for boat hulls, gang planks, and other highly corrosive, marine-type environments (ASM 1993). The UTS for $5 x x x$ series alloys ranges from $18 \mathrm{ksi}$ to $51 \mathrm{ksi}$ (ESAB 2011). However, since 
these alloys are not heat treatable, any alloy with more than $3 \% \mathrm{Mg}$ is not recommended for service at temperatures above $150^{\circ} \mathrm{F}$ because of its poor mechanical performance. Since all alloys with a strength similar to 6061T6 alloy have Mg concentrations above 3\% (ESAB 2011; ASM 1993), these alloys can be excluded from further consideration.

\section{XXX SERIES}

Overview

The 6xxx series alloys are formed using magnesium and silicon as the primary alloying components. The magnesium and silicon form a quasibinary section with the Mg2Si precipitate providing excellent precipitationhardening capabilities. 6xxx series alloys have UTS ranging from $18 \mathrm{ksi}$ to $58 \mathrm{ksi}$ (ESAB 2011). 6xxx series alloys are notable as being among the easiest to extrude, so they are widely used for complex parts such as those involving multiple hollows or finned shapes (Kaufman 2000). They are also easily joined using most commercial processes (Kaufman 2000). One of the most common of these alloys is 6061 alloy, which is currently used for the AM2 runway matting. The 6061 alloy has many properties that made it an appropriate selection for the AM2 matting, with the primary choice related to ease of extruding to the full width of the AM2 design.

\section{1 aluminum alloy}

6061-T6 is frequently used for varied applications in the aerospace, construction, transportation, and industrial fields and is produced as sheets, plates, foils, pipes, structural forms, forgings, and extrusions (Dorward 1998). The chemical composition of 6061 is given in Table 9. The composition, however, does allow for enough variation to alter the mechanical properties, with the ranges given in Table 9 (J ogi 2008). The overall strength of AA6061 alloy tends to increase with the weight percentage of $\mathrm{Si}$ with an average of $45 \mathrm{ksi}$. Historically, the alloy was thought to become more brittle due to excess $\mathrm{Si}$ particles at the grain boundary contributing to coarse slip behavior and dislocation pile-ups at grain boundaries. However, excess $\mathrm{Si}$ has since been shown to have a beneficial effect of dispersing slip in the grain interior and raising the strain hardening rate ( $\mathrm{n}$ value) (Dorward 1998). To balance this, in contemporary AA 6061, the ratio of weight percentage, Mg: $\mathrm{Si}$, is 1.73 (Dorward 1998). 
Table 8. Chemical composition of AA6061 (wt.\%) (Jogi et al. 2008).

\begin{tabular}{|l|l|l|l|l|l|l|l|}
\hline Element & Mg & Si & Cu & Mn & Fe & Cr & Al \\
\hline Min. & 0.8 & 0.4 & 0.15 & - & - & 0.04 & Bal. \\
\hline Max. & 1.2 & 0.8 & 0.4 & 0.15 & 0.01 & 0.35 & \\
\hline
\end{tabular}

AA 6061 is widely used because of its high strength-to-weight ratio, excellent weldability, high ductility, and excellent resistance to stress corrosion cracking, deformation, market acceptance, and relative ease of use (J ogi 2008; Srivatsan et al. 2002). In structural components, AA 6061 alloys fail primarily under fatigue loading, due to cracks forming along grain boundaries at the edge of the material and propagating through the material (J ogi 2008; Bhandwale and Vasudevan 1978).

Most of the work on fatigue of 6061-T6 is focused on stress life, crack initiation, and crack propagation. Like most non-ferrous alloys, 6061-T6 alloy does not exhibit an endurance limit and failure can occur up to at least 109 cycles (Wang 2010). Figure 41 shows the strain-life results of forged 6061 aluminum alloy (Wong 1984). Regarding microstructure effect, finer grain sizes have been shown to appreciably reduce the lowcycle fatigue life of 6061-T6 alloy as well as other materials (Höppel 2006). Lastly, elevated temperature effect on strain-life fatigue behavior is not reported in literature.

\section{3 aluminum alloy}

The 6013 alloy is an Al-Mg-Si-Cu-Mn alloy that offers a 25\% increase in strength compared to 6061 alloy and can be successfully welded (MMPDS). The 6013 alloy further offers better toughness, fatigue characteristics, and stretch forming characteristics (MMPDS) compared to the 6061 alloy.

\section{XXX SERIES}

Overview

Zinc is the main alloying component in 7xxx series aluminum alloys with a concentration ranging from $0.8 \%$ to $12 \%$ by volume. $7 x x x$ series alloys are among the highest strength aluminum alloys with ultimate tensile strengths ranging from $32 \mathrm{ksi}$ to $88 \mathrm{ksi}$ (ESAB 2011). Unfortunately, these alloys also tend to have a lower toughness and are more susceptible to stress-corrosion cracking without special treatments (Kaufman 2000). 
Figure 41. Strain-life results of 6061-T6 aluminum alloy (Wong 1984).

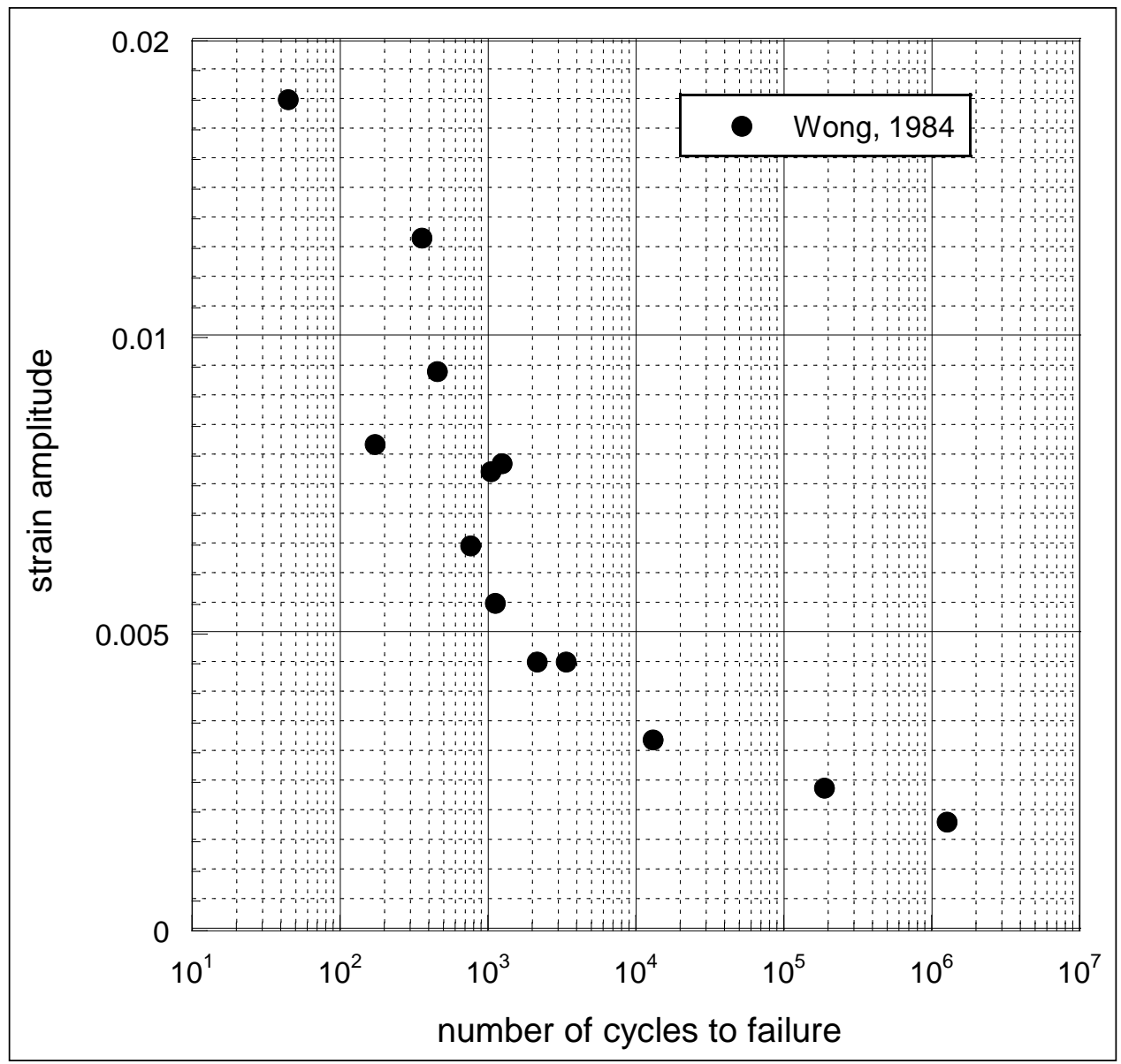

7049/7149 aluminum alloy

The 7049/ 7149 alloys are essentially identical to the 7149 alloy, having more stringent restrictions of iron and silicon impurities. In the T73xx, both of these alloys have similar fatigue strength to 7075-T6 alloy, but with significant increases in toughness (MMPDS). The fatigue limit is given for the 7049 alloy at varying temperatures in Table 10, where the trend illustrates the degradation in mechanical properties due to elevatedtemperatures.

Table 9. Heat degradation of the fatigue limit for 7049 (Jones 1972).

\begin{tabular}{|l|l|l|l|}
\hline Extrusion Config & RT (ksi) & $250^{\circ} \mathrm{F}(\mathrm{ksi})$ & $350^{\circ} \mathrm{F}(\mathrm{ksi})$ \\
\hline Smooth Bar & 53.0 & 37.5 & 31.5 \\
\hline
\end{tabular}


7050 aluminum alloy

The 7050 alloy is an Al-Zn-Mg-Cu-Zr alloy designed to have a high strength, fatigue strength, and stress-corrosion cracking resistance (MMPDS). Having zirconium in place of chromium makes this alloy less sensitive to quenching and, therefore, can be used in thick sheets in highstrength applications (MMPDS). Figure 42 shows the fatigue behavior of the 7050 alloy and, in conjunction with Figure 3, shows that the fatigue performance of 7050 alloy outperforms 2024 alloy but is slightly outperformed by the 2026 alloy.

Figure 42. S-N curve for 7050 at different stress ratios (MMPDS).

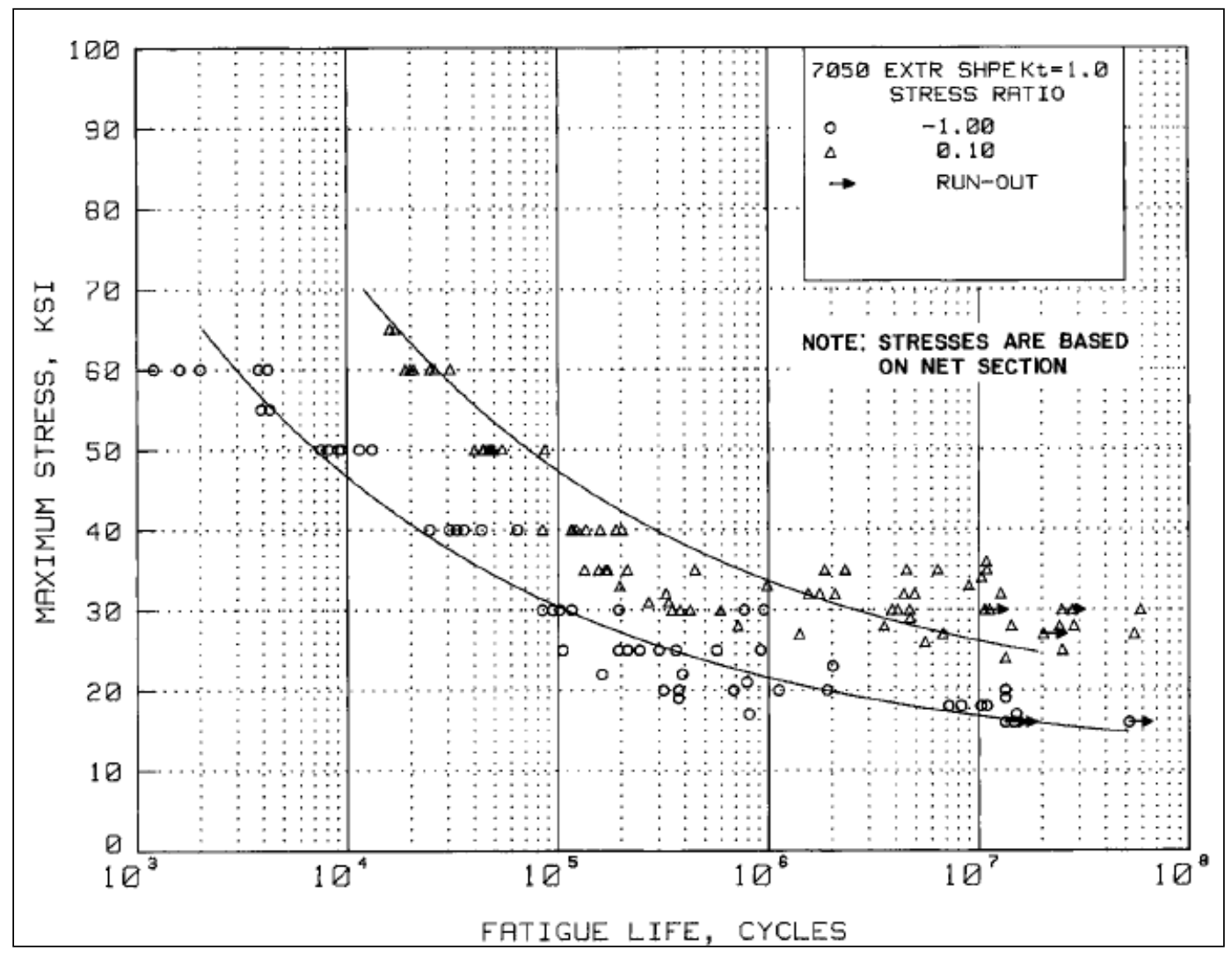

\section{5 aluminum alloy}

This alloy has additives of $\mathrm{Zn}$-Mg-Zr-Si-Cu similar to the 7050 and 7150 alloys. The mix of alloying components is given in Table 11.

The 7055-T7751 alloy in plate form has numerous advantages over 7150 in both T6 and T76 tempers, including a 10\% and 30\% higher strength, respectively. The 7055 alloy also offers improved corrosion resistance and fracture toughness to 7150 alloy while maintaining a comparable resistance 
to the growth of fatigue cracks (Srivatsan 2002). Srivatsan attributes these improvements to the higher ratios of $\mathrm{Zn}$ to $\mathrm{Mg}$ and $\mathrm{Cu}$ to $\mathrm{Mg}$ (2002). Chen et al. (2010) found that inter-granular precipitates played a much larger role in slowing crack growth compared with either precipitates along grain boundaries or precipitate-free zones along grain boundaries.

Table 10. Nominal chemical composition (Srivatsan 2002).

\begin{tabular}{|l|l|l|l|l|l|l|l|l|}
\hline \multirow{2}{*}{ Alloy } & \multicolumn{7}{|c|}{ Composition (wt. \%) } \\
\cline { 2 - 10 } & Cu & Mg & Zn & Zr & Fe & Si & Cr & AL \\
\hline 7055 & 2.31 & 2.10 & 8.0 & 0.12 & 0.15 & 0.10 & - & Balance \\
\hline 7050 & 2.30 & 2.2 & 6.2 & 0.12 & 0.15 & 0.11 & - & Balance \\
\hline 7150 & 2.20 & 2.40 & 5.40 & 0.12 & 0.15 & 0.10 & - & Balance \\
\hline 7075 & 1.60 & 2.50 & 5.60 & - & 0.50 & 0.40 & 0.25 & Balance \\
\hline
\end{tabular}

This alloy exhibits superplasticity at $420^{\circ} \mathrm{F}$ (Mondal et al. 2007). Therefore, at that temperature, this alloy is extrudable at a 20:1 ratio with a ram speed of $3 \mathrm{~mm} / \mathrm{s}$. It can then be heat-treated to peak age the structure at the T6 temper to maximize hardness, ultimate tensile strength, and yield strength (Mondal et al. 2007).

As temperature increases, fatigue performance decreases dramatically as shown in Figure 43 (Srivatsan et al. 2000). Also the temperature increase had a more pronounced change in the transverse direction as opposed to the longitudinal one (Srivatsan et al. 2000). This alloy could potentially be problematic at elevated temperatures, but it does warrant further investigation.

Figure 43. (Left) Stress-life fatigue data for 7055 at ambient temp. (Right) Stress-life fatigue data at $190^{\circ} \mathrm{C}$ (Srivatsan et al. 2000).
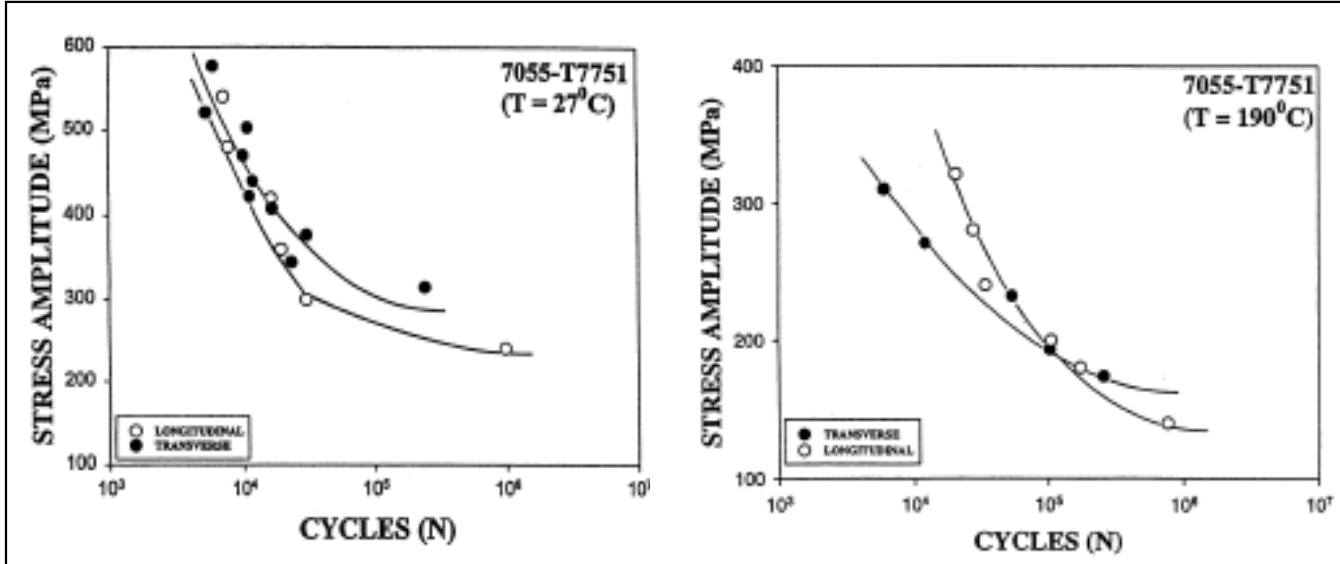
7075 aluminum alloy

The 7075 alloy is the most common 7xxx series alloy and is used widely in the aerospace industry for structural applications. Figure 44 shows the significant boost in fatigue performance 7075 alloy has over the 6061 alloy.

Again referring to Figure 44, there is also a marked increase in fatigue life of 7075 over 2024 (Wang 2010).

Figure 44. S-N curve comparing 6061 and 7075 (Wang 2010).

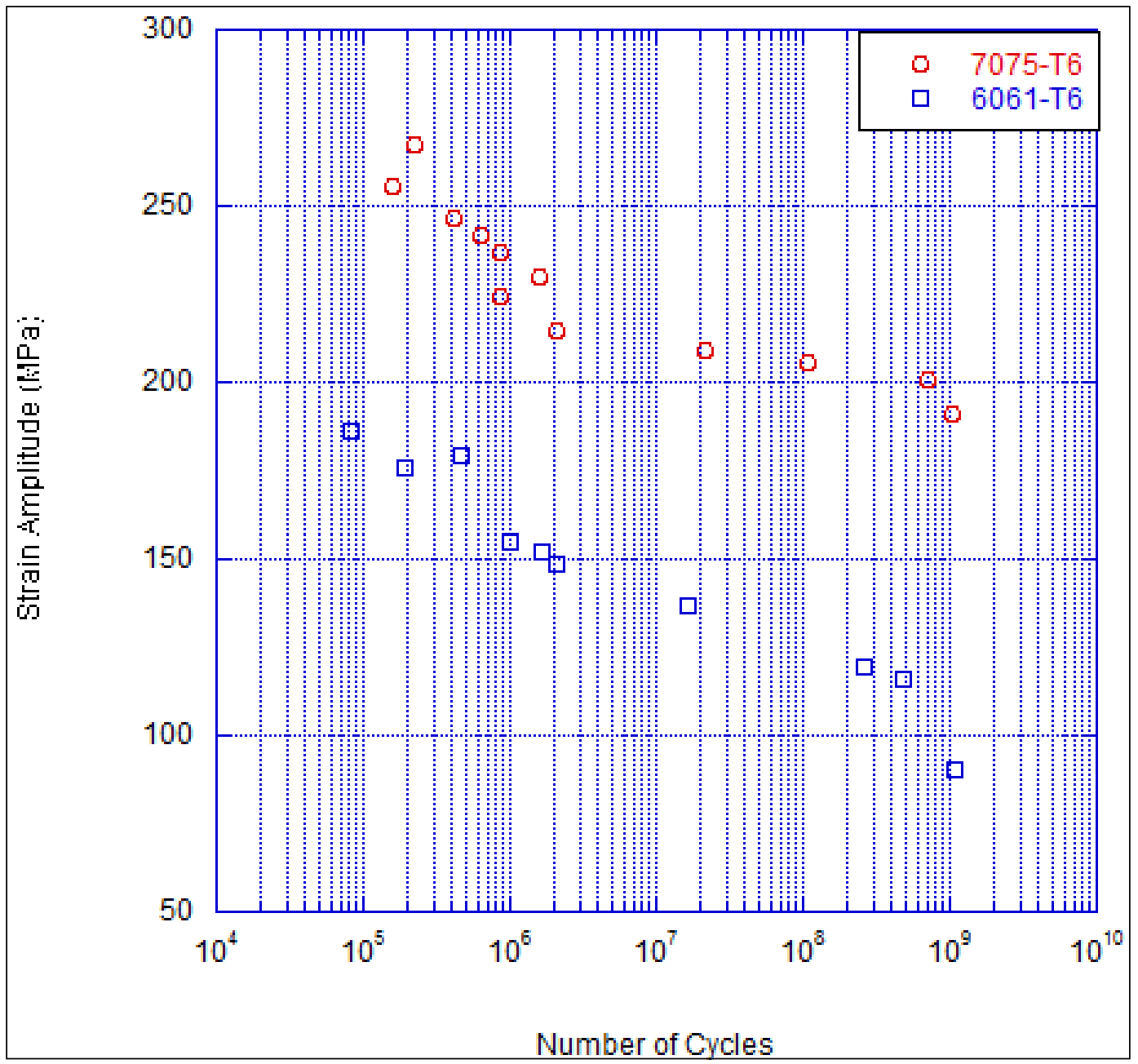

\section{XXX SERIES}

8xxx series alloys have multiple principle alloying components, making it a catch-all group. The main principle alloys found in this group are aluminum-lithium alloys and aluminum-titanium alloys (ASM 1993). Aluminum-titanium alloys have been excluded from consideration because of the availability of other lower-cost alternatives that still provide 
significant improvement over the current design. Aluminum-lithium alloys follow very similar trends compared to 2090, so those alloys have been covered in that section (Venkateswara Rao et al. 1988).

\section{Manufacturability}

The operational conditions of the AM2 matting system make the use of compatible, but more lightweight materials difficult. This difficulty is primarily seen in the manufacturing challenges of shaping most highstrength metals into effective structural systems. This was one of the primary reasons for the implementation of 6xxx series heat-treated aluminum for the AM2 airfield matting. The 6xxx aluminum alloys have an adequate set of material properties, are easy to produce, and many are industry standards and therefore affordable. The 6061-T6 alloy's ability to be used in large-scale extruding is a major advantage in producing the large and uniquely profiled sheets required by the matting structure.

There are multiple aluminum alloys that would provide mechanical improvements over the 6061 that is currently being used. However, with the increased mechanical properties also come increased manufacturing difficulties. Some of the best options, if the manufacturing constraints can be overcome, would be to use alloys like 2024, 2524 2090, 6013, 7055, or 7075 alloys. With any of these alloys there would be significant improvement in load capacity, fatigue performance, and, in conjunction with an optimization of the design, the weight of the AM2 matting could be decreased significantly. The 7055 alloy was primarily designed for ease of extruding. However, documentation supporting this claim was not found.

The proceeding sections explore the issues relating to the extrusion of high-strength aluminum alloys.

\section{Domestic extrusion capacity}

Taber Extrusions of Arkansas has been the sole extruder of the AM2 runway matting since its development in the late 1960s and early 1970s. In addition, the company produced a large range of profiles from 2xxx, 5xxx, 6xxx, and 7xxx series material (Taber Extrusions 2011). Taber operates the second largest extrusion press in the United States at 8600 tons with a maximum 18-in. hard alloy extrusion circle. The Taber extruder is capable of both 20-in.-diam round and 10-in.-by-28-in. rectangular billets. The company defined circle dimension as the largest dimension, whether it is 
width, height, or diameter, that can be extruded by the machine for a given alloy. In the case of hard alloy extrusion, the high demand on equipment can be seen in the significant reduction in the circle dimension from 26 in. in soft alloys, like in 6xxx alloys, to the 18-in. dimension seen with hard alloys. Because of the large and capable press and extensive expertise in most commercially viable aluminum alloys, Taber has developed a history of producing very large and uniquely profiled extrusion for both military and commercial projects (Taber Extrusions 2011).

Alcoa operates the largest extrusion press in the United States at its Lafayette, Indiana, facility. This press has a maximum ram force of 15500 tons, which can extrude a billet of 20 in. in diameter through a die with a maximum circle size of $31.5 \mathrm{in}$. Alcoa also operates a large piercer extrusion press, which allows for the creation of seamless hollow profile tubing. This press is noted for producing much higher quality hollow profiles in hard alloy extrusion than seen in porthole die extrusions (American Extruders Council 2011).

Kaiser aluminum facilities in both Newark, Ohio, and J ackson, Tennessee, have the most powerful and largest extrusion rams next to Taber's in the United States. The rams are capable of producing forces in excess of 6600 tons fed by 9-in. billets for a maximum extrusion circle dimension of 9 in. As noted earlier, they are not capable of producing single-hollow, let alone multi-hollow, profiles using 7xxx series alloys (American Extruders Council 2011).

\section{Production issues}

In extruding 7xxx alloys, there are five production issues. The first issue is related to the creation of the mandrels for the hollow profile. To prevent both elastic displacement and low-cycle failure of the mandrels, larger bridging structures would need to be used to connect the mandrels to the extrusion die for direct extrusion. This both increases the ram force requirements, the cost of die production, and the possibility of defects in the post-extrusion material. The only real solution to this problem is to form the profiles using either indirect extrusion or piercing mandrel extrusion techniques (Swartz 2012).

The indirect extrusion eliminates the possibility of producing continuous seamless extrusions of the material and possibly limiting the length of the final extrusion product. The piercing mandrel extrusion technique requires 
the forcing of mandrels fixed to the ram head through the billet and into the extrusion die before the primary ram head begins compressing the billet. This technique, while eliminating the bridging issue, can have a much lower degree of precision and can greatly decrease the production rate of the extrusion product, which is also a problem for indirect extrusion (Acroman 2012).

The second obstacle facing 7xxx extrusion is post-mandrel welding of the aluminum material. After passing over the supporting bridge work of the mandrel, the sloping sides of the die normally compress the separated material back into a solid structure. However, $7 x x x$ series alloys have proved to be very difficult to compression-weld back together. The end process typically produces gaps, air pockets, or simply incomplete interphase bonding in the final extruded alloy (Althardt 2012). This material's merging issue is further exaggerated by the need for larger mandrel bridging, which increases the risk of defective 7xxx series extrusions.

The third issue is related to the substantial amount of ram power required to produce complex profiles of $7 \mathrm{xxx}$ alloys. There are rams available that can handle the loadings, but even these are greatly limited in the size of the extrusion that they can produce. The high power requirements for the rams also greatly limit the available manufactures and potentially increase the difficulty in acquiring sufficient time for producing the extrusions (Althardt 2012; Smith 2012).

The fourth issue listed concerns the high reduction ratio experienced in hollow profile extrusions. The reduction ratio dictates, among other things, the level of startup force required to initiate an extrusion. The reduction ratio could prevent the extrusion from even starting, even if the ram is large enough to extrude the profile after initiation. The reduction ratio of the 7xxx series extrusions superseding the extrusion press force capacity as a major limiter of 7xxx series extrusions (Althardt 2012) can be implied.

Besides the above stated issues regarding extruding a 7xxx alloy, a more serious problem is not so much related to a successful extrusion, but the efficiency of the production. The high flow stress seen in 7xxx series extrusions alone would greatly reduce the production rate of any extrusion of these alloys. One estimate places this difference as much as an $80 \%$ reduction in foot length per minute (Althardt 2012). This fact, taken with 
the other obstacles facing 7xxx series extrusion, will only continue to increase the time it takes to produce the required extrusions. Figure 45 shows the relative comparison of extrusion for a wide range of aluminum alloys. A significant increase in flow stresses induced for a given extrusion speed is noted.

Figure 45. Flow stress versus extrusion rate for aluminum alloys (ASM 1993).

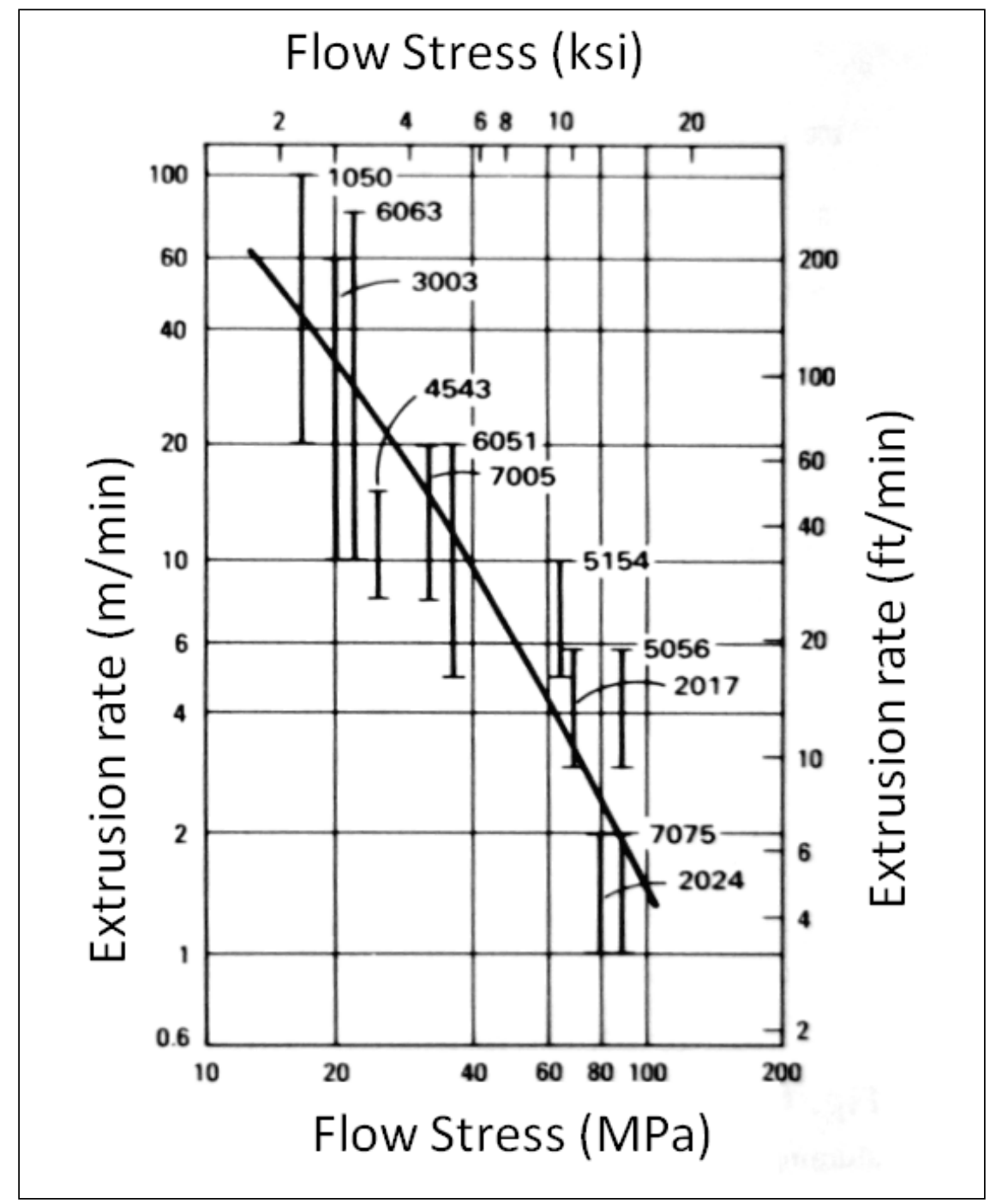

Alternatives to fully extruded design

Complex profiles are difficult to manufacture with modern extrusion technology as indicated by all three manufacturers (Alcoa, Tabar, Kaiser), and all of the companies can fairly easily manufacture solid, square, and rectangular profiled bar stock. This is mainly due to the elimination of the mandrels and various other structures required in forming a hollow 
profile, as well as reducing the (cross-sectional area/ perimeter) ratio of the extrusions (Swartz 2012).

In order to achieve a structural design similar to current AM2 using 7xxx alloys, a design could be manufactured using a fastener/ weld-based assembly technique. The top and bottom plates could be made out of panels of the desired 7xxx series aluminum. These sheets would then be fastened/ welded to the bar stock in place of the vertical webbing, using rivets, bolts, or even seam welds. This design would utilize high-strength materials that are commonly manufactured by both companies and therefore easier to acquire, potentially lowering cost (Acroman 2012). In analyzing this design, it was confirmed that the current AM2 matting design could potentially be modified to this manufacturing technique. The flanges placed along the edge of the matting could be formed using the current extrusion technique. The matting surface should be thick enough to allow for countersinking using flathead bolts and screws or flush rivets; thus, eliminating potential snag points across the surface. In the case of any of the three previously noted fasteners, the flange segments that join the panels together should be fairly interchangeable. However, computation and experimental analysis of any design will need to be conducted in depth.

The use of rolled sheets for the matting surface would allow for varying the thickness of the top and bottom plates independent from one another. This could be an effective cost and weight saving option, as material could be removed from one section of matting not requiring additional thickness to carry loads. The use of discrete components would also allow optimized material placement. High load and wear components such as the flange connections could be made of higher strength 7050 or 7055 alloys, while the main body of the matting could be produced from the reliable and lower-cost 7075 alloy (ALCOA Mill Products 2011) or even 6061, seeing that the core structure of the matting is not the weak point in the current system. This could potentially increase the efficiency and endurance of the matting, as well as the cost. This component assembly technique could potentially increase the manufacturing time and complexity required to produce the matting. However, the use of pre-manufactured components would greatly, if not completely, eliminate the need for large metal forming equipment. 


\section{Summary}

In summary, several companies are capable of manufacturing a range of extruded 7xxx series products. However, the profitability and feasibility of producing large and complex extrusions are very limiting factors in largescale production of 7xxx series extrusions. A range of issues results in a production rate of available $7 \mathrm{xxx}$ series profiles that is very likely much lower compared to the 6061 extrusion. The conclusion from this analysis is that, while the base manufacturing technology is available, it is not equal to the task of effectively extruding 7xxx series materials on the scale required to replicate the AM2 profile. As such, an alternative design should be considered that takes advantage of current manufacturing capabilities and confronts the issues surrounding the current deployment of 6061-T6 based AM2 airfield matting.

\section{Joining}

One of the best techniques for joining long seams without significantly impacting the surface of the material is welding (Lakshminarayanan et al. 2009). Conventional arc welding offers several advantages (speed, on-site implementation) over other joining techniques. However, while arc welding is extremely compatible with steels, it becomes much harder to weld other materials. In the case of aluminum, the extreme temperatures produced by fusion welding (up to 10,000F) and high concentrations of energy prove to be a problem in welding these alloys (ASM 1993). These welding conditions affect the molecular structure and compositions and can lead to poor mechanical behavior.

The microstructure of fusion-welded aluminum is much coarser than seen in the un-welded material. Because of the low melting temperature and high conductivity of aluminum (much more so than in other metals), the grain structure produces very brittle interfaces between the base and filler material (ASM 1990). This is further exaggerated by the increase in or complete elimination of amalgamations of alloy particles in the material, greatly altering the material's mechanical responses (Praveen and Yarlagadda 2005). Evidence has been found that vaporization of alloying materials occurs within the aluminum, significantly altering the mechanical characteristics of the material and leading to post-weld cracking (Praveen and Yarlagadda 2005), particularly in 2xxx and 7xxx series alloys. 
For creating high-efficiency joints in 2xxx and 7xxx, FSW is proposed. FSW is a solid-state welding process that is being adopted by the aerospace community for its excellent weld properties. In general, FSW is free of many of the defect formation issues commonly associated with fusion welding because the temperature attained during the process is less than the melting point of the base material. In addition, FSW is more energy efficient and clean when compared to other welding techniques. Other advantages include no need for cooling agents or filler materials. FSW can also be easily adapted to computer numerical control system (CNC) for manufacturing automation. The FSW process, seen in Figure 46, has been shown to effectively produce very consistent butt welds over long distances (Su et al. 2003; Mishra and Ma 2005).

Three issues of concern in using FSW in the matting are fatigue life, weld efficiency, and elevated temperature performance. The literature on fatigue life and elevated temperature performance of welding joints in 2xxx and 7xxx material is limited in both volume and scope (Mishra and Ma 2005). However, several studies were found that characterized the mechanical efficiency performance of these welds versus the base material and fusion welding joints under static loading. In one study, FSW butt joints in 7075T651 aluminum alloy exhibited yield and tensile strengths as high as $365 \mathrm{MPa}$ and $525 \mathrm{MPa}$, which gave it a weld efficiency of $84.4 \%$ at failure (Mahoney et al. 1998). A post-welding heat treatment $\left(120^{\circ} \mathrm{C} / 24 \mathrm{hr}\right.$ ) could increase the strength of the joint. The recorded increase in the yield strength of the joint was about $90 \mathrm{MPa}$ ( $455 \mathrm{MPa}$ ) with a slight decrease in weld efficiency at failure, from $84.4 \%$ to $79.7 \%$ (Mahoney et al. 1998). Another investigation (Dixit et al. 2008) studied the 7050-T7451 aluminum alloy under similar testing conditions. The overall weld efficiency of these joints was found to be about $59.4 \%$, from yield strengths of $489.5 \mathrm{MPa}$ to $291 \mathrm{MPa}$. Here, they also used a predictive model to compare to the experimental yield strength data collected. In this predicted data, in a preheat-treated condition, the strength of the weld center "nugget" was lower than the HAZ. In a heat-treated condition, an inverse relationship was observed with the nugget possessing a significantly higher strength. While the experimental data is not shown for the individual regions of the weld, the elongation in the untreated weld joint was over $50 \%$ more than when heat treated (Dixit et al. 2008). 
Figure 46. Schematic illustration of the friction-stir-weld process: (a) rotating tool prior to penetration into the butt joint; (b) tool probe makes contact with the part, creating heat; (c) shoulder makes contact, restricting further penetration while expanding the hot zone; and (d) part moves under the tool, creating a friction-stir-weld nugget (Mahoney et al. 1998).

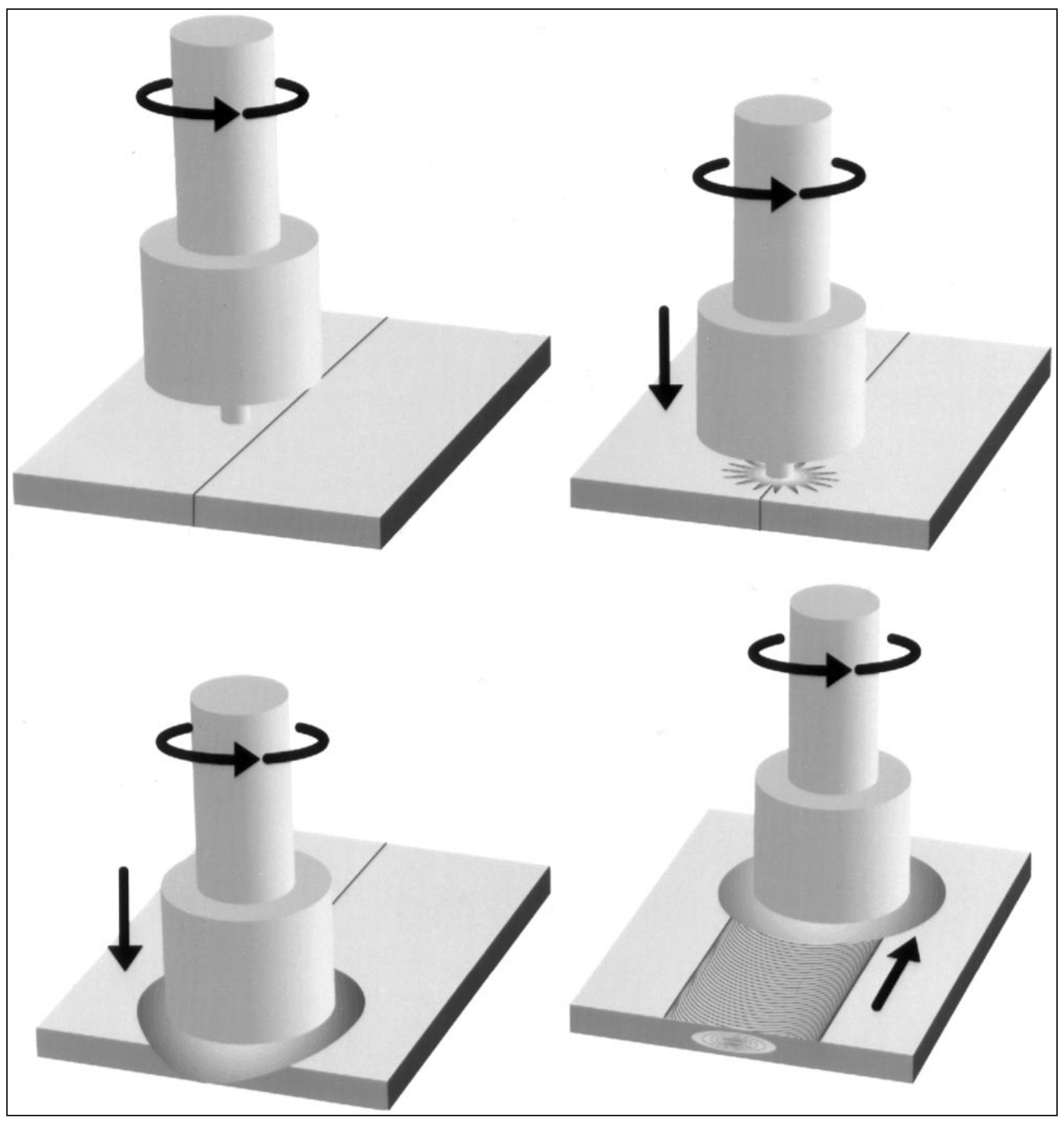

The change in elongation noted by Dixit et al. (2008) confirms the existence of stiffening in the nugget and a strengthening of the material after heat treatment. Even with the weaker nugget prior to treatment, it was observed by both Mahoney et al. (1998) and Dixit et al. (2008) that the fracture points in both types of welded specimens were located consistently within the HAZ as shown in Figure 47. Here, Mahoney et al. (1998) noted the existence of larger alloying MgZn2 intermetallic particle and strengthening from unknown composition precipitants at the fracture surface than at any other region in the material. These large precipitants could indicate that the base material experienced high enough tempera- 
tures to experience clustering of intermetallic particles and, therefore, a weakening and stiffening of the material within the HAZ zone, leading to reduced failure strains. Furthermore, increase in alloy vol\% within the material could potentially increase the effect of the alloy congealing and, thus, decrease the weld efficiency (Mahoney et al. 1998; Dixit et al. 2008).

Figure 47. Image of the cross section of a non-heat-treated FSW 7075 tensile specimen with the edge of fracture surface visible. Image is orientation so the weld seam is transverse to the visible plain (Mahoney et al. 1998).

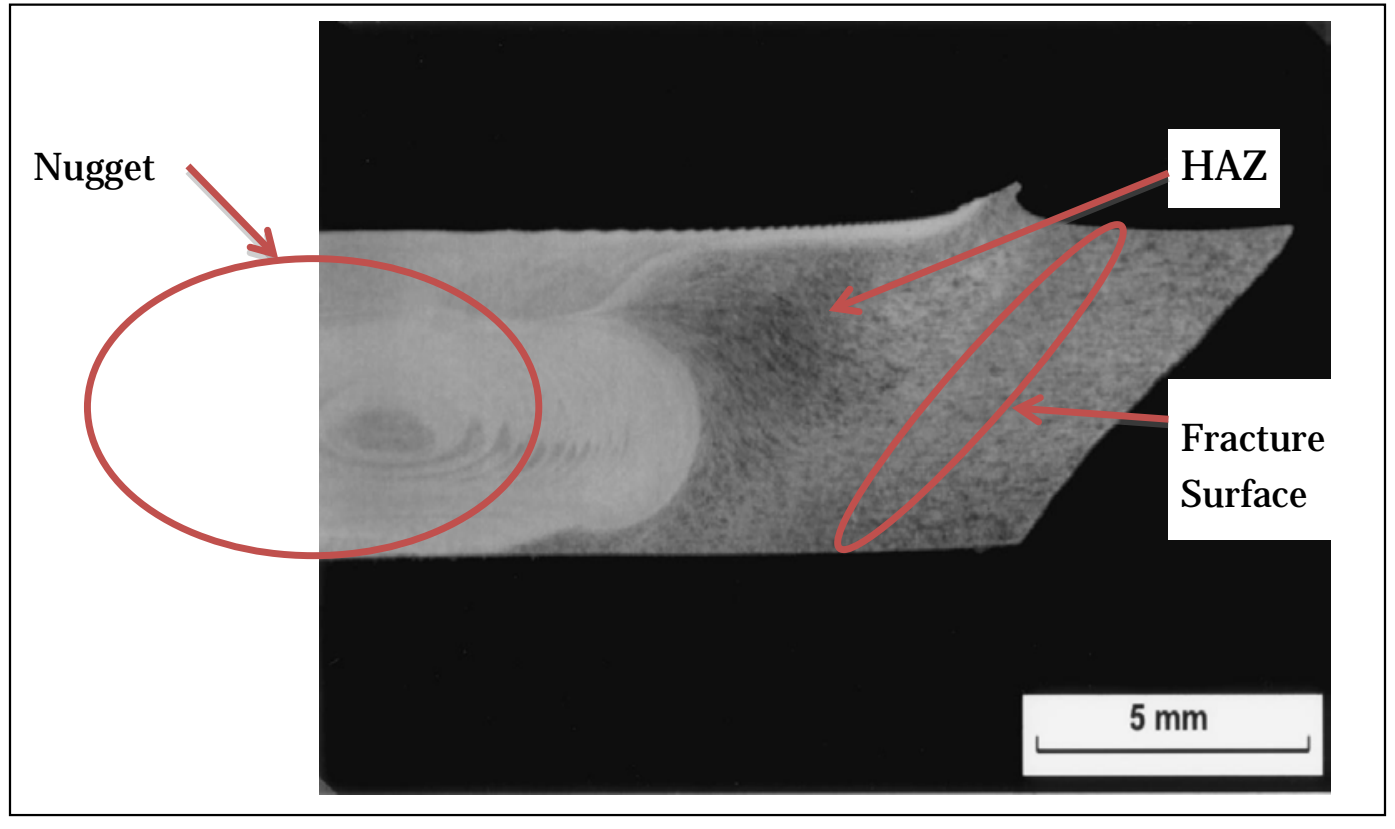

Quenching the 7xxx series aluminum during welding improved the performance of the welded joint. The material as a whole displayed a significant improvement in tensile strengths with increases in the cooling rate, as seen in Figure 48. The 7075-T73 alloy is especially sensitive to this trend concerning the cooling rate. The 7075 alloy was seen to have tensile strengths of $450 \mathrm{MPa}$ at cooling rates of $10^{\circ} \mathrm{C} / \mathrm{s}$, which then increased to $525 \mathrm{MPa}$ at $1000^{\circ} \mathrm{C} / \mathrm{s}$ (Nelson et al. 2003).

In a study by Nelson et al. (2003), the quenching of 7075-T73 was observed to increase its yield strength compared to unquenched specimens. Here, an active, cooling high-pressure water mist at a temperature of $70^{\circ} \mathrm{C}$ was noted as having an increase of about $10 \%$ in tensile strength from $410 \mathrm{MPa}$ to over $455 \mathrm{MPa}$ (Nelson et al. 2003). The yield strength increase was even more significant, with a $24 \%$ improvement in strength and the recorded tensile elongation, almost doubling over the base material. 
Figure 48. Tensile strength of eight alloys as a function of average cooling rate during quenching (Nelson et al. 2003).

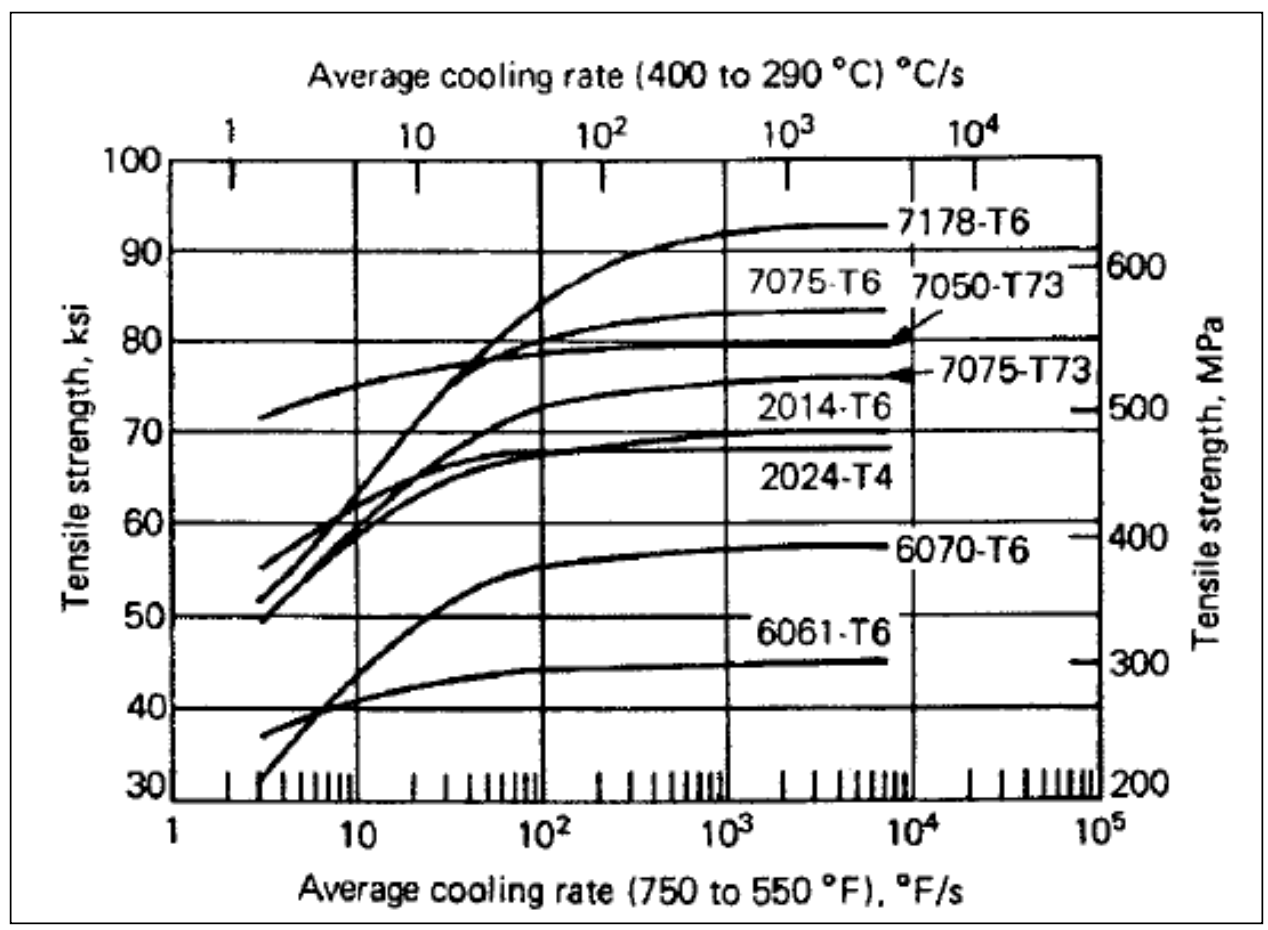

This trend was confirmed in a related study on water cooling of 7050 aluminum alloy during submerged FSW. The increase in mechanical performance over the base material was very similar to observations by Nelson et al. (2003) and showed that hot water $\left(90^{\circ} \mathrm{C}\right)$ cooling of the weld improved the tensile performance of the material by $13.8 \%$ from $325 \mathrm{MPa}$ to $370 \mathrm{MPa}$ (Rui-Dong et al. 2011). This was a significant improvement compared to the cold water $\left(8^{\circ} \mathrm{C}\right)$ cooling that showed a $4.6 \%$ increase to $340 \mathrm{MPa}$ (Rui-Dong et al. 2011). Figure 49 clearly shows the increase in material performance seen with both quenching techniques. An increase in the joint's ductility was also noted as can be seen in Figure 50. However, that cold water cooling of the 7050 alloy decreased the elongation performance of the material. This is likely an indicator of an optimum cooling rate that was simulated by the cold mist and high temperature water submersion, but exceeded by the cold water submersion.

In general, fatigue performance of FSW is typically better than fusion welding techniques. Figure 51 shows the stress-life results of FSW and MIG welded joints on a 5xxx series alloy (Zhou et al. 2005). Another study compared the fatigue performance of 6082 aluminum alloy welded using GTAW-TIG, MIG Pulse, and FSW techniques. As in the study by Zhou et al. (2005) the MIG weld joints were easily outperformed by their FSW 
Figure 49. Stress/Strain Graph of water quenched, air cooled, base 7050 aluminum alloy specimens (Rui-Dong et al. 2011).

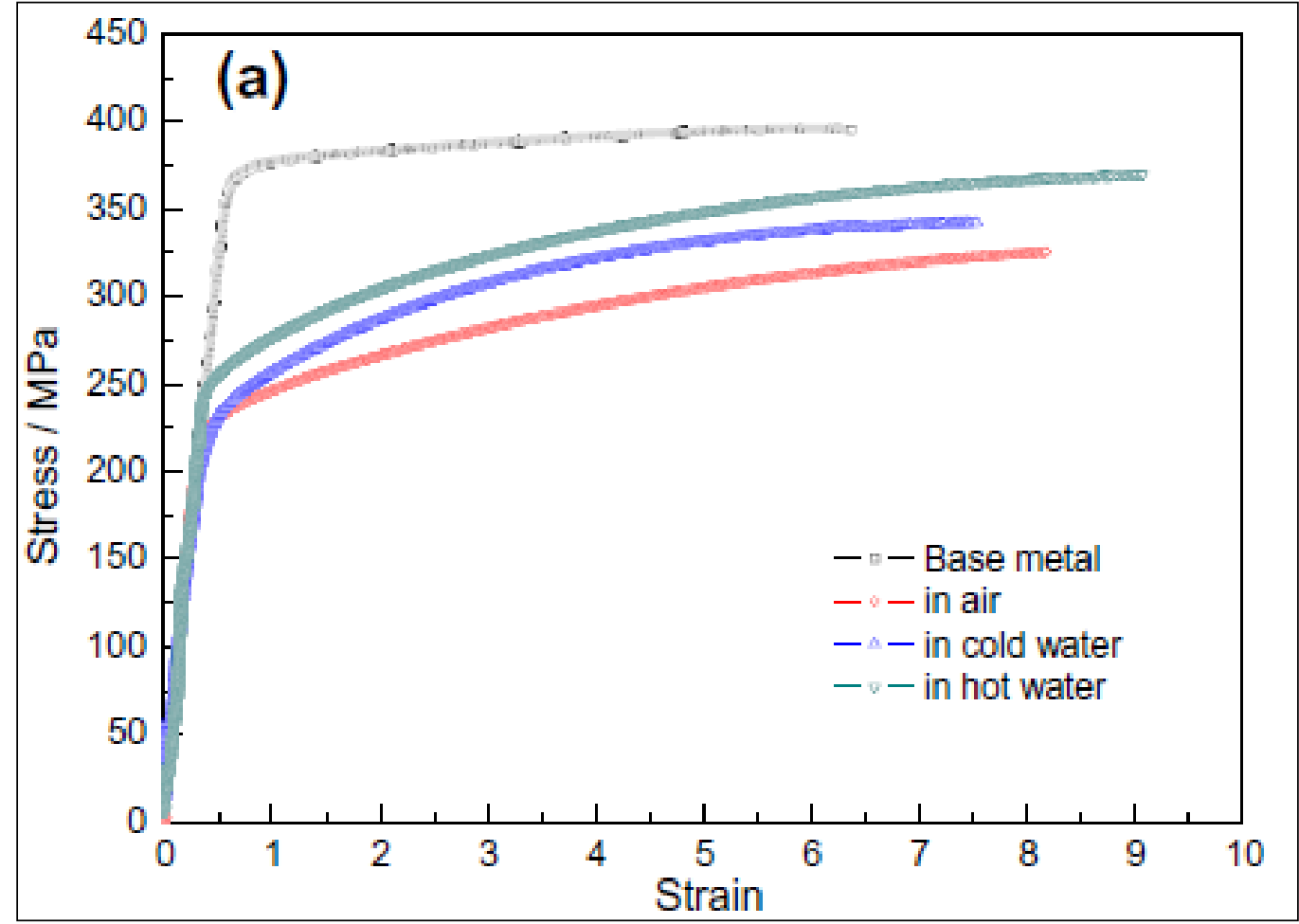

Figure 50. Graph comparing ultimate strength and elongation of water quenched, air cooled, base 7050 aluminum alloy specimen (Rui-Dong et al. 2011).

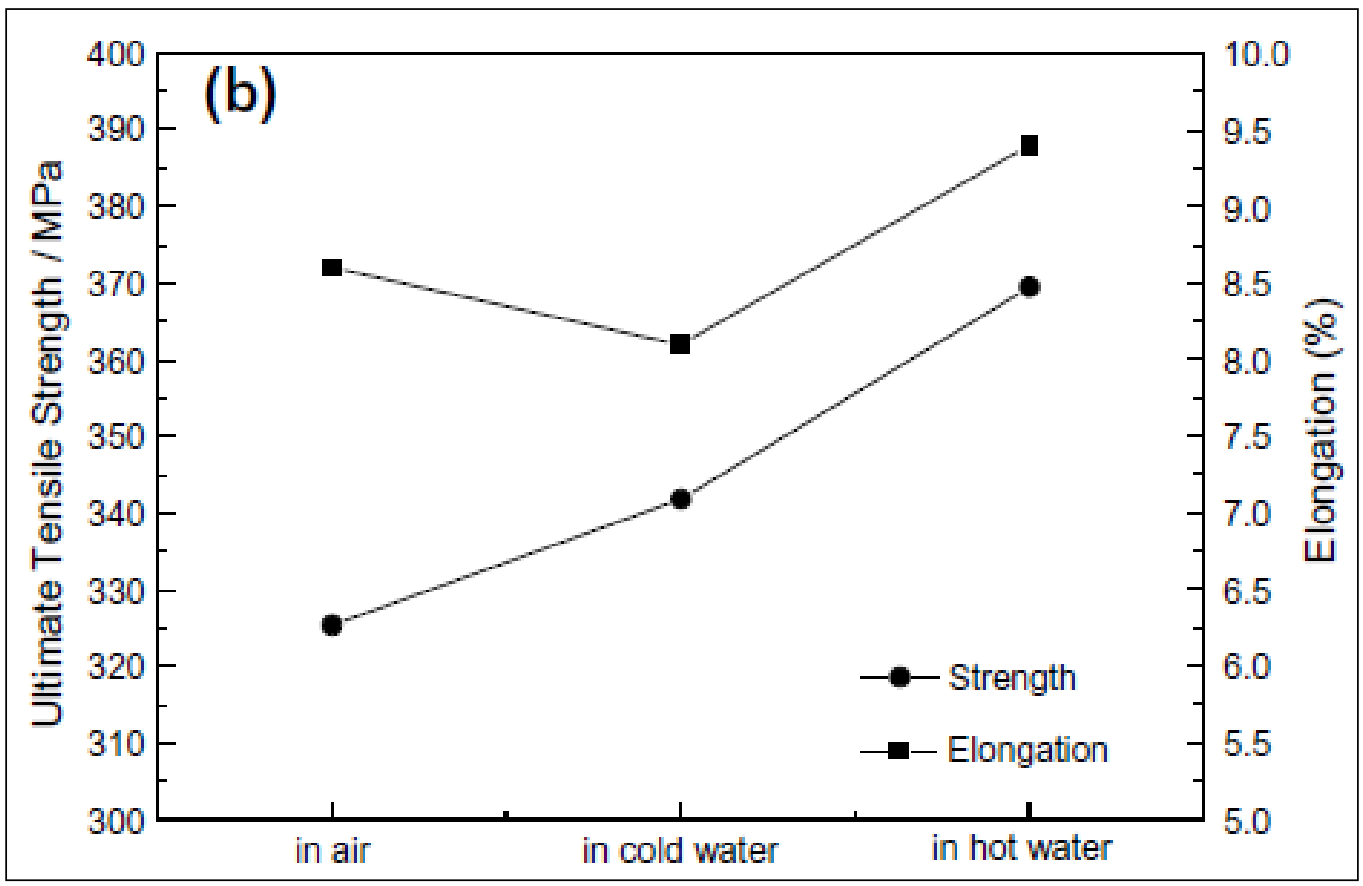


Figure 51. Stress amplitude ( $R=.1$ ) fatigue life curves for 5083 MIG and FSW joints (Zhou 2005).

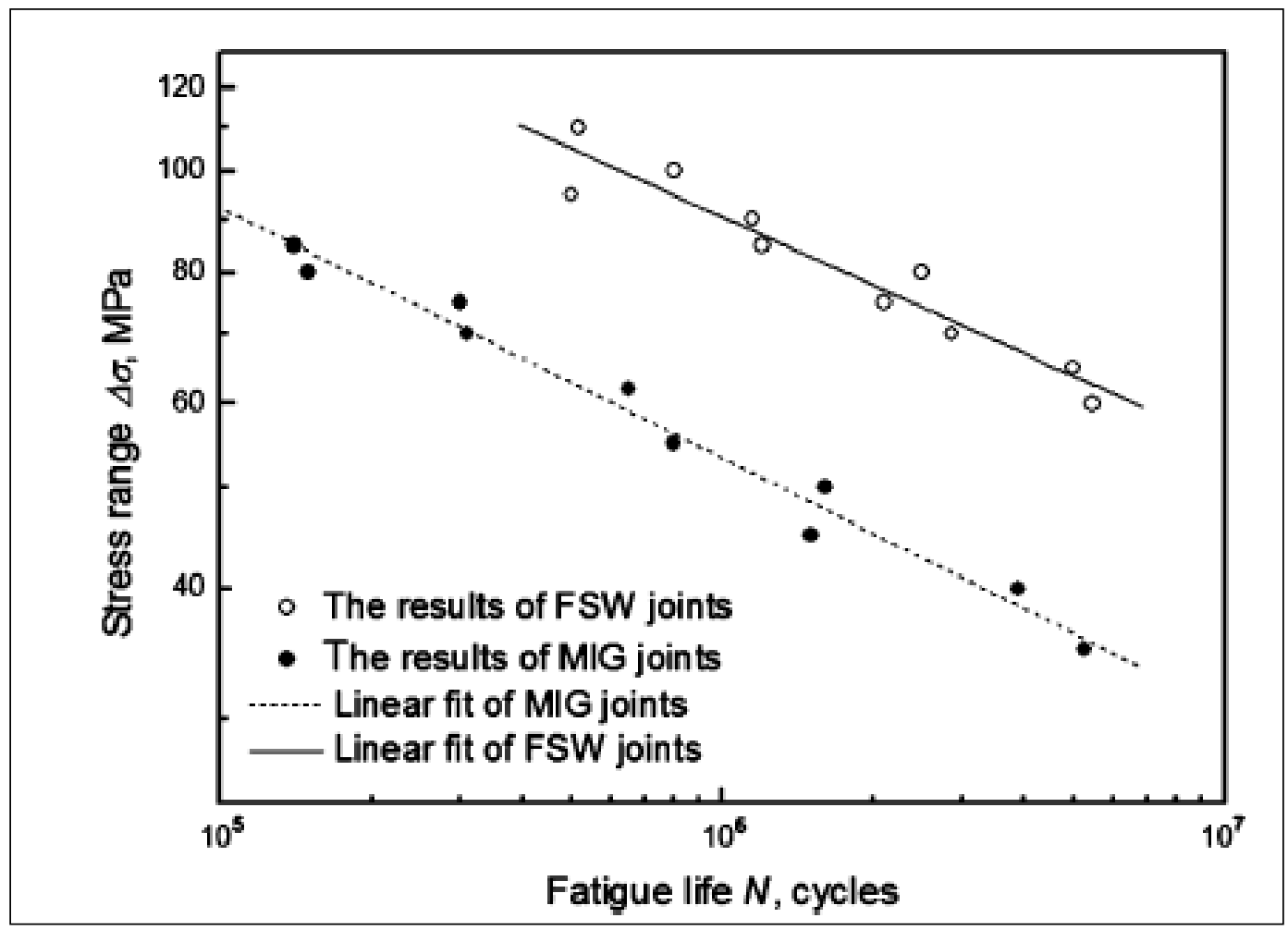

counterparts. This observation was also noted elsewhere (Ericsson and Sandstram 2003) as shown in Figure 52. It is important to note that, while the FSW welds were still easily the best performing of the three types investigated, the TIG welds showed a great deal of improvement over the MIG joints. In some cases, the TIG joints even exhibited similar performance to the FSW joints. However, the TIG joints were much less consistent than both the MIG or FSW joints (Ericsson and Sandstram 2003).

The effect of tool transverse speed on the FSW joint was also investigated on the fatigue life of 6082 at two different tempers, T4 + PWAT and T6. The joint performance at three different weld speeds, labeled high ( $1400 \mathrm{~mm} / \mathrm{min})$, low $(700 \mathrm{~mm} / \mathrm{min})$, and extra-low $(350 \mathrm{~mm} / \mathrm{min}$ was evaluated (Ericsson and Sandstram 2003). Only slight differences were noted in the high-cycle fatigue range for the different process conditions. However, for the low-cycle range, the extra-low speed welds tended to have the highest fatigue life values (Ericsson and Sandstram 2003).

In conclusion, FSW as an alternative solid state joining technique for fusion welding in high-strength aluminum alloys is an effective technology. An increase in joint efficiency and higher fatigue life compared to traditional 
fusion-welded joints makes FSW an excellent replacement for use in joining high-strength aluminum alloys for implementation in the AM2 airfield matting systems.

Figure 52. Stress amplitude fatigue life chart for MIG-pulse, TIG, and FSW high and low speed specimens (Ericsson and Sandstram 2003).

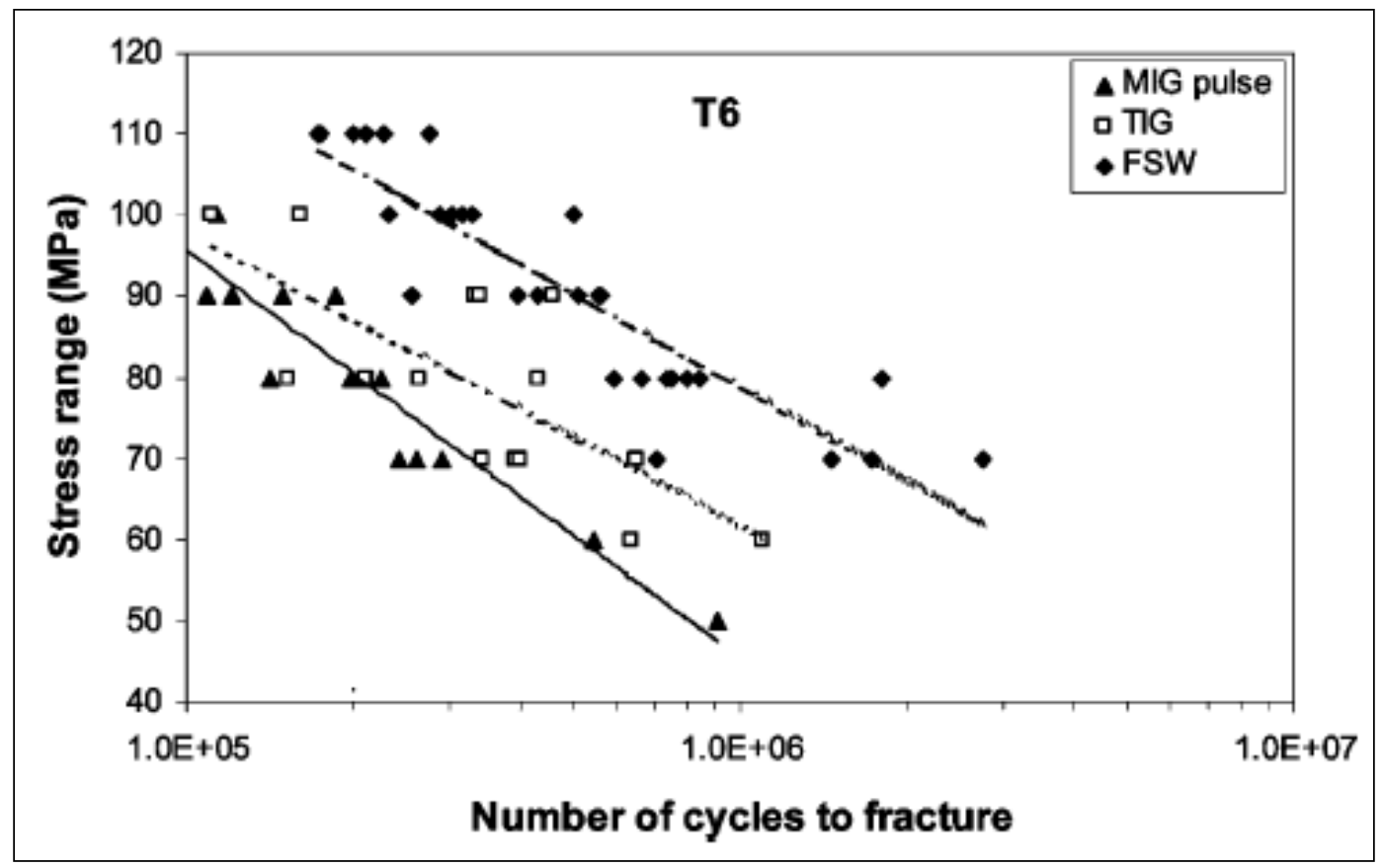




\section{Market Cost Analysis}

In this section, an analysis of the cost of acquisition and production of high-strength 7xxx aluminum and magnesium alloys is presented.

\section{Cost analysis for $7 \times x x$ Series aluminum alloys}

One of the major issues found during the initial research of high-strength hard alloys for use in the AM2 is that there exists a very limited and narrow market for these alloys. An understanding of the requirements of acquisition for extruded 7xxx series alloys, specifically 7050, 7055, and 7075 for both lab testing, prototyping and large-scale production is needed. In order to facilitate the cost analysis for a potential 7xxx series material, the existing AM2 design and production model was used.

To form the basis of the cost analysis, the availability of 7xxx series alloys is explored through several industrial companies. Three distinct aspects were noted in this investigation. First was the cost of $7 \mathrm{xxx}$ series aluminum products versus 6061-T6 products of similar manufacture and shape. The price for 7xxx series sheet and milled round stock was between two to three times that of 6061-T6 of equivalent dimensions and finishes (McMasterCarr Incorporated). With increasing size, the price difference tended to decrease. This could be an indicator that the price difference is not so much in a greater material cost, but higher fabrication costs. This can be inferred, because a base-line manufacturing cost would become a much smaller percentage of the product cost in larger-scale products, causing the price difference to decrease as the size and production volume of the product increased.

Secondly, the predominance of the 7075 alloy versus other high-strength alloys was noted: 7050 and 7055 alloys. The much higher availability of 7075 series product leads directly from two factors. First, this availability can be traced to 7075's early aeronautical applications, as far back as World War II, by the J apanese for their fighter aircraft (HIDEO 2005). The material gained a predominance in Asian industry early and, therefore, became the industry standard for 7xxx series alloys. The second factor leading to more widespread use of 7075 is that it, while less corrosive resistant and in some case possessing lower strengths than 7050 or 7055, is much more stable. The 7075 alloys possess mechanical properties that are 
much more consistent, which leads to easier and more efficient production, including quality control and reliability.

The third item noted was that even with the differences in availability, 7075 was still very limited in its variety, with only simple extruded barand rod-stock available beyond the very common sheet stock seen in most of the cataloged metals. This could be an indicator of potential difficulties and/ or costs in manufacturing extruded hollow profile products comparable to those seen in 6xxx series alloys.

Next, an analysis of the raw extrusion billets was needed for an idea of base material cost. Two major suppliers were contacted for pricing. Alcoa Global stated that it no longer manufactured extrusion billets for external purchasing (Global 2012) and then referred to Vista Metal Corporation for raw aluminum alloy supply. Based upon information from Vista Metals, a billet of 6061 with a length of $230 \mathrm{in}$. and diameter between 8 and $12 \mathrm{in}$. costs around \$1.34 to $\$ 1.35$ per pound. From here, the price of 7075 increased one cent per pound to about $\$ 1.36$. For 7050, an increase of 4 to 5 cents to $\$ 1.40$ per pound is expected (Tringham 2012). This is an interesting contrast to what was seen in the end product cost from vendors like McMasters and supports the conclusion that manufacturing issues related to $7 \mathrm{xxx}$ series extrusions are a major contributor to the difference in end product cost.

The second aluminum producer consulted in this report was Kaiser Aluminum Corporation. This is one of the only large-scale 7xxx series extruders next to Alcoa based in the United States. Kaiser Aluminum financially is about a 20th the size of Alcoa, but still is maintaining its external sales capacity for its foundry division. For forged billets of 6061 aluminum, the estimated cost for dimensions of $9 \mathrm{in}$. in diameter and between 12 and $14 \mathrm{ft}$ long was estimated at about \$ 1.66 per pound (Kaiser Aluminum Inc. 2012).

The cost stated for 7050 and 7075 billets of equal dimension was $\$ 2.26$ and $\$ 2.11$ per pound, respectively (Swartz 2012). The higher cost difference compared to Vista Metal Corp's estimate was stated as possibly being due in part to the limited manufacturing time reserved for the billets. The company only manufactures these materials in billeted form once every quarter. An explanation for the larger price difference between 6061 and 7xxx series billets could not be determined. 
Alcoa is one of the largest suppliers of extruded aluminum products in the country and, while it is not a supplier of 7xxx series aluminum extrusion billets, it does manufacture extrusions composed of either 7055 or 7075 aluminum materials. However, concern was shown by the company as to its ability to manufacture even a greatly reduced profile similar to the AM2 runway matting (Smith 2012). Some rough cost estimates per pound mass were given for 6061, 7055, and 7075. In the case of 6061, for a basic solid extrusion shape such as 2-in.-by-3-in. bar stock, the cost was about $\$ 2$ per pound. The 7075 extrusions of similar shape was estimated to be about $\$ 7 \mathrm{a}$ pound (3.5 times greater compared to 6061) and 7055 was stated as costing around $\$ 15$ a pound (7.5 times greater compared to 6061) (Smith 2012).

For a hollow profile, the estimated cost was not specified. However, it was noted that, compared to 6061, a hollow 7075 extrusion could conservatively cost around 7 to 8 times more and a 7055 extrusion 10 to 15 times more. The lower cost of 7075 compared to 7055 was stated as being caused by two factors. First, the material was easier to produce because of its ability to undergo a single stage T6 or T73 aging process to achieve the desired characteristics. The 7055 requires high-precision, multi-stage aging processes such as T7651 and T7451, which was stated as being the largest contributor to the differences in cost between 7075 and 7055 extrusions (Smith 2012). The second reason stated was demand, mainly caused by the 7075 alloy's very stable and overall evenly characterized properties as noted earlier. A notation should be made that 7055 possessed much higher strengths both in compression and tensile loading for the increased cost. While there might exist a possibility of extruding 7075 with a hollow rectangular, producing an equivalent profile with 7055 is not possible with the current technology (Alloy 7075 Plate and Sheet-All Around Consistent Performance 2011; Alloy 7050 Plate and Sheet-Best Combination of Properties 2011).

Regarding the feasibility of extruding 7xxx alloys, the extrusion division of Kaiser Aluminum indicated that extruding a multi-hollow profile, even if greatly segmented, exceeded the limits of their manufacturing capacity (Farrar 2012). They identified that the largest possible extrusion cross section they could produce is a hollow rectangular tube with a 2-in.-by3-in. profile and wall thicknesses between .018 in. and 0.25 in. However, the profile was not manufactured typically and no factory cost estimate could be given. Furthermore, the company's distributors would have to be consulted (Acroman 2012). However, because of the low demand for this 
type of extrusion, the distributors do not keep a substantial quantity of these extrusions on hand. Therefore, they could not give a price for the tubing, stating that a custom order would have to be submitted, and the facility engineers would have to generate the cost estimate (AM Castle \& Co. 2012). However, an estimated cost was received for solid extruded bar of the same dimensions stated above. For solid 2-in.-by-3-in. extrusions of 7075 alloys with T6 or T6511 heat treatments, the cost was stated as around \$3.66 per pound. To manufacture a similar profile in 7050 with a T7611 heat treatment, the cost was stated as potentially increasing by $10 \%$ to about $\$ 4.03$ per pound (Acroman 2012).

In addition to these extruders, Taber Extrusions of Arkansas provided cost estimates. Currently, Taber is the sole producer of the AM2 matting system and has experience with extruding 7xxx series alloys using their current extrusion press. The assumption was made that Taber could produce the closest cost estimate for the production of 7xxx series extrusions close to those required to upgrade the AM2 matting. However, the company could not provide an estimate on the cost of extrusions of a similar profile currently used in the AM2 matting. The representative did state that a hollow profiled rectangular extrusion of any size could easily reach 10 times the cost seen in equivalent 6061 systems (Althardt 2012). He also indicated that this would most likely increase substantially with increase in profile complexity, but the profile would then become infeasible from a manufacturing viewpoint.

In summary, from the information collected from the manufacturers, the cost of acquiring $7 \mathrm{xxx}$ series extrusions could easily surpass 8 to 10 times the cost of extruding 6061 aluminum alloy. Furthermore, the complexity of extruding multi-hollow profiles similar to the AM2 design could render these estimates non-conservative.

\section{Cost analysis for magnesium alloys}

In view of selecting a new material for implementation in the AM2 runway platform, a feasibility and cost estimate study of magnesium alloys has been conducted. As many of the aspects of the target application are cutting edge in terms of the application of magnesium, much of the cost analysis will be based off small-scale acquisition for laboratory analysis.

As a replacement for aluminum alloys, magnesium alloys have shown the ability to mimic and surpass several of the primary characteristics of 
aluminum alloys. This ability is especially notable in the case of 6061-T6 alloys. Key to their effectiveness as a replacement for aluminum is magnesium's superior strength-to-weight ratio. These observations were confirmed through literature review and substantiated through prior experience with implementation of magnesium alloys in previous generations' portable runway designs.

Because of their lower density and comparable strength and stiffness to the current 6061-T6 aluminum, AM30, AZ31, AZ61, and ZK60A wrought magnesium alloys were analyzed as potential candidate materials for lab scale testing. To gain an understanding of the cost of acquisition, a cost estimate for manufacture of magnesium panels using the current AM2 profile was performed. In addition to this, sources for the acquisition of magnesium billets were contacted in order to establish the cost of acquisition for extrusion billets of the targeted magnesium alloys

Historically, Taber Extrusions of Arkansas has had previous experience in the extrusion of magnesium using their 8800 ton extrusion press. This experience has been focused primarily on the extrusion of open, semihollow and solid profiles. In fact, they have significant experience in the extrusion of magnesium in both the current production model and previous $R \& D$ prototypes of the portable airfield matting project. Their use of magnesium during the airfield matting development stage primarily focused on AZ31 magnesium alloys, implemented in solid and semi-hollow profiles.

For the primary feasibility analysis, a general market cost estimate was obtained from Taber Extrusions. With current market conditions, the cost for the extrusion of a minimum quantity of three billets of magnesium alloy was estimated at approximately $\$ 105,000$. This cost estimate accounts for additional costs such as tooling and billet container treatment. However, the amount does not account for pre-extrusion billet processing and the cost of shipment for the final product and scrap alloy. In addition, Taber stated that they could utilize one of its older AM2 extrusion dies for this production run to further reduce the cost estimate. However, Taber made clear that the final product dimensional tolerances would undeniably be inferior to a standard production run profile, which utilizes a strict die rotation schedule in accordance with an optimum tooling life cycle. Also, since the old die would be optimized for the extrusion of aluminum, the die would not account for variances in material friction or flow patterns during extrusions 
that are unique for magnesium alloys. The use of this type of die would potentially lower the cost estimate by $\$ 39,000$ to approximately $\$ 66,000$.

The lead time for production of a magnesium alloy extrusion would be between 24 and 26 weeks. An expedited lead time is possible, however, for an additional $\$ 2000$ per press $\mathrm{hr}$. The expedited lead time would shorten expected shipment to approximately 12 weeks after the establishment of a contract. Both the estimated cost and production schedule are subject to market fluctuations and will vary accordingly.

For material acquisition, Magnesium Elektron Incorporated's Wrought Product division based in Madison, Illinois, was contacted for estimates on AZ31, AZ61, and ZK60. Due to the shifting magnesium market, a supplier for AM30 was not found and therefore no estimate could be generated for this material. As the design of the Tabor extrusion press allows for the processing of both cylindrical and rectangular extrusions billets, cost estimates for both geometries were obtained. Taber also noted that while they can extrude the profile using cylindrical billets, the rectangular billets will produce much more consistent and stable results. The resulting estimated costs for billets are listed below:

\section{AZ31B Mg Alloy:}

Cylindrical Billet - May 31, 2012 Magnesium Alloy \& Form: As-Cast AZ31B Billet Surface: Scalped Surface

NDT: Ultrasonic Inspection to AMS 2154 Class A

Spec: Chemical Conformance to ASTM B91

Size: 15.35-in.-diam $\times$ Random Lengths

Minimum Quantity: 3,351lb @ \$13.15 per lb >>4 billets @ \$11,016.41 each @ 46.2 in. in length

Estimated Dispatch: 8 weeks after receipt of order

Quotation Validity: Expires in 30 days

Rectangular Billet - May 25, 2012 Magnesium Alloy \& Form: As-Cast AZ31B Slab Surface: Scalped Surface and Sawn (one edge and both ends) Spec: Chemical Conformance to ASTM B90 or ASTM B107 Size: 10 in. thick $\times 28$ in. wide $\times 55$ in. long maximum >>1,509.2lb@ \$8.90 per lb 
Minimum Quantity: 1 piece @ \$13,427.00

Quotation Validity: Expires in 30 days

\section{AZ61 Mg Alloy:}

Cylindrical Billet - May 31, 2012

Magnesium Alloy \& Form: As-Cast AZ61A Billet

Surface: Scalped Surface

NDT: Ultrasonic Inspection to AMS 2154 Class A

Spec: Chemical Conformance to ASTM B91

Size: 15.35-in. diam $\times$ Random Lengths

Minimum Quantity: 3,351lb @ \$14.20 per lb

>> 4 billets @ \$11,896.05 each @ 46.2 in. long

Quotation Validity: Expires in 30 days

Rectangular Billet - July 05, 2012

Magnesium Alloy \& Form: As-Cast AZ61A Slab (Scalped)

Surface: Machined Top Surface and Sawn to 28-in. width dimension

Spec: Chemical Conformance to ASTM B107 or ASTM 90

Size: 10 in. thick $\times 28$ in. width $\times 52.5 \mathrm{in}$. long

Minimum Quantity: 3 pieces @ \$16,339 per piece

$>>1440.6 \mathrm{lb} @ \$ 11.34$ per lb

Estimated Dispatch: 6 to 8 weeks after receipt of order

Quotation Validity: Expires in 30 days

\section{ZK60A Mg Alloy **}

Cylindrical Billet - May 31, 2012

Magnesium Alloy \& Form: As Cast Billet

Surface: Scalped surface

Size: 15.875-in. diam $\times$ 42-in. length

Quantity: 1 billet @ \$ 8780.00

$$
\gg>814.69 \mathrm{lb} @ \$ 10.78 \text { per lb }
$$

Estimated Dispatch Lead-time: 4 to 5 weeks ARO

Quotation Validity: Expires in 21 days

** Magnesium Elektron indicated that a rectangular cast billet of ZK60 Mg Alloy is not possible with their current DC continuous casting system. A substantial upgrade of the system is required to meet the baseline requirements for the casting of ZK60. Also, based on industry experience, the ZK60 
Mg alloy is more susceptible to substantial centerline cracking during cooling of large billets, making the billet unsuitable for post-processing and extrusion. The increased size and unique geometry of the rectangular billet would likely increase the casting's susceptibility to this cracking. 


\section{Conclusions and Recommendations}

\section{Conclusions}

The following conclusions were derived from the analysis of possible materials for use in the AM2 airfield matting system for the purpose of lightweighting. In addition, material characterization and modeling was performed on the samples machined from several locations of the existing AM2 matting:

1. While providing increase in yield strength, metal matrix composites (MMC) do not show significant improvement in fatigue resistance over unreinforced alloys. In addition, the reinforcements will increase flow stress during extrusion and, thus, large-scale manufacturing of MMCs is problematic.

2. Several polymer matrix composites exist for elevated temperature applications, including PETI-5 carbon reinforced composites. While weight savings could be realized, these composites are very expensive and would likely negate any operational savings achieved from lightweighting the AM2.

3. Magnesium alloys exhibit comparable fatigue resistance to the 6061 aluminum alloy and exhibit comparable flow stresses to 6061 aluminum alloy. However, several issues remain, including fatigue resistance at elevated temperature and appropriate coatings to protect against corrosion. Even with these shortfalls, a magnesium alloy has been successfully extruded into an AM2 profile even though the end product did not meet expectations. Further research may lead to the ability to create an AM2-like structure using an Mg alloy.

4. Several high-strength aluminum alloys including 2024, 7055, 7075 would provide substantial weight savings because of their high strength. However, the current manufacturing capability makes extruding these alloys in the full cross-section width of the AM2 difficult. As such, smaller cross sections and/ or open profiles could be extruded and then seam welded with a high-fidelity welding technique like friction-stir welding to create a mat panel.

This research determined that the best possible candidates to date are magnesium and high-strength aluminum alloys. To produce matting with 
either of these materials requires further testing, which was out of the scope of work for this study.

\section{Recommendations for further research}

The following recommendations are required to determine an appropriate replacement for aluminum alloy 6061 in the AM2 matting system:

1. Examine the temperature effects on the fatigue life of the higher strength aluminum alloys friction-stir weld coupons. The suggestion is to examine welds of similar and dissimilar alloys.

2. Perform electrochemical experiments on the high-strength aluminum alloys and friction-stir weld coupons.

3. Determine the electrochemistry effect on the monotonic and cyclic behavior of the higher strength aluminum alloys and friction-stir weld coupons. 


\section{References}

Acroman, D. 2012. Interview by R. MoCullough, J anuary 19, 2012, Extrusion Capabilities of Kaiser Aluminum Arizona.

Agnew, S. R., P. Mehrotra, T. M. Lillo, G. M. Stoica, and P. K. Liaw. 2005. Texture evolution of five wrought magnesium alloys during route a equal channel angular extrusion: Experiments and simulations. Acta Materialia 53(11): 3135-3146.

Ahmad, H., W. S. J ohnson, and W. A. Counts. 2003. Evaluation of bolt bearing behavior of highly loaded composite joints at elevated temperature. J ournal of Composite Materials 37(6):559-571.

ALCOA Global. 2012. Interview by R. McCullough, J anuary 16, 2012, Extrusion Capabilities of Alcoa Global - Massena Operation.

ALCOA Mill Products. 2011. Alloy 7050 plate and sheet - Best combination of properties. http://www.alcoa.com/global/en/products/product.asp?prod_id=606.

. 2011. Alloy 7075 plate and sheet - All around consistent performance. http://www.alcoa.com/mill_products/catalog/pdf/alloy7075techsheet.pdf.

Althardt, S. 2012. Interview by R. McCullough, J anuary 23, 2012, 7xxx Series extrusion capabilities of Taber extrusions

AM Castle \& Co. 2012. Interview by R. McCullough, J anuary 19, 2012, Price of in-stock aluminum extrusions.

Anonymous. 2009. Aluminum standards and data 2009. The Aluminum Association.

Armstrong, R. W., and G. T. Horne. 1962. Fatigue behaviour in shear of oriented magnesium single crystals. J ournal of the Institute of Metals 91.

ASM Committee. 1990. Properties and selection: Nonferrous alloys and special purpose materials. ASM Handbook, Volume 02: ASM International.

ASM Committee. 1990. Welding, brazing, and soldering. ASM Handbook, Volume 06: ASM International.

ASM International Handbook Committee. 1993. ASM specialty handbook: Aluminum and aluminium alloys. Materials Park: ASM International.

ASM International Staff. 1991. Properties and selection: Nonferrous alloys and specialpurpose materials. ASM Handbook, Vol. 2: ASM International.

Atwell, Dale L., and Matthew R. Barnett. 2007. Extrusion limits of magnesium alloys. Metallurgical and Materials Transactions A 38 (12): 3032- 3041.

Bache M. R., W. J . Evans, V. Randle, and R. J. Wilson. 1998. Characterization of mechanical anisotropy in titanium alloys. Mater Sci Eng A, A257:139-44. 
Bakshi, S. R., D. Lahiri, and A. Agarwal. 2010. Carbon nanotube reinforced metal matrix composites. International Materials Reviews 55(1).

Bakshi, Srinivasa R., and Arvind Agarwal. 2011. An analysis of the factors affecting strengthening in carbon nanotube reinforced aluminum composites. Carbon 49:533-544.

Bao, R., and X. Zhang. 2010. Fatigue crack growth behavior and life prediction for 2324T39 and 7050-T7451 aluminium alloys under truncated load spectra. International J ournal of Fatigue 32.7:1180-1189.

Begum, S., D. L. Chen, S. Xu, and A. A. Luo. 2009a. Effect of strain ratio and strain rate on low cycle fatigue behavior of AZ31 wrought magnesium alloy. Mater Sci Eng A 517: 334-43.

. 2008. Strain-controlled low-cycle fatigue properties of a newly developed extruded magnesium alloy. Metall Mater Trans A 39A: 3014-26.

. 2009b. Low cycle fatigue properties of an extruded AZ31 magnesium alloy. Int J Fatigue 31: 726-35.

Bellett, D., F. Morel, A. Morel, and J . L. Lebrun. 2011. A biaxial fatigue specimen for uniaxial loading. Strain: An International J ournal for Experimental Mechanics 47-3: 227-240.

Bernard, J . D., J . B. J ordon, M. F. Horstemeyer, H. El Kadiri, J . Baird, D. Lamb, and A. A. Luo. 2010. Structure-property relations of cyclic damage in a wrought magnesium alloy. Scripta Mater. 63:751-756.

Bhandwale, A. S. and P. Vasudevan. 1978. Low-cycle fatigue studies on commercial aluminum in combined bending and torsion. J ournal of the Indian Institute of Science 60(7): 283-292.

Bray, G. H, M. Glazova, R. J . Riojaa, D. Lib, and R. P. Gangloffb. 2001. Effect of artificial aging on the fatigue crack propagation resistance of 2000 series aluminum alloys. International J ournal of Fatigue 23. Supplement 1: 265-276. Web. 27 May 2011.

Brown, D., K. Cochran, R. Dunn, B. Harris, C. Hawkins, D. Moore, L. Waldo, and FILE. 2006. Lightweight landing mat static test results summary.

Ceschini, L., I. Boromei, G. Minak, A. Morri, and F. Tarterini. 2007. Effect of friction stir welding on microstructure, tensile and fatigue properties of the AA7005/ 10 vol.\% $\mathrm{Al}_{2} \mathrm{O}_{3}$ p composite. Composites Science and Technology, 605-615. . 2007. Microstructure, tensile and fatigue properties of AA6061/20 vol. $\% \mathrm{Al}_{2} \mathrm{O}_{3} \mathrm{p}$ friction stir welded joints. Composites: Part A 38: 1200-1210.

Chamos, A. N., S. G. Pantelakis, G. N. Haidemenopoulos, and E. Kamoutsi. 2008. Tensile and fatigue behavior of wrought magnesium alloys AZ31 and AZ61. Fatigue Fract Eng Mater Struct 31:812-21.

Chandrasekaran, Margam, and Yong Ming Shyan J ohn. 2004. Effect of materials and temperature on the forward extrusion of magnesium alloys. Materials Science and Engineering: A 381(1-2): 308-319. 
Chen, J . Z., L. Zhen, S. J . Yang, and S. L. Dai. 2010. Effects of precipitates on fatigue crack growth rate of AA 7055 aluminum alloy. Transactions of Nonferrous Metals Society of China 20(12): 2209-2214.

Cheng, Ying-liang, Ting-wei Qin, Hui-min Wang, and Zhao Zhang. 2009. Comparison of corrosion behaviors of AZ31, AZ91, AM60 and ZK60 magnesium alloys. Transactions of Nonferrous Metals Society of China 19(3): 517- 524.

Chino, Yasumasa, Katsuya Kimura, and Mamoru Mabuchi. 2008. Twinning behavior and deformation mechanisms of extruded AZ31 Mg alloy. Materials Science and Engineering: A 486 (1-2): 481- 488.

Cho, D., and L. T. Drzal. 1999. Thermal characterization of LaRC PETI-5 as a potential high temperature sizing material. International Composite Materials Conference 12.

Cho, D., S. Lee, G. Yong, H. Fukushima, and L. Drzal. 2005. Dynamic mechanical and thermal properties of phenylethynyl-terminated polyimide composites reinforced with expanded graphite nanoplatelets. Macromolecular Materials and Engineering 179-187.

Choi, H. J ., G. B. Kwon, G. Y. Lee, and D. H. Bae. 2008. Reinforcement with carbon nanotubes in aluminum matrix composites. Scripta Materialia 59:360-363.

Choi, H. J ., J . H. Shin, and D. H. Bae. 2011. Grain size effect on the strengthening behavior of aluminum-based composites containing mutli-walled carbon nanotubes. Composites Science and Technology 1-6.

Counts, W. A., and W. S. J ohnson 2002. Bolt bearing fatigue of polymer matrix composites at elevated temperature. International J ournal of Fatigue 197-204.

Davies, Chris, and Matthew Barnett. 2004. Expanding the extrusion limits of wrought magnesium alloys. J OM 56 (5): 22- 24.

DeBartolo, E. A., and B. M. Hillberry 1998. Effects of constituent particle clusters on fatigue behavior of 2024-T3 aluminium alloy. International J ournal of Fatigue 20.10:727-735.

Ding, H. Z., H. Biermann, and O. Hartmann. 2002. A low cycle fatigue model of a shortfibre reinforced 6061 aluminium alloy metal matrix composite. Composite Science and Technology, 2189-2199.

Dixit, M., R. S. Mishra, and K. K. Sankaran. 2008. Structure property correlations in Al 7050 and Al 7055 high-strength aluminum alloys. Materials Science and Engineering: A 478: 163-172.

Dorward, R. C., and C. Bouvier. 1998. A rationalization of factors affecting strength, ductility, and toughness of AA6061-type Al-Si-Mg- $(\mathrm{Cu})$ alloys. Materials Science and Engineering (A254):33-44.

Ericsson, M., and R. Sandstram. 2003. Influence of welding speed on the fatigue of friction stir welds, \& comparison with MIG and TIG. International J ournal of Fatigue 25(12):1379-1387. 
ESAB North America. 2011. Understanding the Aluminum Alloy Designation System. http:/ / www.esabna.com/ us/ en/ education/ knowledge/ qa/-Understanding-theAluminum-Alloy-Designation-System.cfm.

Farrar, L. 2012. Interview by R. McCullough, J anuary 19, 2012, Extrusion Capabilities of Kaiser Extrusion - Tennalum Facilities.

Femandez, G. J ., and L. E. Murr. 2004. Characterization of tool wear and weld optimization in the friction-stir welding of cast aluminum $359+20 \% \mathrm{SiC}$ metal-matrix composite. Materials Characterization 52:65-75.

Galiyev, A., R. Kaibyshev, and G. Gottstein. 2001. Correlation of plastic deformation and dynamic recrystallization in magnesium alloy ZK60. Acta Materialia 49(7): 1199- 1207.

Gall, K., G. Biallas, H. J . Maier, P. Gullett, M. F. Horstemeyer, D. L. McDowell, and J . Fan. 2004. In-situ observations of high cycle fatigue mechanisms in cast AM60B magnesium in vacuum and water vapor environments. Int J Fatigue 26: 59-70.

Gall, K., G. Biallas, H. J . Maier, P. Gullett, M. F. Horstemeyer, and D. L. McDowell. 2004. In-situ observations of low-cycle fatigue damage in cast AM60B magnesium in an environmental scanning electron microscope. Metall Mater Trans A 35:321-31.

Garcia, L., T. W. Rushing, and Q. S. Mason. 2014. AM2 25 CBR Subgrade Sensitivity Test. TR-14-7. Vicksburg, MS: US Army Research and Development Center.

Gertler, J eremiah. 2011. F-35J oint Strike Fighter (J SF) Program: Background and Issues for Congress. Congressional Research Service. 7-5700 RL30563.

Goh, C. S., J . Wei, L. C. Lee, and M. Gupta. 2008. Ductility improvement and fatigue studies in Mg-CNT nanocomposites. Composites Science and Technology 68:1432-1439.

Gray, J . E., and B. Luan. 2001. Protective coatings on magnesium and its alloys - a critical review. Journal of Alloys and Compounds 336(1-2):88-113.

Gupta, Manoj, and Nai Mui Ling Sharon. 2011. Magnesium, magnesium alloys, and magnesium composites. Hoboken, NJ : Wiley Publications.

Halliday, M. D., C. Cooper, P. Pooleb, and P. Bowena. 2003. On predicting small fatigue crack growth and fatigue life from long crack data in 2024 aluminium alloy. International J ournal of Fatigue 25.8: Int. J . Fatigue (UK) 709-18.

Han, N. L., Z. G. Wang, and G. D. Zhang. 1997. Effect of reinforcement size on the elevated-temperature tensile properties and low-cycle fatigue behavior of particulate $\mathrm{SiC} / \mathrm{Al}$ composites. Composites Science and Technology 87:14911499.

Hartmann, O., M. Kemnitzer, and H. Biermann. 2002. Influence of reinforcement morphology and matrix strength of metal-matrix composites on the cyclic deformation and fatigue behaviour. International J ournal of Fatigue 215-221.

Hasegawa, S., Y. Tsuchida, H. Yano, and M. Matsui. 2007. Evaluation of low cycle fatigue life in AZ31 magnesium alloy. IntJ Fatigue 29:1839-45. 
Hexcel Corporation. 2011. Hexcel Aerospace Prepreg Selection Guide. http://www.hexcel.com/Resources/Prepreg-Data-Sheets.

Hexcel Corporation. 2011. HexPly ${ }^{\circledR} \mathrm{M} 36-180^{\circ} \mathrm{C}\left(350^{\circ} \mathrm{F}\right)$ curing epoxy matrix. http://www.hexcel.com/Resources/Prepreg-Data-Sheets.

Hexcel Corporation. 2011. HexTow IM7. http://www.hexcel.com/Resources/Cont-Carbon-FiberData-Sheets.

Hexcel Corporation. 2011. Prepreg Technology Guide. http://www.hexcel.com/resources/technology-manuals.

Hilditch, Tim, Dale Atwell, Mark Easton, and Matthew Barnett. 2009. Performance of wrought aluminium and magnesium alloy tubes in three-point bending. Materials \& Design 30(7):2316- 2322.

Hochreiter, E., M. Panzenbock, and F. J eglitsch. 1993. Fatigue properties of particlereinforced metal-matrix composites. International J ournal of Fatigue 15(6):493499.

. 1993. Fatigue properties of particle-reinforced metal-matrix composites. Int. J . Fatigue 15(6):493-499.

Höppel, H. W., M. Kautz, C. Xu, M. Murashkin, T. G. Langdon, R. Z. Valiev, and H. Mughrabi. 2006. An overview: Fatigue behavior of ultrafine-grained metals and alloys. Int. J . Fatigue (28):1001-1010.

International Magnesium Association. 2011. Magnesium components blazing new trails for automakers. www.intlmag.org/showcase/MgShowcase15_Feb2011printer.pdf.

J eong, D. Y. 2004. Mixed mode fatigue crack growth in test coupons made from 2024-T3 aluminum. Theoretical and Applied Fracture Mechanics 42.1:35-42.

J ogi, B. F., P. K. Brahmankar, V. S. Nanda, and R. C. Prasad. 2008. Some studies on fatigue crack growth rate of aluminum alloy 6061. J . of Materials Processing Technology 201:380-384.

J ones, R. E. 1972. Mechanical properties of 7049-T73 and 7049-T76 aluminum alloy extrusions at several temperatures. AFML-TR-72-2. Wright-Patterson Air Force Base, $\mathrm{OH}$ : Air Force Materials Laboratory.

J ordon, J . B., J . Gibson, M. F. Horstemeyer, H. El Kadiri, J . Baird, and A. A. Luo. 2011. Effect of twinning, slip, and inclusions on the fatigue anisotropy of extrusiontextured AZ61 magnesium alloy. Mat Sci Eng. A. 528:6860-6871.

Kaiser Aluminum Inc. 2012. Interview by R. McCullough, January 25, 2012, Cost of 6061 Extrusion Billets at Newark Facility.

Kamp, N., N. Gaoa, M. J . Starinka, and I. Sinclair. 2007. Influence of grain structure and slip planarity on fatigue crack growth in low alloying artificially aged $2 \mathrm{xxx}$ aluminum alloys. International J ournal of Fatigue 29.5:869-878.

Kaufman, J . G. 2000. Introduction to aluminium alloys and tempers. Materials Park: ASM International. 
Khomamizadeh, F., B. Nami, and S. Khoshkhooei. 2005. Metallurgical and Materials Transactions A. Volume 36A.

Klaska, Arne M., Tilmann Beck, Alexander Wanner, and Detlef Lohe. 2009. Residual stress and damage development in the aluminum alloy EN AW-6061 article reinforced with $\mathrm{Al}_{2} \mathrm{O}_{3}$ under thermal fatigue loading. Materials Science and Engineering A 501: 6-15.

Kondoh, Katsuyoshi, Thotsaphon Threrujirapapong, Hisashi Imai, J unko Umeda, and Bunshi Fugetsu. 2009. Characteristics of powder metallurgy pure titanium matrix composite reinforced with multi-wall carbon nanotubes. Composites Science and Technology: 1077-1081.

Krkoska, M., S. A. Barterb, R. C. Alderliestenc, P. Whiteb, and R. Benedictus. 2010. Fatigue crack paths in AA2024-T3 when loaded with constant amplitude and simple underload spectra. Engineering Fracture Mechanics 77.11: 1857-1865.

Kuo, T. Y., H. S. Lin, and H. T. Lee. 2005. The relationship between of fracture behaviors and thermo mechanical effects of alloy AA2024 of T3 and T81 temper designations using the center crack tensile test. Materials Science and Engineering A 394.1-2: 28-35.

Lacy, T., Y. Yamada, J . Newman J r., B. L. Smith, and B. Kumar. 2007. Effects of crack closure on fatigue crack-growth predictions for 2024-T351 aluminum alloy panels under spectrum loading. International J ournal of Fatigue 29.8: Int. J . Fatigue (UK) 1503-1509.

Lakshminarayanan, A., V. Balasubramanian, and K. Elangovan. 2009. Effect of welding processes on tensile properties of AA6061 aluminum alloy joints. The International J ournal of Advanced Manufacturing Technology 40(3):286-296.

Lee, D., H. V. Tippur, B. J . J ensen, and P. B. Bogert. 2011. Tensile and fracture characterization of PETI-5 and IM7/ PETI-5 graphite/ epoxy composites under quasistatic and dynamic loading conditions. J ournal of Engineering Materials and Technology 133:1-11.

Lee, D., H. V. Tippur, and P. B. Bogert. 2010. An experimental study of tensile and fracture response of PETI-5 and IM7/ PETI- 5 graphite/ epoxy composites subjected to quasi-static and dynamic loading. World J ournal of Engineering.

Lee, I. S., C. J . Hsu, C. F. Chen, N. J . Ho, and P. W. Kao. 2011. Particle-reinforced aluminum matrix composites produced from powder mixtures via friction stir processing. Composites Science and Technology 71:693-698.

Lee, Sang-Hyoup, Young-Geun Choi, and Sang-Tae Kim. 2010. Initiation and growth behavior of small surface fatigue cracks on $\mathrm{SiC}$ particle-reinforced aluminum composites. Advanced Composite Materials 19: 317-330.

Lim, C. Y. H., D. K. Leo, J . J . S. Ang, and M. Gupta. 2005. Wear of magnesium composites reinforced with nano-sized alumina particulates. Wear 259: 620-625.

Lin X. Z., and D. L. Chen. 2008a. Strain hardening and strain-rate sensitivity of an extruded magnesium alloy. J Mater Eng Perform 17:894-901. 
. 2008b. Strain controlled cyclic deformation behavior of an extruded magnesium alloy. Mater Sci Eng A 496:106-13.

Lincoln, J. E., R. J . Morgan, and E. E. Shin. 2001. Effect of thermal history on the deformation and failure of polyimides. J ournal of Polymer Science Part B: Polymer Physics 39(23):2947-2959.

Ludian, T., and L. Wagner. 2007. Effect of age-hardening conditions on high-cycle fatigue performance of mechanically surface treated Al 2024. Materials Science \& Engineering A: 468-470: Mater. Sci. Eng. A, Struct. Mater., Prop. Microstruct. Process (Switzerland) 210-13.

Mahoney, M., C. Rhodes, J . G. Flintoff, R. A. Spurling, and W. H. Bingel. 1998. Properties of friction-stir-welded 7075 T651 aluminum. Metallurgical and Materials Transactions A 29(7): 1955-1964.

Marzoli, L. M., A. V. Strombeck, J . F. Dos Santos, C. Gambaro, and L. M. Volpone. 2006. Friction stir welding of an AA6061/ Al2O3/20p reinforced alloy. Composites Science and Technology 66: 363-371.

Mayer, H. 2006. Ultrasonic torsion and tension-compression fatigue testing: Measuring principles and investigations on 2024-T351 aluminium alloy. International J ournal of Fatigue 28.11: 1446-1455.

Mazahery, A., H. Abdizadeh, and H. R. Baharvandi. 2009. Development of highperformance A356/ nano-Al2O3 composites. Materials Science and Engineering A 518: 61-64.

McMaster-Carr Incorporated. (n.d.). McMaster-Carr - Raw Materials. http://www.mcmaster.com/\#raw-materials/=fykxf3.

Merati, A. 2005. A study of nucleation and fatigue behavior of an aerospace aluminum alloy 2024-T3. International J ournal of Fatigue 27.1: Int. J . Fatigue (UK) 33-44.

Minak, G., L. Ceschini, I. Boromei, and M. Ponte. 2010. Fatigue properties of friction stir welded particulate reinforced aluminium matrix composites. International J ournal of Fatigue, 218-226.

Mishra, R. S., and Z. Y. Ma. 2005. Friction stir welding and processing. Materials Science and Engineering: R: Reports 50(1-2):1-78.

. 2005. Friction stir welding and processing. Materials Science and Engineering R 50:1-78.

Metallic materials properties development and standardization (MMPDS). 2005. MMPDS-05 Federal Aviation Administration, Washington, D.C.

Mohamed, A., Y. El-Madhoun, and M. N. Bassim. 2005. The effect of tempering on low cycle fatigue behavior of Al-2024. J ournal of Materials Processing Technology 162-163: 362-6.

Mondal, C., A. K. Mukhopadhyay, T. Raghu, and V. K. Varma. 2007. Tensile properties of peak aged 7055 aluminum alloy extrusions. Materials Science and Engineering: A 454: 673-678. 
Morabito, A. E., A. Chrysochoosb, V. Dattomaa, and U. Galietti. 2007. Analysis of heat sources accompanying the fatigue of 2024 T3 aluminium alloys. International J ournal of Fatigue 29.5: Int. J. Fatigue (UK) 977-84.

Murai, Tsutomu, Shin-ichi Matsuoka, Susumu Miyamoto, and Yoshinari Oki. 2003. Effects of extrusion conditions on microstructure and mechanical properties of AZ31B magnesium alloy extrusions. J ournal of Materials Processing Technology 141(2):207- 212.

Nelson, T. W., R. J . Steel, and W. J . Arbegast. 2003. In situ thermal studies and post-weld mechanical properties of friction stir welds in age hardenable aluminum alloys. Science and Technology of Welding \&J oining 8(4):283-288.

Ngiau, C., and D. Kujawski. 2001. Sequence effects of small amplitude cycles on fatigue crack initiation and propagation in 2024-T351 aluminum. International J ournal of Fatigue 23.9: Int. J . Fatigue (UK) 807-15.

Ogawa, N., M. Shiomi, and K. Osakada. 2002. Forming limit of magnesium alloy at elevated temperatures for precision forging. International J ournal of Machine Tools and Manufacture 42(5):607-614.

Pantelakis, Sp. G., P. V. Petroyiannisa, K. D. Bouzakisb, and I. Mirisidis 2007. Surface hardness increase of 2024 aluminum alloy subjected to cyclic loading. Theoretical and Applied Fracture Mechanics 48.1: 68-81.

Papakyriacou, M., H. R. Mayer, S. E. Stanzl-Tschegg, and M. Groschl. 1996. Fatigue properties of AI2Op-particle-reinforced 6061 aluminium alloy in the high-cycle regime. Int. J . Fatigue 18(7):475-481.

Park, B. G., A. G. Crosky, and A. K. Hellier. 2008. Fracture toughness of microsphere Al2O3-Al particulate metal matrix composites. Composites: Part B 39: 12701279.

Peng, Y., and T. K. Chaki. 1995. Fatigue damage in a unidirectional SiC/ A1 composite due to push-pull and zero-pull loading. Material Science and Engineering A200: 3846.

Perng, Chai-Chaw, Jiun-Ren Hwang, and J i-Liang Doong. 1993a. Elevated-temperature, low-cycle fatigue behaviour on a AI_2O_3p/6061-T6 aluminum matrix composite. Composites Science and Technology 225-236.

. 1993b. High strain rate tensile properties of an (A1203 particles)-(Al alloy 606 l-T6) metal matrix composite. Materials Science and Engineering A171:213-221.

Praveen, P., and D. V. Yarlagadda. 2005. Meeting challenges in welding of aluminum alloys through pulse gas metal arc welding. J ournal of Materials Processing Technology 164-165(0):1106-1112.

Prietto, M., M. Tsang, S. Hernandez, J . Roepke, D. Piatkowski, E. Lee, P. Stoyanov, Ramakrishna Naidu, N. K., and Ganesh Sudara Raman, S. 2005. Effect of shot blasting on plain fatigue and fretting fatigue behavior of Al-Mg-Si alloy AA6061. Int. J . Fatigue (27):323-331. 
Prietto, M., M. Tsang, S. Hernandez, J . Roepke, D. Piatkowski, E. Lee, P. Stoyanov, J . Ogren, and O. S. Es-Said. 2011. The effects of heat damage of aluminum 6061-T6 AM-2 Mats and High Power Run-Up Anchor. Engineering Failure Analysis, 18(1), 124-137.

Ren, Zheng. 2007. Mechanical properties of 7075 aluminum matrix composites reinforced by nanometric silicon carbide particulates. University of New South Wales-School of Materials Science and Engineering.

Rodopoulos, C. A., and A. T. Kermanidis. 2007. Understanding the effect of block overloading on the fatigue behaviour of 2024-T351 aluminium alloy using the fatigue damage map. International J ournal of Fatigue 29.2: Int. J . Fatigue (UK). 27688. Print.

Romanova, V. A., R. Balokhonov, and S. Schmauder. 2009. The influence of the reinforcing particle shape and interface strength on the fracture behavior of a metal matrix composite. Acta Materialia 97-107.

Rui-dong, F., S. Zeng-qiang, R. Sun, Y. Li, H. Liu, and L. Liu. 2011. Improvement of weld temperature distribution and mechanical properties of 7050 aluminum alloy butt joints by submerged friction stir welding. Materials \& Design 32(10):4825-4831.

Rushing, T. W., and J . S. Tingle. 2007. AM2 and M19 Airfield Mat Evaluation for the Rapid Parking Ramp Expansion Program. TR-07-5. Vicksburg, MS: US Army Engineer Research and Development Center.

Rushing, T. W., N. Torres, and Q. S. Mason. 2008. AM2 10 CBR Subgrade Sensitivity test for the Rapid Parking Ramp Expansion Program. TR-08-13. Vicksburg, MS: US Army Engineer Research and Development Center.

Rushing, T. W., and Q. S. Mason. 2008. AM2 15 CBR subgrade sensitivity test for the rapid parking ramp expansion program. ERDC/ GSL TR-08-25. Vicksburg: US Army Engineer Research and Development Center.

Sajuri, Z. B., Y. Miyashita, and Y. Mutoh. 2005. Effects of humidity and temperature on the fatigue behaviour of an extruded AZ61 magnesium alloy. Fatigue and Fracture of Engineering Material and Structures 28(4): Dept. of Mech. Eng., Nagaoka Univ. of Technol., Niigata, J apan, 373-379.

Sajuri, Z. B., Y. Miyashita, Y. Hosokai, and Y. Mutoh. 2006. Effects of Mn content and texture on fatigue properties of as-cast and extruded AZ61 magnesium alloys. Int J Mech Sci 2006 48:198-209.

Sarioglu, F., and F. Oe. Orhaner. 1998. Effect of prolonged heating at 130C on fatigue crack propagation of $2024 \mathrm{Al}$ alloy in three orientations. Materials Science \& Engineering A (Structural Materials: Properties, Microstructure and Processing) Mater. Sci. Eng. A, Struct. Mater., Prop. Microstruct. Process. (Switzerland) A248.1-2: 115-19.

Schauder, Thomas J., Terry R. Mcnelley, and Peter N. Kalu. 1992. The effects of thermomechanical processing parameters on elevated-temperature behavior of A6061AL03 metal matrix composite. Naval Post-Graduate School. 
Shahzad, M., D. Eliezer, G. Weimin, Y. Sangbong, and L. Wagner. 2007. Influence of extrusion temperature on microstructure, texture and fatigue performance of AZ80 and ZK60 magnesium alloys. Materials Science Forum 561-565(1): TU Clausthal, Clausthal-Zellerfeld, Germany, 187-190.

Sinha, Niraj, and J ohn T. W. Yeow. 2005. Carbon Nanotubes for Biomedical Applications. IEEE Transactions on Nanobioscience 4(2): 180-195.

Smith, J . 2012. Interview by R. McCullough, J anuary 2012, Extrusion Capacities of Alcoa Global.

Song, Guangling, Andrej Atrens, Xianliang Wu, and Bo Zhang. 1998. Corrosion behaviour of AZ21, AZ501 and AZ91 in sodium chloride. Corrosion Science 40(10):17691791.

Spigarelli, S., M. El Mehtedi, E. Evangelista, and J . Kaneko. 2005. High temperature plastic deformation of a heat-treated AZ 31 magnesium alloy. Metallurgical Science and Technology 23(1):11-18.

Srivatsan, T. S., Meslet Al-Hajri, M. Petraroli, B. Hotton, and P. C. Lam. 2002. Influence of silicon carbide particulate reinforcement on quasi static and cyclic fatigue fracture behavior of 6061 aluminum alloy composites. Materials Science \& Engineering A: 202-214.

Srivatsan, T. S., S. Anand, S. Sriram, and V. K. Vasudevan. 2000. The high-cycle fatigue and fracture behavior of aluminum alloy 7055. Materials Science and Engineering: A, 281(1): 292-304.

Srivatsan, T. S., T. S. Sudarshan, and E. J . Lavernia. 1995. Processing of discontinuouslyreinforced metal matrix composites by rapid solidification. Progress in Materials Science 39:317-409.

Storjahann, D., O. M. Barabash, S. S. Babu, S. A. David, P. S. Sklad, and E. E. Bloom. 2005. Fusion and Friction Stir Welding of Aluminum-Metal-Matrix Composites. Metallurgical and Materials Transactions A 36a:3237-3247.

Su, J . Q., T. W. Nelson, R. Mishra, and M. Mahoney. 2003. Microstructural investigation of friction stir welded 7050-T651 aluminum. Acta Materialia 51(3): 713-729.

Suresh S. 1998. Fatigue of materials. United Kingdom: Cambridge University Press.

Swartz, R.2012. Interview by R. McCullough, J anuary 2012, Extrusion Capabilities of Kaiser Extrusion - Newark Facilities.

Taber Extrusions. 2011. Taber - The leader in Aluminum Extrusion since 1973. http://taberextrusions.com/.

Tjong, Sie Chin. 2007. Novel nanoparticle-reinforced metal matrix composites with enhanced mechanical properties. Advanced Engineering Materials 9(8):639-652.

Tokaji, K., M. Kamakura, Y. Ishiizumi, and N. Hasegawa. 2004. Fatigue behavior and fracture mechanism of a rolled AZ31 magnesium alloy. Int J Fatigue 2004 26: 1217-24. 
Tringham, J . 2012. Interview by R. McCullough, J anuary 2012, Billet Supply Capabilities of Vista Metal Corp.

Uematsu, Y., K. Tokaji, M. Kamakura, K. Uchida, H. Shibata, and N. Bekku. 2006. Effect of extrusion conditions on grain refinement and fatigue behavior in magnesium alloys. Materials Science \& Engineering A (Structural Materials: Properties, Microstructure and Processing), v 434, n 1-2: Dept. of Mech. \& Syst. Eng., Gifu Univ., J apan, 131-140.

Unigovski, Ya., A. Eliezer, E. Abramov, Y. Snir, and E. M. Gutman. 2003. Corrosion fatigue of extruded magnesium alloys. Materials Science and Engineering: A 360 (1-2): 132- 139.

Upadhyaya, P., S. Singh, and S. Roy. 2011. A mechanism-based multi-scale model for predicting thermo-oxidative degradation in high temperature polymer matrix composites. Composites Science and Technology 71: 1309-1315.

Venkateswara Rao, K. T., W. Yu, and R. O. Ritchie. 1988. Fatigue crack propagation in aluminum-lithium alloy 2090: Part II. Small crack behavior. Metallurgical Transactions A 19A: 563-569.

Wang, L., M. Strangwoodb, D. Balinta, J . Lina, and T. A. Dean. 2011. Formability and failure mechanisms of AA2024 under hot forming conditions. Materials Science and Engineering: A 528.6: 2648-2656.

Wang, Q.Y., T. Li, and T. Y. Zeng. 2010. Gigacycle fatigue behavior of high strength aluminum alloys. Procedia Engineering, Fatigue 2010(2):65-70.

Wong, W. A. 1984. Monotonic and cyclic fatigue properties of automotive aluminum alloys. Society of Automotive Eng. Technical Paper 840120.

Whittaker, M. T., W. J . Evans, R. Lancaster, W. Harrison, and P. S. Webster. 2009. The effect of microstructure and texture on mechanical properties of Ti6-4. Int J Fatigue 31: 2022-30.

Xu, Q., R. W. Hayes, W. H. Hunt Jr., and E. J. Lavernia. 1999. Mechanical properties and fracture behavior of layered 6061/ SiCp composites produced by spray atomization and co-deposition. Acta mater 47(1):43-53.

Yang, Xuyue, Hiromi Miura, and Taku Sakai. 2003. Dynamic evolution of new grains in magnesium alloy AZ31 during hot deformation. Materials Transactions 44(1): 197- 203.

Yang, Yong, Jie Lan, and Xiaochun Li. 2004. Study on bulk aluminum matrix nanocomposite fabricated by ultrasonic dispersion of nano-sized $\mathrm{SiC}$ particles in molten aluminum alloy. Materials Science and Engineering A 380: 378-383.

Zhang, X. P., C. H. Wang, L. Ye1, and Y. W. Mai1. 2002. In situ investigation of small fatigue crack growth in poly-crystal and single-crystal aluminium alloys. Fatigue \& Fracture of Engineering Materials \& Structures 25.2: Fatigue Fract. Eng. Mater. Struct. (UK) 141-50. 
Zhao, Ming-Chun, Ming Liu, Guangling Song, and Andrej Atrens. 2008. Influence of the B-phase morphology on the corrosion of the Mg alloy AZ91. Corrosion Science 50(7): 1939- 1953.

Zhou, C., X. Yang, and G. Luan. 2005. Fatigue properties of friction stir welds in Al 5083 alloy. Scripta Materialia 53(10):1187-1191. 


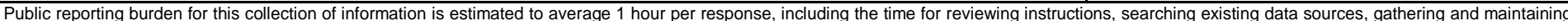

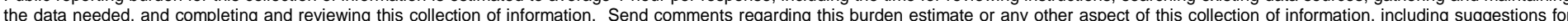

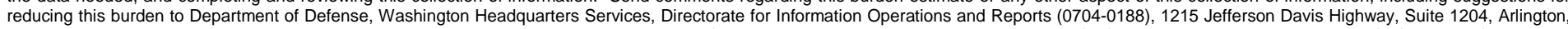

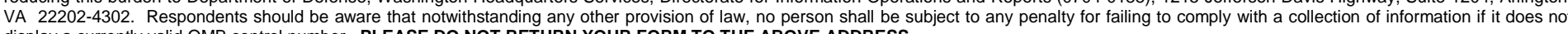
display a currently valid OMB control number. PLEASE DO NOT RETURN YOUR FORM TO THE ABOVE ADDRESS.
1. REPORT DATE (DD-MM-YYYY)
June 2014

\section{TITLE AND SUBTITLE}

Analysis of Lightweight Materials for the AM2 System
3. DATES COVERED (From - To)

5a. CONTRACT NUMBER

5b. GRANT NUMBER

5c. PROGRAM ELEMENT NUMBER

5d. PROJECT NUMBER

5e. TASK NUMBER

5f. WORK UNIT NUMBER

8. PERFORMING ORGANIZATION REPORT NUMBER

ERDC/GSL TR-14-18

Geotechnical and Structures Laboratory

US Army Engineer Research and Development Center

3909 Halls Ferry Road

Vicksburg, MS 39180-6199

\section{SPONSORING / MONITORING AGENCY NAME(S) AND ADDRESS(ES)}

Headquarters, Air Force Civil Engineer Center

Tyndall Air Force Base, FL 32403-5319

10. SPONSOR/MONITOR'S ACRONYM(S)

HQ-AFCEC

11. SPONSOR/MONITOR'S REPORT NUMBER(S)

\section{DISTRIBUTION / AVAILABILITY STATEMENT}

Approved for public release; distribution is unlimited.

\section{SUPPLEMENTARY NOTES}

\section{ABSTRACT}

An analysis was performed on potential materials that could replace the 6061-T6 aluminum alloy currently used in the AM2 airfield matting for the purpose of light-weighting the design. An in-depth analysis was performed on metal and polymer matrix composites. However, neither groups of materials produced a suitable material based on operating conditions of the AM2. Newly developed extruded magnesium alloys were identified that could potentially provide weight savings of 30 to $40 \%$ while maintaining the current performance of the AM2. In addition, traditional high-strength aluminum alloys were identified that could provide substantial weight savings. However, manufacturing issues existed due to the high strength of these aluminum alloys. Finally, analysis was performed to determine the cost of manufacturing the AM2 using these alternate materials.

\begin{tabular}{|c|c|c|c|c|c|}
\hline \multicolumn{2}{|c|}{$\begin{array}{l}\text { 15. SUBJECT TERMS } \\
\text { Lightweight metal } \\
\text { Landing Mat }\end{array}$} & $\begin{array}{l}\text { Airfield Mat } \\
\text { Aluminum } \\
\text { AM2 }\end{array}$ & \multicolumn{3}{|c|}{ Metal Matrix } \\
\hline \multicolumn{3}{|c|}{ 16. SECURITY CLASSIFICATION OF: } & $\begin{array}{l}\text { 17. LIMITATION } \\
\text { OF ABSTRACT }\end{array}$ & $\begin{array}{l}\text { 18. NUMBER } \\
\text { OF PAGES }\end{array}$ & $\begin{array}{l}\text { 19a. NAME OF RESPONSIBLE } \\
\text { PERSON }\end{array}$ \\
\hline $\begin{array}{l}\text { a. REPORT } \\
\text { Unclassified }\end{array}$ & $\begin{array}{l}\text { b. ABSTRACT } \\
\text { Unclassified }\end{array}$ & $\begin{array}{l}\text { c. THIS PAGE } \\
\text { Unclassified }\end{array}$ & & 114 & $\begin{array}{l}\text { 19b. TELEPHONE NUMBER (include } \\
\text { area code) }\end{array}$ \\
\hline
\end{tabular}

